\title{
Mechanistic Development and Recent Applications of the Chan-Lam Amination
}

Matthew J. West, ${ }^{1}$ James W. B. Fyfe, ${ }^{1}$ Julien C. Vantourout, ${ }^{2}$ and Allan J. B. Watson ${ }^{1 *}$

${ }^{1}$ EaStCHEM, School of Chemistry, University of St Andrews, North Haugh, St Andrews, Fife, KY16 9ST, U.K.

${ }^{2}$ Department of Chemistry, The Scripps Research Institute, 10550 North Torrey Pines Road, La Jolla, CA 92037, U.S.A.

*aw260@st-andrews.ac.uk

Dedicated to Dr Dominic Chan and Prof Patrick Lam

in celebration of the $20^{\text {th }}$ anniversary of the Chan-Lam reaction 


\section{CONTENTS}

ABSTRACT

\section{INTRODUCTION}

1.1 Generalities and Context

1.2 $\mathrm{C}-\mathrm{N}$ Bond Formation via Cross-Coupling Reactions

1.3 $\mathrm{C}-\mathrm{N}$ Bond Formation via Nucleophile-Electrophile Cross-Coupling

1.4 C-N Bond Formation via Nucleophile-Nucleophile Cross-Coupling

\section{DISCUSSION}

2.1 Discovery

2.2 Development of Reaction Conditions

2.3 A General Mechanistic Description of the Chan-Lam Reaction

2.4 Reactions Variables and Selection of Reaction Conditions

\section{SCOPE OF THE CHAN-LAM AMINATION}

3.1 Organoboron Variation

3.2 Aryl Amines (Anilines)

3.3 Heteroaryl Amines (Heterocyclic Anilines)

3.4 Alkyl Amines

3.5 Amides

3.6 NH-Heterocycles

3.7 C-N Bond Formation to non-NH-Nucleophiles

3.8 Sulfonamides and Sulfoximes

3.9 Sequential Processes

3.10 C-N Bond Formation on Nucleobases and Peptides

\section{MECHANISM}

4.1 Historical Context

4.2 Mechanistic Investigations in the Etherification Reaction

4.3 Mechanistic Investigations in the Amination Reaction

4.4 Mechanistic Investigations in the Amination Reaction: Ligand-based Systems

4.5 Mechanism Summary

\section{CONCLUSIONS AND OUTLOOK}

ACKNOWLEDGEMENTS

ABBREVIATIONS

REFERENCES 


\begin{abstract}
Transition metal-mediated formation of $\mathrm{C}-\mathrm{N}$ bonds is an essential synthetic methodology. The discovery of the Chan-Lam amination provided a $\mathrm{C}-\mathrm{N}$ bond forming process that was mild, convenient, and inexpensive, offering an alternative to complementary methods using other transition metals (TMs). Over the past 20 years, this reaction has seen considerable development in its scope of application, uptake into industry, and understanding of its mechanism. This review provides an account of the development of the Chan-Lam amination, highlighting progress and notable examples of application since 2011. Focus is given to evolution in mechanistic understanding and selected applications of the methodology within medicinal and process chemistry.
\end{abstract}

\title{
1. INTRODUCTION
}

The formation of $\mathrm{C}-\mathrm{N}$ bonds remains one of the most widely practiced reactions in synthetic chemistry due to the prevalence of this functionality within bioactive molecules and materials. As such, the development of methods for the installation of $\mathrm{C}-\mathrm{N}$ bonds that allow easier/more efficient bond formation, the use of milder/less expensive protocols, or the use of previously recalcitrant substrates remains a particularly vibrant field of research.

Constructing $\mathrm{C}-\mathrm{N}$ bonds within pharmaceutical $\mathrm{R} \& \mathrm{D}$ is the context that is arguably most widely invoked as part of synthetic method development. The utility and impact of $\mathrm{C}-\mathrm{N}$ bonds within the development of active pharmaceutical ingredients (APIs) is especially evident: several studies have highlighted both the prevalence of $\mathrm{C}-\mathrm{N}$ bonds within marketed drug molecules as well as the frequency of $\mathrm{C}-\mathrm{N}$ bond forming methods used within discovery and process phases in pharmaceutical R\&D. ${ }^{1-6}$

In addition to more classical bond forming strategies, significant time and effort have been dedicated to accessing aryl and heteroaryl molecules bearing nitrogenous functional groups through transition metalcatalyzed reactions. Pd-catalyzed $\mathrm{C}-\mathrm{C}$ bond forming methods have been used extensively to prepare carbogenic frameworks that can be further elaborated to access more challenging (hetero)aryl structures. ${ }^{7-12}$ Alongside these $\mathrm{C}-\mathrm{C}$ bond formation reactions, the development of analogous $\mathrm{TM}$-catalyzed methodologies affording new $\mathrm{C}-\mathrm{N}$ bonds has been a pivotal development in the synthesis of organic molecules of biological interest. $^{13,14}$

\subsection{Generalities and Context}

Amide couplings, alkylations, reductive aminations, and $\mathrm{S}_{\mathrm{N}} \mathrm{Ar}$ are some of the most practiced methods for $\mathrm{C}-$ $\mathrm{N}$ bond formation. ${ }^{1,3,5}$ Of these, the $\mathrm{S}_{\mathrm{N}} \mathrm{Ar}$ reaction is particularly significant as it allows the formation of aryl amines, from readily available aryl halides, which have physicochemical properties that are distinct from alkyl amines and are important pharmacophores. ${ }^{6}$ However, the application of $\mathrm{S}_{\mathrm{N}} \mathrm{Ar}$ is necessarily limited to substrates that allow this type of reactivity and can therefore be incompatible for late stage functionalization. 
Cross-coupling reactions have been developed to offer the flexibility and applicability for the formation of C$\mathrm{N}$ bonds that $\mathrm{S}_{\mathrm{N}} \mathrm{Ar}$ lacks and in a direct, cost-effective manner.

\subsection{C-N Bond Formation via Cross-Coupling Reactions}

There are two main approaches towards TM-catalyzed $\mathrm{C}-\mathrm{N}$ cross-coupling: classic (electrophile-nucleophile), typified by the Buchwald-Hartwig and Ullmann-Goldberg reactions, and oxidative (nucleophile-nucleophile), with the Chan-Lam reaction the archetypal example (Scheme 1).

Scheme 1. General approaches to TM-catalyzed C-N cross-coupling.

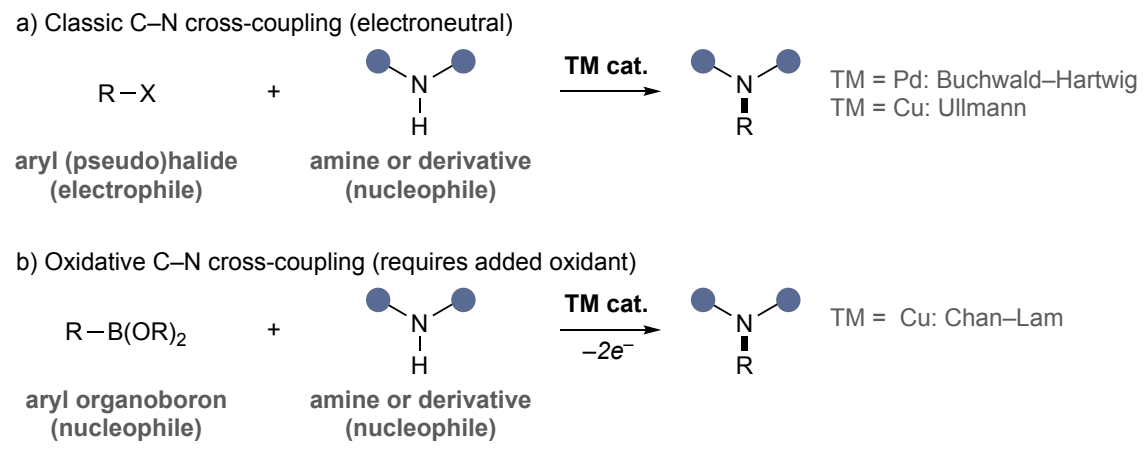

\subsection{C-N Bond Formation via Nucleophile-Electrophile Cross-Coupling}

In a first demonstration of classic electrophile-nucleophile cross-coupling, over 100 years ago, Ullmann and Goldberg reported that aryl halides could react with an amine or amide using stoichiometric or catalytic amounts of a $\mathrm{Cu}$ promoter. ${ }^{15,16}$ However, the low yields obtained, along with the harsh conditions employed, hindered development of this useful transformation. More modern variants based on extensive ligand development and mechanistic understanding have significantly enhanced the applicability of UllmannGoldberg-type C-N (as well as C-X) bond formation. ${ }^{17-22}$ Nevertheless, despite notable advances and the potential advantages that can be afforded by $\mathrm{Cu}$ catalysis, the uptake and application of Ullmann-Goldbergbased approaches has been largely overshadowed by developments in Pd catalysis.

Building on reports by Migita in 1983, ${ }^{23}$ and Boger and Panek in $1984,{ }^{24}$ Pd-catalyzed C-N cross-coupling caught the attention of the scientific community in 1994 following independent reports from Hartwig and Buchwald. ${ }^{25-28}$ The development of mechanistic understanding and generally milder/more applicable reaction conditions as compared to the Ullmann-Goldberg reaction subsequently led to the Buchwald-Hartwig reaction to become one of the primary methods used for catalytic $\mathrm{C}-\mathrm{N}$ bond formation from aryl (pseudo)halides. ${ }^{14,29-}$

32 Despite extensive and insightful investigations of ligand effects in particular, some limitations persist, including the general requirement of elevated temperatures, typically strong bases, and expensive Pd (pre)catalysts are often required for the best results. ${ }^{33,34}$ 
The significant acceleration in oxidative addition and improved turnover, along with the possible benefits of reduced base metal cost have encouraged the development of Ni-catalyzed $\mathrm{C}-\mathrm{N}$ cross-coupling. ${ }^{35,36}$ Building on reports by Hughes, Cramer, and Cristau dating from 1950-1975, ${ }^{37-39}$ developments by Buchwald, ${ }^{40}$ Fort, ${ }^{41}$ and others ${ }^{42}$ have provided effective Ni-catalyzed protocols for $\mathrm{C}-\mathrm{N}$ bond formation. As with the Pd-catalyzed variant, these processes have several constraints, including the use of air-sensitive $\mathrm{Ni}(0)$ catalysts or bespoke ligand systems. This has been somewhat compounded by underdeveloped understanding of ligand design for $\mathrm{Ni}$ catalysis and the 'forced-fit' use of ligands from Pd catalyzed processes that are not necessarily optimal. ${ }^{43}$ More recently, the combination of Ni catalysis with photoredox catalysis ${ }^{44}$ or electrochemical methods ${ }^{45,46}$ have provided an alternative approach to traditional TM-catalyzed $\mathrm{C}-\mathrm{N}$ bond forming reactions that can offer lower temperatures and can employ simple Ni(II) salts, obviating the dependency on phosphine ligands. In parallel, recent developments in photoredox catalysis are also adding to the armamentarium of methods for generation of $\mathrm{C}(\operatorname{aryl})-\mathrm{N}$ bonds but that do not rely upon reductive elimination as the $\mathrm{C}-\mathrm{N}$ bond forming event. $^{47}$

The development trajectory for classical nucleophile-electrophile $\mathrm{C}-\mathrm{N}$ cross-coupling has been to greater efficiency, scope, and, more recently, reconciling increased synthetic efficiency with decreased dependency on expensive metals or ligands. Achieving this goal is not straightforward: the Ullmann-Goldberg approach would seem to offer the best financial efficiency based on inexpensive $\mathrm{Cu}$ salts and relatively simple ligands; however, the scope is not as broad as Pd catalysis, which often require the most expensive ligand systems.

\subsection{C-N Bond Formation via Nucleophile-Nucleophile Cross-Coupling}

Nucleophile-nucleophile (oxidative) cross-coupling offers an alternative approach to TM-catalyzed C-N bond formation. In this regard, and in the context of the cost/scope considerations outlined above, oxidative $\mathrm{Cu}$ catalysis has become an important method for $\mathrm{C}-\mathrm{N}$ bond formation. Historically, the interests in development of $\mathrm{Cu}$-based oxidative $\mathrm{C}-\mathrm{N}$ cross-coupling began with a report by Dodonov ${ }^{48}$ leading to work by Barton ${ }^{49,50}$ and later by Dodonov ${ }^{51}$ and Chan ${ }^{52}$ using arylbismuth reagents, as well as additional reports using aryllead reagents again by Barton ${ }^{53,54}$ and afterwards by Avendano. ${ }^{55}$ Subsequently, Lam demonstrated that siloxanes were suitable reagents for the $\mathrm{N}$-arylation of various $\mathrm{N}$-nucleophiles using $\mathrm{Cu}(\mathrm{OAc})_{2} \cdot{ }^{56}$ Later, the same group reported that aryl stannanes could also be used. ${ }^{57}$ While these Cu-catalyzed/promoted methods offered some versatility, such as inexpensive $\mathrm{Cu}$ source and mild reaction conditions, the use of expensive or unfriendly aryl donor reagents, or lack of accessibility of these reagents, limited uptake.

A breakthrough in this field was realized in 1998 in the discovery of the Cu-promoted Chan-Lam coupling reaction with boronic acids (Scheme 2 ). ${ }^{58-60}$ 
Scheme 2. Discovery of the Chan-Lam reaction: Cu-mediated $\mathrm{C}-\mathrm{N}$ bond formation using arylboronic acid reagents.

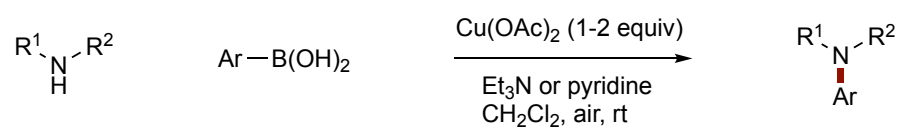

The mild reaction conditions required (room temperature, weak base, ambient atmosphere) and the use of readily available arylboronic acids, which at that time were very much in vogue due to developments in Suzuki-Miyaura cross-coupling, afforded a $\mathrm{C}-\mathrm{N}$ bond forming process that was more accessible than the $\mathrm{Cu}-$ catalyzed/promoted methods using arylbismuth, aryllead, or arylsiloxane reagents, and potentially significant advantages over complementary nucleophile-electrophile methods using $\mathrm{Cu}$ and $\mathrm{Pd}$.

Over the past 20 years, a large number of research teams have made significant progress in expanding this methodology to deliver a series of protocols for $\mathrm{C}-\mathrm{N}$, as well as an extensive range of $\mathrm{C}-\mathrm{X}$ bond formations, which have proven to be mild, versatile, and robust. ${ }^{18,22,61-68}$ These studies have detailed a vast volume of data relating to the optimization of the reaction conditions for each transformation, with various catalyst sources, solvents, bases, additives, ligands, and alternative boron reagents investigated, in addition to the expansion of heteroatomic nucleophile scope as well as mechanistic studies. It is worthwhile noting that, similar to many other synthetic methods, to date there is no general set of reaction conditions, and while many conditions are similar, seemingly subtle changes can have a significant impact on the success of a given reaction. This review focusses on Chan-Lam amination. The following sections will summarize the progress made in this area, with general guidance to aid understanding of the effect of variables, where possible.

\section{DISCUSSION}

\subsection{Discovery}

The discovery of the Chan-Lam reaction originates from work by Chan and coworkers at DuPont to develop new aryl nucleophiles for $\mathrm{N}$-arylation reactions, stemming from work by Chan on the use of arylbismuth reagents for this purpose. ${ }^{52}$ Changing the aryl nucleophile from a triarylbismuth reagent to the more commercially and synthetically accessible arylboronic acid was subsequently found to produce equivalent results and, in 1998, delivered the first examples of what is now known as the Chan-Lam reaction. These results were disclosed in a first publication that demonstrated the reaction to be broadly applicable to a wide range of $N$-nucleophile coupling partners, including alkyl amines, anilines, amides, ureas, and sulfonamides, as well as $O$-donors such as phenols (Scheme $3 \mathrm{a}){ }^{58}$

Scheme 3. The first reports of the Chan-Lam reaction. (a) The first report by Chan. (b) Evans' application of the $O$-arylation. (c) The first report by Chan and Lam. 
(a) Chan's $\mathrm{N}$ - and O-arylation

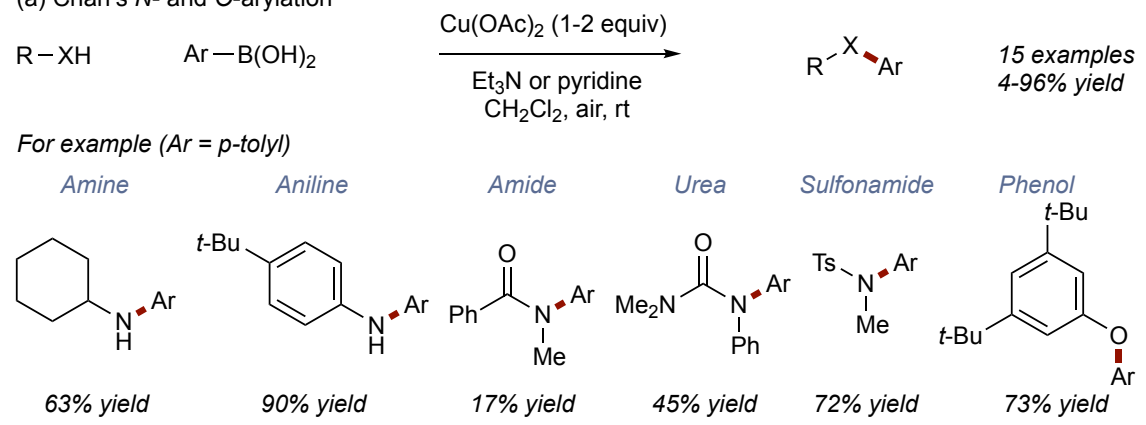

(b) Evans' application of the O-arylation<smiles>CCOC(=O)N[C@H](CC)Cc1cc(I)c(O)c(I)c1</smiles><smiles>COc1ccc(Br)cc1</smiles>

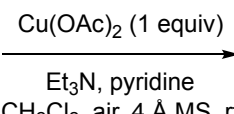
$\mathrm{CH}_{2} \mathrm{Cl}_{2}$, air, $4 \AA \mathrm{MS}, \mathrm{r}$

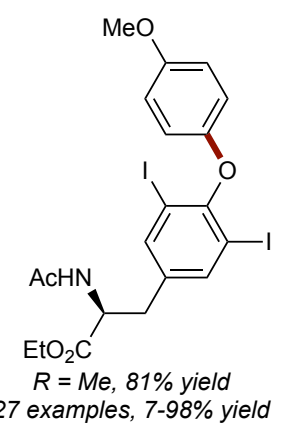

(c) Azaheterocycle $\mathrm{N}$-arylation by Chan and Lam

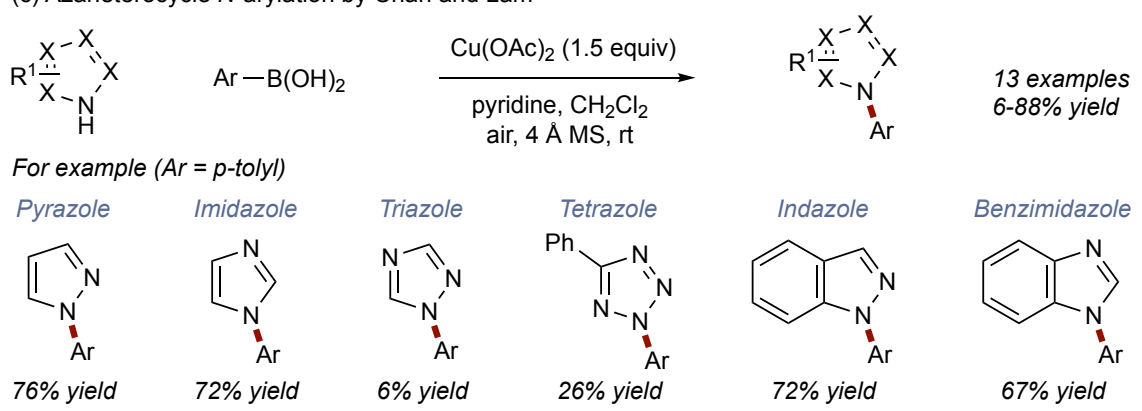

Contemporaneous interactions between the Evans group and colleagues at DuPont resulted in further application of the $O$-arylation methodology, resulting in a formal synthesis of $L$-thyroxine (Scheme $3 \mathrm{~b}$ ). ${ }^{59}$ Similarly, concurrently at DuPont, Lam began to explore the use of $\mathrm{C}-\mathrm{N}$ coupling processes in the development of Factor Xa inhibitors. In collaboration with Chan, Lam and coworkers demonstrated that the new $\mathrm{Cu}$-catalyzed reaction accommodated aromatic azaheterocycles, including imidazoles, pyrazoles, triazoles, tetrazoles, benzimidazoles, and indazoles (Scheme 3c). ${ }^{60}$ This wider project eventually yielded the blockbuster anticoagulant Eliquis ${ }^{\circledR}$ (Figure 1), although, interestingly, the $\mathrm{C}(\operatorname{aryl})-\mathrm{N}$ bond (highlighted) was formed by Ullmann-Goldberg chemistry in the medicinal chemistry campaign. ${ }^{69}$

Figure 1. Eliquis ${ }^{\circledR}$.<smiles>COc1ccc(-n2nc(C(N)=O)c3c2C(=O)N(c2ccc(N4CCCCC4=O)cc2)CC3)cc1</smiles> 
These three back-to-back papers established the foundation of the Chan-Lam reaction. The main advantage of this new $\mathrm{Cu}$-mediated cross-coupling platform was the high functional group tolerance achievable from the mild reaction conditions employed as well as the cheap $\mathrm{Cu}$ promoter and readily accessible substrates. The wide diversity of $\mathrm{N}$-nucleophile substrates, as well as indications of wider generality to $\mathrm{C}-\mathrm{X}$ bond formation, even in these initial explorations was also striking; however, low yields were obtained for some coupling partners such as amides, ureas, and specific aromatic azaheterocycles (see Scheme $3 \mathrm{a}$ and $3 \mathrm{c}$ for several examples). In addition, at this stage the reaction required stoichiometric amounts of $\mathrm{Cu}$ and excesses of organoboron component. Extensive work over the past 20 years has focused on developing improved conditions and expanding the scope of this useful reaction.

\subsection{Development of Reaction Conditions}

The classic Chan-Lam reaction is notable for its relative simplicity. Typically, a mixture of the heteroatomic nucleophile, arylboronic acid, anhydrous $\mathrm{Cu}(\mathrm{OAc})_{2}$, and base (e.g., $\mathrm{Et}_{3} \mathrm{~N}$ or pyridine) was stirred at room temperature in $\mathrm{CH}_{2} \mathrm{Cl}_{2}$ for 1-3 days under air to deliver the desired product. ${ }^{58-60}$

Since 1998, numerous papers and patents have highlighted the use of the Chan-Lam reaction. ${ }^{18,22,61-67}$ Many groups have directed their efforts to the optimization of the reaction conditions, investigating catalyst sources, solvents, bases, ligands, and additives, to afford an efficient cross-coupling of aryl and alkyl boronic acids or derivatives with various heteroatom-based nucleophiles, most commonly $\mathrm{C}-\mathrm{N}$ and $\mathrm{C}-\mathrm{O}$ but with numerous other including $\mathrm{C}-\mathrm{S}, \mathrm{C}-\mathrm{P}, \mathrm{C}-$ halide, etc.

Based on the utility and breadth of impact of $\mathrm{C}-\mathrm{N}$ bond formation within bioactive molecule design, much of the development of Chan-Lam methodology has focused on this bond formation. The following sections describe observations relating to specific reaction conditions.

\subsection{A General Mechanistic Description of the Chan-Lam Reaction}

To contextualize and aid the discussion of reaction variables and application, a brief description of the general reaction mechanism is essential.

The mechanistic operation of the Chan-Lam reaction remains underdeveloped. A number of studies over the past 20 years have contributed in various ways to the present understanding of this reaction; $;^{59,70-78}$ however, a complete mechanistic description remains elusive. This is largely due to two key issues: (i) the multiple roles of the $\mathrm{Cu}$ catalyst/promoter and (ii) the solution speciation of $\mathrm{Cu}$ complexes. Moreover, as noted above, the Chan-Lam reaction is now particularly broad in scope and, as will be seen below, a large selection of variables can (and have) been changed, all of which may affect the kinetics of individual steps of the reaction or alter the pathway entirely (see Section 4 for mechanistic discussion). 
For the purposes of clarity in the following sections, a very concise and general representation of the key events of the Chan-Lam reaction using $N$-nucleophiles and 'classic conditions' $\left(\mathrm{Cu}(\mathrm{OAc})_{2}\right.$ as the $\mathrm{Cu}$ source and $\mathrm{Et}_{3} \mathrm{~N}$ as the base) is shown in Scheme 4.

Scheme 4. General representation of the key events in the Chan-Lam reaction using $N$-nucleophiles under classic conditions. $\mathrm{S}=$ solvent.

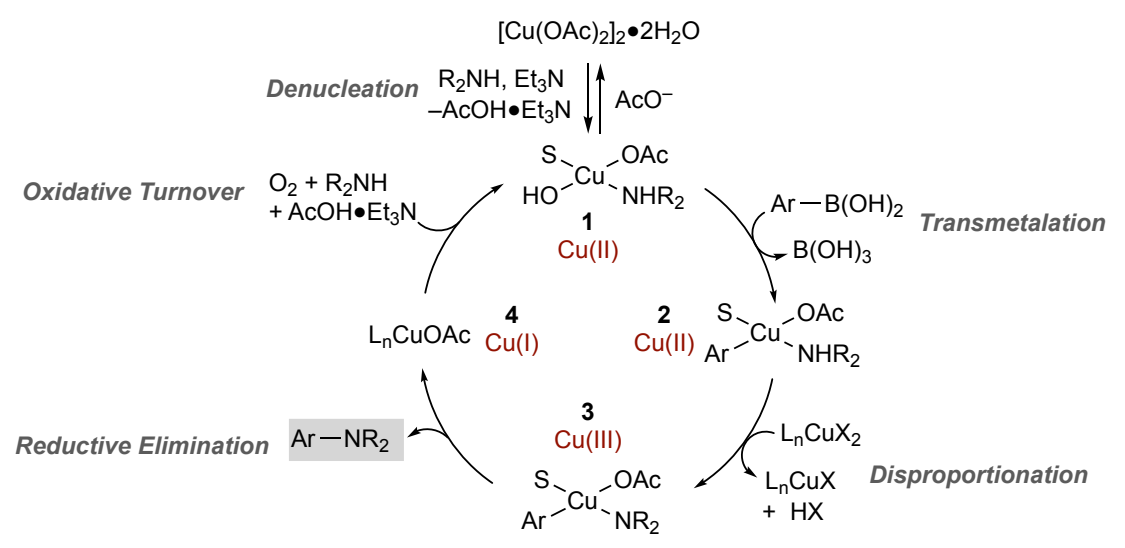

$\mathrm{Cu}(\mathrm{OAc})_{2}$ is dimeric, existing as the dicopper tetraacetate 'paddlewheel' or 'lantern' complex that is usually solvated in the axial sites, typically by $\mathrm{H}_{2} \mathrm{O}$, such that the classic conditions actually employ $\left[\mathrm{Cu}(\mathrm{OAc})_{2}\right]_{2} \bullet 2 \mathrm{H}_{2} \mathrm{O}$ as the $\mathrm{Cu}$ source (see Section 4). Thus, the reaction begins by denucleation of $\left[\mathrm{Cu}(\mathrm{OAc})_{2}\right]_{2} \bullet 2 \mathrm{H}_{2} \mathrm{O}$ to a mononuclear $\mathrm{Cu}(\mathrm{II})$ complex $\mathbf{1}$ by the heteroatomic nucleophile, in this case an amine. Transmetalation of the organoboron compound, here a boronic acid, delivers $\mathrm{Cu}(\mathrm{II})$ complex 2. Disproportionation using a second $\mathrm{Cu}$ (II) delivers the key $\mathrm{Cu}(\mathrm{III})$ complex $\mathbf{3}$. Reductive elimination forges the $\mathrm{C}-\mathrm{N}$ bond, liberating the product and a $\mathrm{Cu}(\mathrm{I})$ species 4 . Oxidative turnover of $\mathrm{Cu}(\mathrm{I})$ to $\mathrm{Cu}(\mathrm{II})$, i.e., $\mathbf{4} \rightarrow \mathbf{1}$, using a terminal oxidant, most commonly $\mathrm{O}_{2}$, completes the catalytic cycle.

Several points of this basic mechanism are worth noting at this stage:

(1) Depending on the $\mathrm{Cu}$ source used, the denucleation event may not be necessary. Indeed, ligation of the heteroatomic nucleophile can occur after transmetalation. ${ }^{76,77}$

(2) Very few relevant $\mathrm{Cu}(\mathrm{II})$ complexes have been isolated, ${ }^{79,80}$ in particular the key $\mathrm{Cu}(\mathrm{II})(\mathrm{Ar})$ complexes (such as 2 ) are unknown (mass ions consistent with the proposed structures have been detected ${ }^{75}$ ).

(3) The absence of robust information on the $\mathrm{Cu}$ (II) complexes and the issue with ligand speciation renders an understanding of the bonding, geometry, electronics, and therefore reactivity very difficult to predict or rationalize by computational methods.

(4) Transmetalation of organoboron species to $\mathrm{Cu}(\mathrm{II})$ complexes is poorly understood.

(5) The disproportionation reaction is a critical event that delivers the key $\mathrm{Cu}$ (III) complex. By necessity, this implies a redox gradient between two $\mathrm{Cu}$ (II) species. This in turn suggests that these $\mathrm{Cu}$ (II) complexes have 
different ligand sets. Related to (2) above, the ligand speciation and solution dynamics that enable this are, so far, not understood at all. In addition, the mechanism of this disproportionation event is underdeveloped.

(6) The reaction requires $2 \times \mathrm{Cu}$ per turnover. This is important when considering the stoichiometry of $\mathrm{Cu}$ used in catalytic Chan-Lam reactions is commonly $20-50 \mathrm{~mol} \%$.

It is important to note that Chan-Lam reactions can often generate byproducts, and these are invariably derived from the organoboron compound (Scheme 5). Specifically, oxidation and protodeboronation of the arylboronic acid leads to phenol and arene byproducts, respectively. ${ }^{75,77}$ The production of phenolic byproducts can then lead to formation of diaryl ethers by Chan-Lam etherification of the phenol byproduct with the parent boronic acid (oxidative homocoupling) ${ }^{75}$ Reductive homocoupling of the organoboron has also been observed but appears generally less problematic than protodeboronation and oxidation pathways, ${ }^{75,77}$ although $\mathrm{Cu}$-catalyzed homocoupling of organoboron species is well known ${ }^{81-89}$

Scheme 5. Common side reactions and byproducts of Chan-Lam reactions.

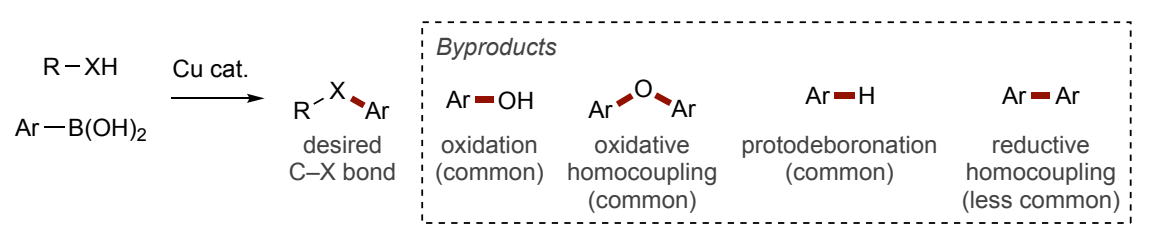

Lam established that oxidation results from water in the system, ${ }^{70}$ i.e., a competing Chan-Lam $\mathrm{C}-\mathrm{O}$ bond formation using $\mathrm{H}_{2} \mathrm{O}$ as the heteroatomic nucleophile. Phenol, and consequently diaryl ether, formation can therefore be diminished by using dry equipment/reagents/solvents and by inclusion of molecular sieves. ${ }^{59}$ However, it should be noted that some reactions work more effectively with added water or water as solvent. ${ }^{76,81,90-92}$ Protodeboronation of organoboron compounds using $\mathrm{Cu}$ (II) has been known for $>80$ years $;{ }^{93,94}$ however, whether this is a parallel competing process or proceeds via a common $\mathrm{Cu}$ (aryl) species is unknown. Similarly, the mechanistic origin of reductive homocoupling is underdeveloped. ${ }^{82}$ In addition, a general lack of reported empirical data on observations of protodeboronation and reductive homocoupling within Chan-Lam processes precludes even a surface level trend analysis.

Despite the absence of data and discussion of byproduct production in almost all Chan-Lam methodology studies, the general requirement for superstoichiometric quantities of the organoboron component ( 2 equiv is common) suggests it is highly likely that these undesired pathways are operational in most systems. Some recent studies have shown how analysis of byproducts alongside mechanistic understanding and ligand design can allow development of conditions that can improve reaction efficiency while lowering byproduct formation (discussed in more detail in Section 4). ${ }^{75,77,78}$ 


\subsection{Reactions Variables and Selection of Reaction Conditions}

As noted above, methodology studies have provided a wide variety of reaction conditions for Chan-Lam couplings. Despite the breadth of $\mathrm{C}-\mathrm{X}$ bonds that can be made, the most common Chan-Lam reactions are, by far, amination using alkyl and aryl amines. Based on the available evidence, classic Chan-Lam conditions (stoichiometric $\mathrm{Cu}(\mathrm{OAc})_{2}, \mathrm{Et}_{3} \mathrm{~N}, \mathrm{CH}_{2} \mathrm{Cl}_{2}$, air, rt) can likely be expected to deliver the desired product, at least in straightforward systems. ${ }^{58,60}$ However, there exists a multitude of published conditions, each offering either stated advantages (e.g., ability to use catalytic $\mathrm{Cu}$ ) or simply stating that the variant of reaction conditions works for the described process. This potentially renders selection of a set of conditions for a new transformation non-obvious. ${ }^{77}$ Indeed, in early studies of the heteroatomic nucleophile scope of the Chan-Lam reaction, Cundy commented on "the somewhat capricious nature of this reaction". ${ }^{95}$ However, from the available data, some direction can be obtained. Examples of the range of variables used for Chan-Lam reactions are provided in Table 1, the most common of each is indicated.

\begin{tabular}{|c|c|}
\hline Variable & \\
\hline $\mathrm{Cu}$ source & $\begin{array}{l}\mathbf{C u}(\mathrm{OAc})_{2}, \mathrm{Cu}(\mathrm{OTf})_{2}, \mathrm{Cu}(\mathrm{OPiv})_{2}, \mathrm{Cu}(\mathrm{acac})_{2}, \mathrm{Cu}(\mathrm{TFA})_{2}, \mathrm{CuBr}_{2}, \mathrm{CuCl}_{2}, \mathrm{CuSO}_{4}, \\
\mathrm{CuFAP},\left[\mathrm{Cu}(\mathrm{DMAP})_{4} \mathrm{I}\right] \mathrm{I},[\mathrm{Cu}(\mathrm{OH}) \cdot \mathrm{TMEDA}]_{2} \mathrm{Cl}_{2}, \mathrm{Cu}(\mathrm{MeCN})_{4} \mathrm{PF}_{6}, \mathrm{CuCl}, \mathrm{Cu}_{2} \mathrm{O}, \\
\mathrm{Cu}_{2} \mathrm{~S} \text {, heterogenized } \mathrm{Cu}\end{array}$ \\
\hline Oxidant & $\mathrm{O}_{2}$ (air), $\mathrm{O}_{2}$, pyridine $N$-oxide, TEMPO, $(t-\mathrm{BuO})_{2}$ \\
\hline Base & $\begin{array}{l}\mathbf{E t}_{3} \mathbf{N},(i \text {-Pr })_{2} \mathrm{NEt} \text {, pyridine, 4-methylpyridine, 2,6-lutidine, } \mathrm{K}_{2} \mathrm{CO}_{3}, \mathrm{~K}_{3} \mathrm{PO}_{4}, \mathrm{KO} t \text { - } \\
\mathrm{Bu}, N \text {-methylpiperidine, } n \text { - } \mathrm{Bu}_{4} \mathrm{NOH}, \mathrm{NaOSiMe}_{3} \text {, none }\end{array}$ \\
\hline Solvent & $\begin{array}{l}\mathbf{C H}_{2} \mathbf{C l}_{2}, \mathrm{MeCN}, \mathrm{EtOAc}, \mathrm{MeOH}, \mathrm{EtOH}, 1 \text {,4-dioxane, NMP, THF, DMF, PhMe, } \\
\text { DMSO, } \mathrm{H}_{2} \mathrm{O}, t-\mathrm{BuOH}\end{array}$ \\
\hline Ligand & $\begin{array}{l}\text { None, TMEDA, DMAP, NacNac derivatives, pyridine, 1,10-phenanthroline, } \\
\text { iminoarylcarboxylates, iminoarylsulfonates }\end{array}$ \\
\hline Additive & None, myristic acid, urea, $\mathrm{B}(\mathrm{OH})_{3}$ \\
\hline Temperature & rt, $40-100{ }^{\circ} \mathrm{C}$ \\
\hline
\end{tabular}

Table 1. Examples of the range of variables compatible with Chan-Lam reactions. Most common indicated in bold.

Cu source. $\mathrm{Cu}(\mathrm{OAc})_{2}$ has become the 'classic' $\mathrm{Cu}$ source for Chan-Lam reactions and was used in all three initial studies, ${ }^{58-60}$ as well as the preceding works using arylbismuth, ${ }^{50,52}$ aryllead, ${ }^{55}$ arylsiloxanes, ${ }^{56}$ and arylstannanes. ${ }^{57}$ This remains the $\mathrm{Cu}$ source most widely used for Chan-Lam reactions. With regards to the frequently troublesome (and often academic) question of stoichiometry, the early studies used superstoichiometric (1-2 equiv) $\mathrm{Cu}(\mathrm{OAc})_{2},{ }^{58-60}$ with Evans specifically demonstrating that stoichiometric amounts of $\mathrm{Cu}(\mathrm{OAc})_{2}$ and aerobic conditions were required for the $\mathrm{C}-\mathrm{O}$ bond forming process to proceed in good yield. ${ }^{59}$ Mechanistically, the process is believed to require $\mathrm{Cu}(\mathrm{II})$ at the outset; however, in situ $\mathrm{Cu}(\mathrm{I})$ disproportionation ${ }^{96}$ or oxidation of $\mathrm{Cu}(\mathrm{I})^{97,98}$ likely explains why $\mathrm{Cu}(\mathrm{I})$ sources can be used. 
Although the number of examples is lower, the use of $\mathrm{Cu}$ (II) halides $\left(\mathrm{CuCl}_{2}, \mathrm{CuBr}_{2}\right)$ has been reported. Despite halogenation of arylboronic acids and derivatives being known to proceed via ipso-substitution using $\mathrm{X}_{2}$ generated in situ by the well-known $\mathrm{Cu}(\mathrm{II}) / \mathrm{X}^{-} \rightarrow \mathrm{Cu}(\mathrm{I}) / \mathrm{X}_{2}$ redox process (Scheme 6), ${ }^{93,96,97}$ coupling to counteranions derived from the $\mathrm{Cu}$ source has not been reported. However, this is somewhat achievable under certain circumstances; for example, acetate esters are not reported when using $\mathrm{Cu}(\mathrm{OAc})_{2}$, although it is possible to prepare phenolate esters by Chan- $\mathrm{Lam}$ of $\mathrm{AcOH}$ (and other carboxylic acids) using $\mathrm{Cu}(\mathrm{OTf})_{2} .{ }^{99}$

Scheme 6. Halogenation of arylboronic acids using $\mathrm{CuX}_{2}$.

$\mathrm{Cu}(\mathrm{II})+\mathrm{x}^{-} \stackrel{-\mathrm{Cu}(\mathrm{I})}{\longrightarrow} \mathrm{x}_{2} \stackrel{\mathrm{Ar}-\mathrm{B}(\mathrm{OH})_{2}}{\text { ipso-substitution }} \quad \mathrm{Ar}=\mathrm{X}$

Many methodology studies focus on delivering processes that are catalytic in $\mathrm{Cu}$, and despite the advantages that this might hold in the context of sustainable chemistry and/or process design, stoichiometric $\mathrm{Cu}(\mathrm{OAc})_{2}$ is inexpensive and is generally effective for many reactions, often requiring less forcing conditions or additives/ligands (some of the most effective ligands are bespoke). The tradeoff between stoichiometric $\mathrm{Cu} v s$. the need for higher temperatures or additives using catalytic $\mathrm{Cu}$ is one that can only be justified by considering the totality of a chemical process in context. While showing the potential for catalysis is useful, the downstream (e.g., industrial) utility is not necessarily clear from an academic methodology study. In addition, while there are very effective catalytic processes in the literature, in the authors' opinion and based on experience in Chan-Lam amination, ${ }^{75,78,100}$ attempting catalytic $\mathrm{Cu}$ often causes more problems than it solves and, depending on the context, when attempting a new reaction, using stoichiometric $\mathrm{Cu}(\mathrm{OAc})_{2}$ would seem to be the most pragmatic approach from a synthetic perspective, at least initially.

Finally, it is worth noting that heterogenized copper sources have also been reported, including those immobilized in inorganic frameworks ${ }^{101,102}$ and organic resins. ${ }^{103,104}$ These systems seem to offer increased tolerance to $\mathrm{H}_{2} \mathrm{O}$ than more common $\mathrm{Cu}$ sources.

Oxidant. Based on current understanding, the reaction requires $2 \times \mathrm{Cu}(\mathrm{II})$ per $\mathrm{C}-\mathrm{X}$ bond formed. ${ }^{73-78}$ Note that this does not necessarily mean per desired $\mathrm{C}-\mathrm{X}$ bond formed but rather for the total conversion of $\mathrm{ArB}(\mathrm{OH})_{2}$ to $\mathrm{Ar}-\mathrm{X}$ or $\mathrm{Ar}-\mathrm{Ar}$, where $\mathrm{Ar}-\mathrm{X}$ is the desired product, phenol (from oxidation), or diarylether (oxidative homocoupling), and $\mathrm{Ar}-\mathrm{Ar}$ arises from reductive homocoupling, which is also promoted by $\mathrm{Cu}^{81-89}$ Consequently, full conversion of organoboron requires (at least) two relative stoichiometric equivalents of $\mathrm{Cu}$ and where the stoichiometry is less than this, a terminal oxidant is required for oxidative turnover. By far the most widely used, and indeed convenient, oxidant is $\mathrm{O}_{2}$ as derived from an atmosphere of air. ${ }^{105}$ Evans demonstrated that an atmosphere of argon led to poorer yield in $\mathrm{C}-\mathrm{O}$ bond formation ${ }^{59}$ and Stahl has unequivocally shown the role of $\mathrm{O}_{2}$ in driving the catalytic reaction using gas uptake studies and kinetic analysis. ${ }^{73,74}$ A pure $\mathrm{O}_{2}$ atmosphere has been used in several studies and has shown some benefits in these 
systems as compared to air, ${ }^{75,78}$ presumably originating from improved $\mathrm{O}_{2}$ uptake. Once again, the use of $\mathrm{O}_{2}$ must be objectively balanced based on the increased experimental risk and complexity, particularly in the context of industrial processes. ${ }^{78}$ Similarly, solid oxidants such as pyridine $N$-oxide and TEMPO have shown utility and may offer advantages in certain cases but also increase complexity/cost. ${ }^{101,106,107}$ It should also be noted that there has been two isolated reports of oxidant-free Chan-Lam processes, wherein the authors propose the formation of boranes $\left(\mathrm{HB}(\mathrm{OH})_{2}\right)$ as byproducts, but these seem to be the exception. ${ }^{108,109}$

There have also been examples where photocatalysis has been used to bolster catalytic Chan-Lam amination. ${ }^{110}$ The oxidizing power of photoexcited organometallic complexes has been proposed to assist the essential $\mathrm{Cu}(\mathrm{II}) \rightarrow \mathrm{Cu}(\mathrm{III})$ oxidation and thereby accelerate the reaction. If mechanistically correct, this has the potential to significantly improve catalytic Chan-Lam processes more generally. Similarly, Chan-Lam arylation of anilines has recently been developed, where the electrochemical set up is proposed to assist oxidative turnover. ${ }^{111}$ Although, while potentially very helpful, this does add an additional element of complexity to a reaction that has benefitted from the relative simplicity of reaction set up.

Base. There is a mechanistic dichotomy related to the role of the base. Ligation of the heteroatomic substrate to $\mathrm{Cu}(\mathrm{II})$ is essential and in the context of the amination process this requires an available $N$-lone pair. Since the reaction generates an equivalent of acid (HX) during the disproportionation step (with the quantity of HX present therefore correlating with the quantity of $\mathrm{Cu}(\mathrm{I})$ present), a base is required to mitigate substrate protonation that would otherwise impair ligation to $\mathrm{Cu}$ (II) (note that amine ligation to $\mathrm{Cu}(\mathrm{I})$ has also been implicated as beneficial for oxidative turnover ${ }^{75}$ ). Despite HX being essential to, and consumed during, $\mathrm{Cu}(\mathrm{I}) \rightarrow \mathrm{Cu}$ (II) oxidation for catalyst turnover, ${ }^{73,75}$ its presence can impair overall reaction efficiency due to substrate protonation. Accordingly, HX is both hero and villain, with its presence essential to one key mechanistic event and detrimental to another. HX must therefore be modulated effectively using a suitable base.

Early studies demonstrated that the addition of a base improves reaction yield, ${ }^{58-60}$ and reactions with bases are certainly more common; however, 'base-free' Chan-Lam amination reactions are well-known. ${ }^{75,81,108,112-}$ 115 This could be explained by the amine substrate, and the resulting amine product, fulfilling this role. Analysis of the most widely used bases reveals relatively weak organic bases, in particular $\mathrm{Et}_{3} \mathrm{~N}$, have been most common. Inorganic bases are less common but have seen success in certain situations. The potential reasons for the relative lack of methods using inorganic bases are undesired interactions with $\mathrm{Cu}$ and the organoboron. For example, in the classic Chan-Lam amination, denucleation of $\mathrm{Cu}(\mathrm{OAc})_{2}$ dimer is driven by the amine substrate and, depending on the Lewis basicity of the amine, is inhibited by $\mathrm{AcO}^{-} .{ }^{75} \mathrm{An}$ additional largely unrecognized issue relates to ligand speciation and the need for a redox gradient between two $\mathrm{Cu}(\mathrm{II})$ species to drive the disproportionation. While most mechanistic efforts have focused on establishing a 
reasonable description of the $\mathrm{Cu}$ within the main catalytic cycle, the ligation state of the $\mathrm{Cu}(\mathrm{II})$ oxidant, which is essential, remains unknown. The oxidation potential of $\mathrm{Cu}$ complexes is profoundly affected by the counteranion. ${ }^{98,116}$ Accordingly, use of inorganic bases that can coordinate $\mathrm{Cu}$ may affect the oxidation potential of the $\mathrm{Cu}$ (II) oxidant, thereby influencing the pivotal $\mathrm{Cu}(\mathrm{II}) \rightarrow \mathrm{Cu}(\mathrm{III})$ event.

Current understanding of the Chan-Lam mechanism suggests engagement of a $\mathrm{Cu}$ complex with the organoboron via Lewis pairing process. ${ }^{73-78}$ This requires the organoboron to be neutral and formation of boronates via interaction of the base may affect this event. ${ }^{117}$

Solvent. An analysis of Chan-Lam reaction shows that $\mathrm{CH}_{2} \mathrm{Cl}_{2}$ is the most frequently used solvent, although others have been successful-this is purely empirical. In their 1998 publication, Chan and Lam established the following order for the solvent in terms of reactivity for the $N$-arylation of imidazole: ${ }^{60} \mathrm{CH}_{2} \mathrm{Cl}_{2}>$ 1,4-dioxane $=\mathrm{NMP}=\mathrm{THF}=\mathrm{DMF}>>$ EtOAc $=$ Toluene $=\mathrm{DMSO}(\mathrm{MeOH}=\mathrm{NR})$.

The origin of solvent effects is unclear; however, solubility of $\mathrm{Cu}$ is likely to be critical. Many Chan-Lam reactions will appear heterogeneous due to low solubility of many $\mathrm{Cu}$ salts. Solubility is improved in alcoholic solvents but, while specific examples of Chan-Lam reactions have been shown in $\mathrm{MeOH}$ and $\mathrm{EtOH},{ }^{76,102,118-}$ 131 competing etherification can generate additional byproducts. Watson and coworkers have shown that MeCN:EtOH (20:1) mixtures can improve Chan-Lam amination reactions of anilines by assisting the denucleation of the $\mathrm{Cu}(\mathrm{OAc})_{2}$ dimer; ${ }^{100}$ however, the authors note that small amounts of ethyl ether were generated. In addition to solubility of $\mathrm{Cu}$, the solubility of the organoboron will vary. ${ }^{117}$

Ligand. The majority of Chan-Lam processes do not use a ligand; however, a number of processes using either preformed $\mathrm{Cu}$ complexes or with added ligands have been documented. Specific examples of preformed complexes include $[\mathrm{Cu}(\mathrm{OH}) \bullet \mathrm{TMEDA}]_{2} \mathrm{Cl}_{2},{ }^{71,72}\left[\mathrm{Cu}(\mathrm{DMAP})_{4} \mathrm{I}\right] \mathrm{I},{ }^{120}$ and Schaper's bespoke complexes (see Section 4) ${ }^{76,77}$ Besides preformed complexes, a number of other ligands have been used and/or assessed in various ways and with a range of success. ${ }^{17,72,90,112,130,132-136}$

Due to the different roles of $\mathrm{Cu}$ species and the potential of ligand speciation, the specific role of ligands in the Chan-Lam is rather ambiguous. Well-defined $\mathrm{Cu}$ complexes are beginning to allow more rigorous interrogation in these systems, for example, the complexes developed by Schaper. ${ }^{76,77}$ However, for the majority of systems that use simple salts ("ligand-free") identification of the structure and reactivity of $\mathrm{Cu}$ complexes, to allow processes to be tuned more effectively, remains especially difficult (see Section 4).

Additive. Similar to the above, the majority of Chan-Lam reactions do not use an additive. Buchwald found the addition of myristic acid to be beneficial for the Chan-Lam arylation of alkyl and aryl amines under 
catalytic conditions, ${ }^{137}$ with Yudin later finding the same catalytic conditions to be effective for the arylation of aziridines. ${ }^{138}$ However, the specific role of myristic acid is unknown, with the efficiency gains attributed to possible increased solubility of $\mathrm{Cu}$ species. ${ }^{137}$ Similarly, Cheng found the addition of urea enabled more effective arylation of carboxylic acids, yet the role of urea remains unknown (similar effects were noted with benzamide). ${ }^{99}$ Watson reported the use of $\mathrm{B}(\mathrm{OH})_{3}$ to enable a more effective coupling of arylboronic acid pinacol esters (BPin) with a range of nucleophiles under catalytic conditions. ${ }^{75}$ In this case, the role of $\mathrm{B}(\mathrm{OH})_{3}$ was established as precluding catalyst inhibition by pinacol while promoting oxidative turnover of $\mathrm{Cu}(\mathrm{I})$ to a similar extent as $\mathrm{Et}_{3} \mathrm{~N} \bullet \mathrm{AcOH}$. However, the same group reported that the $\mathrm{B}(\mathrm{OH})_{3}$ conditions were less effective for arylation of $N$-aryl sulfonamides, again highlighting the issue of generality across substrate types. $^{78}$

Temperature. Chan-Lam reactions are most often conducted at room temperature. Some reactions have required to be heated anywhere from $40-100{ }^{\circ} \mathrm{C}$ but the origin of this requirement is unknown. While heating is most common when using substoichiometric $\mathrm{Cu}$, numerous catalytic reactions do work effectively at room temperature. Accordingly, it is unclear what mechanistic event(s) require thermal promotion to ensure efficiency or if this is due to physical properties of the reagents, for example, solubility of the $\mathrm{Cu}$ source.

Substrates. As notoriously dangerous as making assumptions/predictions is, the majority of 'simple' ChanLam reactions, specifically those using alkyl or aryl amines or alcohols with arylboronic acids, can usually be expected to work reasonably effectively (i.e., deliver some desired product) using classic Chan-Lam reaction conditions with stoichiometric $\mathrm{Cu}(\mathrm{OAc})_{2}$. Greater general scope in the amination process has been demonstrated using the processes described by Phukan, ${ }^{120}$ Schaper, ${ }^{76,77}$ and Watson. ${ }^{75,78,100}$

Issues arise, however, when attempting to use different heteroatomic nucleophiles, even those that seem relatively innocuous. ${ }^{95}$ As noted briefly above (and will be discussed in more detail in Section 4), based on the current understanding of the process, substrate- $\mathrm{Cu}$ interactions are key. Of course, it is essential to have the heteroatomic nucleophile on the metal such that reductive elimination of the desired $\mathrm{C}-\mathrm{X}$ bond can take place. However, prior to this event, the substrate can be involved in denucleation (depending on the $\mathrm{Cu}$ source). In addition, and perhaps more importantly, the ligation of the heteroatomic nucleophile will affect the oxidation potential of the $\mathrm{Cu}$ (II) complex, affecting the key disproportionation. Moreover, it has been shown that the oxidative turnover of $\mathrm{Cu}(\mathrm{I})$ is influenced by heteroatomic nucleophile in Chan-Lam aminations. ${ }^{75}$ In this light, it is perhaps unsurprising that reaction efficiency is hugely affected by the heteroatomic substrate and this influence is not understood or, consequently, easily predicted.

There are subtle complexities even within tried and tested amination reactions. For example, a reaction that is effective with arylboronic acids can be challenging by the seemingly straightforward change to using the equivalent BPin compound. ${ }^{75,100,139-142}$ In addition, the electronics of the aryl ligand can reasonably be 
expected to affect $\mathrm{Cu}(\mathrm{II})$ disproportionation. There is a general issue with ortho-substitution of the aryl organoboron, where reactions tend to be less effective with increasing bulk around the borylated position again the reasons are unclear.

With regards to understanding, it is important to recognize when a Chan-Lam reaction is a Chan-Lam reaction and not something else. Chan-Lam methods are distinct from other methods using organoboron compounds for cross-coupling and also distinct from other $\mathrm{Cu}$-mediated $\mathrm{C}-\mathrm{X}$ bond forming reactions. While this may sound obvious, there are several instances of confusion where the Chan-Lam amination has been referred to as a Suzuki reaction ${ }^{143,144}$ or as an Ullmann reaction. ${ }^{145}$

\section{SCOPE OF THE CHAN-LAM AMINATION}

The substrate scope of the Chan-Lam amination is broad, with the majority of the routine compound classes containing a functionalizable NH position explored as substrates. In addition, certain compounds ostensibly non-compliant with this remit (i.e., lacking a conventional $\mathrm{N}-\mathrm{H}$ ) have also undergone $\mathrm{C}-\mathrm{N}$ bond formation under Chan-Lam conditions (vide infra). There have been several preceding reviews of Chan-Lam C-N/C-X bond formation and the reader is directed to these resources for additional accounts of scope. ${ }^{18,22,61-67}$ The following sections provide examples of the successful use of the Chan-Lam reaction to forge $\mathrm{C}-\mathrm{N}$ bonds since 2011. Where possible, examples have been selected that show the utility of the chemistry in nonacademic methodology projects, i.e., preferentially presenting applications from industrial medicinal chemistry studies. Methodological examples are provided where this has not been possible. The scope of utility is particularly large; accordingly, only selected examples of the particular $\mathrm{C}-\mathrm{N}$ bond-forming reaction classes are discussed.

\subsection{Organoboron Variation}

The vast majority of Chan-Lam aminations employ arylboronic acids - examples of these are provided in the following sections. That other organoboron compounds are less frequently used perhaps indicates that these are less readily accommodated. Indeed, the comparative difficulty in using arylboronic acid pinacol esters (ArBPin) has been noted, with the origin of this problem proposed to be due to $\mathrm{Cu}$ inhibition ${ }^{75}$ or lower reactivity relative to the equivalent boronic acid. ${ }^{142}$ However, there has been a number of developments in the application of various other organoboron reagents, providing additional substrate breadth of the Chan-Lam amination; a selection of these are highlighted in this section.

Arylboronic acids are, by far, the most common coupling partners for Chan-Lam reactions, with the analogous alkylboronic acids much less frequently employed; however, there have been a number of reports employing simple alkylboronic acids such as $\mathrm{MeB}(\mathrm{OH})_{2}$ or $c$-propylB $(\mathrm{OH})_{2}(\mathrm{Scheme} 7)$. 
Pudlo and coworkers showed that $\mathrm{MeB}(\mathrm{OH})_{2}$ could be employed for aniline $N$-methylation using superstoichiometric $\mathrm{Cu}$ (Scheme 7a), ${ }^{146}$ demonstrating the use of a Chan-Lam coupling as an unconventional alternative to classical electrophile-based methylation.

Cyclopropyl motifs are common within medicinal chemistry and agrochemistry, with methods for their installation broadly desired. ${ }^{147} \mathrm{Zhu}$ and Neuville demonstrated $c$-propylboronic acid can readily undergo Chan-Lam coupling with a range of anilines and aliphatic amines (Scheme $7 \mathrm{~b}$ ). ${ }^{148}$ The reaction required stoichiometric $\mathrm{Cu}(\mathrm{OAc})_{2}$ and 2,2'-bipyridine as a ligand to proceed, with catalytic attempts significantly reducing reaction yields. These reaction conditions were subsequently used in a structure-activity relationship (SAR) study of verapamil (Scheme 7c). ${ }^{149}$

Scheme 7. Chan-Lam amination using alkylboronic acids.

(a) Use of $\mathrm{MeB}(\mathrm{OH})_{2}$<smiles>COC(=O)c1cc(OC)c(OC)cc1N</smiles>

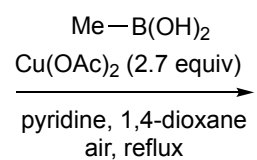<smiles>CCCCCCNNc1cc(OC)c(OC)cc1C(=O)OC</smiles>

(b) Use of c-propylB $(\mathrm{OH})_{2}$ (methodology)<smiles>CC(C)CNC(=O)C1CCCNC1</smiles>

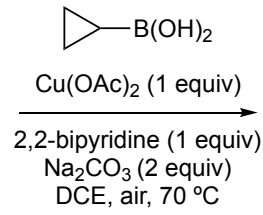

(c) Use of c-propylB $(\mathrm{OH})_{2}$ (target synthesis)<smiles>COc1ccc(CCNCCCC(C)(c2ccc(OC)c(OC)c2)C(C)C)cc1OC</smiles><smiles>COc1ccc(CCN(CCCC(C)(c2ccc(OC)c(OC)c2)C(C)C)C2CC2)cc1OC</smiles>

The direct use of arylboroxines have seen limited development within Chan-Lam couplings in general. Although it should be noted that where reaction mixtures are dry (as is common for Chan-Lam chemistry in order to avoid phenol formation) then it is highly likely that boroxine is formed in situ from the parent boronic acid. ${ }^{117}$ An example of boroxine-based amination from $\mathrm{Yu}$ and coworkers used catalytic $\mathrm{Cu}(\mathrm{OTf})_{2}$ in the absence of ligand/base and allowed effective $N$-arylation of amines and NH-heterocycles (Scheme 8). ${ }^{150}$ Despite the reaction being performed in $\mathrm{EtOH}$, no competing etherification was reported. In fact, protic solvents were found to be key for successful cross-coupling with the more common Chan-Lam solvents 
$\left(\mathrm{PhMe}, \mathrm{MeCN}, \mathrm{CH}_{2} \mathrm{Cl}_{2}\right.$ ) entirely ineffective. It is therefore likely that EtOH assists hydrolysis of the boroxine to the corresponding boronic acid diethyl ester, which may be more reactive.

Scheme 8. Chan-Lam amination of boroxines.<smiles>c1ccc2[nH]cnc2c1</smiles><smiles></smiles>

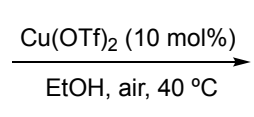<smiles></smiles>
$99 \%$ yield
18 other examples 30-98\% yield

Triolboronates are generally stable to air and water and are competent nucleophiles in Pd-catalyzed crosscoupling. ${ }^{151}$ Miyaura reported the Chan-Lam amination of a range of primary and secondary amines and heterocycles using potassium triolboronates under simple catalytic Chan-Lam conditions (Scheme 9). ${ }^{113,151}$ Perhaps most notable of these examples was the successful use of 2-pyridyl triolboronate, as the equivalent boronic acid is notoriously prone to protodeboronation. ${ }^{152,153}$

Scheme 9. Chan-Lam amination of triolboronates.<smiles></smiles><smiles>C1CCNCC1</smiles>

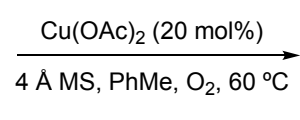

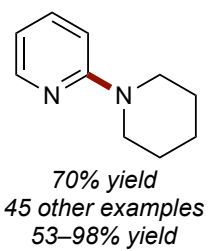

Batey demonstrated the compatibility of aryl potassium trifluoroborates $\left(\mathrm{ArBF}_{3} \mathrm{Ks}\right)$ as substrates for ChanLam amination soon after the initial discovery. ${ }^{112}$ Building on this earlier work, alkynyl, alkenyl, and alkyl $\mathrm{BF}_{3} \mathrm{Ks}$ have also been shown to effectively participate in Chan-Lam amination (Scheme 10). Evano and coworkers reported the synthesis of a range of ynamides using alkynyl $\mathrm{BF}_{3} \mathrm{Ks}$ (Scheme 10a). ${ }^{154}$ This process employed catalytic $\mathrm{CuCl}_{2} \bullet 2 \mathrm{H}_{2} \mathrm{O}$ in combination with 1,2-dimethylimidazole as a ligand, which was found to be crucial for reactivity. Interestingly, where electron-rich monodentate $N$-ligands (e.g., imidazoles) were effective, bidentate ligands (e.g., phenanthroline) completely inhibited the reaction.

In contrast, Batey developed the Chan-Lam coupling of alkenyl $\mathrm{BF}_{3} \mathrm{Ks}$ to a range of amides under ligandless conditions (Scheme 10b). ${ }^{155}$ This protocol was later expanded upon to enable the synthesis of enol esters from alkenyltrifluoroborate and carboxylic acids or carboxylates. ${ }^{156}$

Lastly, complementary to the use of $c$-propylB $(\mathrm{OH})_{2}$, Engle and McAlpine demonstrated the use of $c$-propyl $\mathrm{BF}_{3} \mathrm{~K}$ reagents for the alkylation of phenols and azaheterocycles (Scheme 10c). ${ }^{157}$ In their reaction development, the authors reported that copper(II) formate, rarely employed in Chan-Lam couplings, was as effective as $\mathrm{Cu}(\mathrm{OAc})_{2}$, although the latter was the preferred $\mathrm{Cu}$ source for the majority of the study. 
Scheme 10. Examples of the Chan-Lam amination of potassium trifluoroborates.

(a) Acetylinic $\mathrm{BF}_{3} \mathrm{~K}$<smiles>O=C1NCCO1</smiles>

(b) Alkenyl $\mathrm{BF}_{3} \mathrm{~K}$<smiles>NC(=O)c1ccccc1</smiles>

(c) c-propyl $\mathrm{BF}_{3} \mathrm{~K}$<smiles>O=c1cccc[nH]1</smiles>

$\mathrm{CuCl}_{2} \cdot 2 \mathrm{H}_{2} \mathrm{O}(15 \mathrm{~mol} \%)$

$\underset{4 \AA \mathrm{MS}, \mathrm{CH}_{2} \mathrm{Cl}_{2}, \mathrm{O}_{2} \text {, rt }}{\stackrel{\text { 1,2-dimethylimidazole }}{\longrightarrow}}$<smiles>[As]C1CC1C#CBr</smiles>

$\leadsto \mathrm{BF}_{3} \mathrm{~K}$

$\underset{\mathrm{DMSO} / \mathrm{CH}_{2} \mathrm{Cl}_{2}(1: 1)}{\stackrel{\mathrm{Cu}(\mathrm{OAc})_{2}(10 \mathrm{~mol} \%)}{\longrightarrow}}$ $4 \AA \mathrm{MS}, \mathrm{O}_{2}, 40^{\circ} \mathrm{C}$

$\mathrm{Cu}(\mathrm{OAc})_{2}(25 \mathrm{~mol} \%)$ $\underset{\mathrm{K}_{2} \mathrm{CO}_{3}(2 \text { equiv })}{\stackrel{1,10 \text {-phen }(12.5 \mathrm{~mol} \%)}{\longrightarrow}}$ $\mathrm{PhMe} / \mathrm{H}_{2} \mathrm{O}, \mathrm{O}_{2}, 60^{\circ} \mathrm{C}$

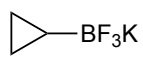

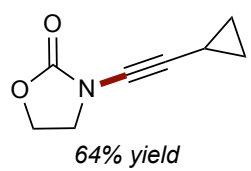

23 other examples

$27-99 \%$ yield

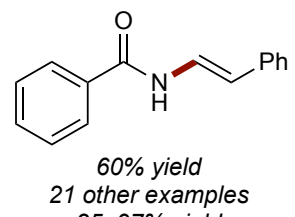

$25-97 \%$ yield

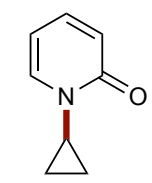

$87 \%$ yield

29 other examples $27-89 \%$ yield

Boronic acid pinacol esters (BPin) are common components within cross-coupling chemistry in general; however, they have seen much more limited uptake within Chan-Lam chemistry. As noted above, the reasons for this are likely due to poor reactivity as a result of $\mathrm{Cu}$ inhibition by pinacol, released during the reaction or due to lower reactivity. ${ }^{75,142}$ An early report from Hartwig successfully used arylBPin for the arylation of a range of primary amines in moderate to good yield by using KF as an additive (Scheme 11a). ${ }^{142}$ The origin of the KF effect is unclear but it is likely that this drives formation of a boronate, although the question remains whether this then facilitates hydrolysis or undergoes transmetalation.

A report from Kuninobu in 2016 demonstrated the catalytic Chan-Lam amination (and etherification) of amides using primary and secondary alkylBPin reagents, again highlighting the use of Chan-Lam chemistry as an alternative to more traditional alkylations (Scheme 11b) ${ }^{139}$ The reaction required the unusual use of $(t$ $\mathrm{BuO})_{2}$ as the terminal oxidant but organoboron oxidation was not reported to be problematic. Watson subsequently reported the catalytic amination of a wide range of functionalized alkylBPin but using a more complex mixture of catalyst and reagents, including a NacNac ligand, silanoate base, and, similar to Kuninobu, stoichiometric peroxide as terminal oxidant. ${ }^{158}$ 
Scheme 11. Methods for Chan-Lam amination using arylBPin. 
(a) Hartwig's arylBPin amination

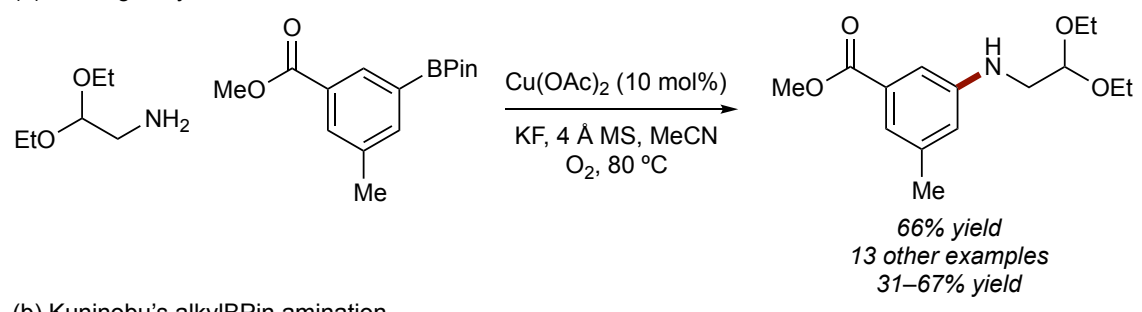

(b) Kuninobu's alkylBPin amination

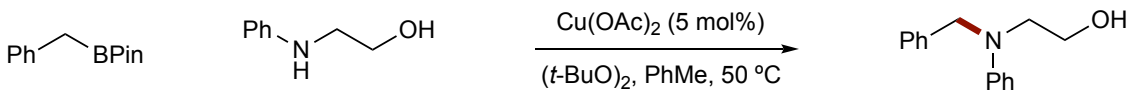

(c) Watson's process using NacNac ligands

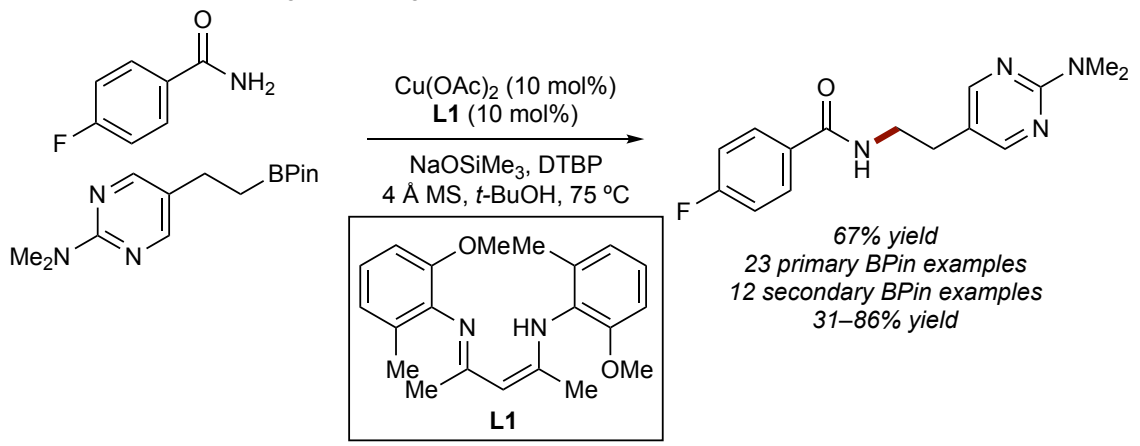

(d) Clark's arylBPin amination

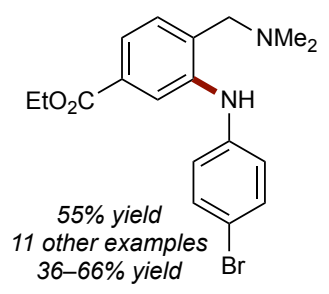

(e) Watson's arylBPin amination using mixed solvent
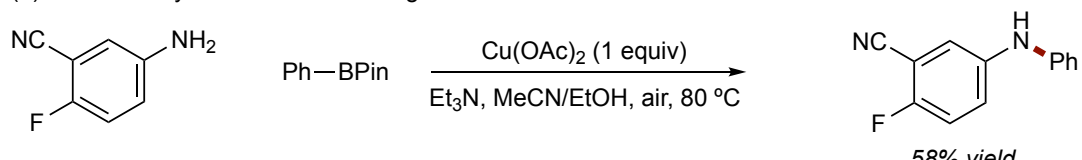

$$
58 \% \text { yield }
$$

61 other examples $10-91 \%$ yield

(f) Watson's arylBPin amination using $\mathrm{B}(\mathrm{OH})_{3}$<smiles>Cc1ccc(NC(=O)c2ccc(CN3CCN(C)CC3)cc2)cc1-c1ccccc1</smiles>

(g) Watson's arylBPin amination of sulfonamides<smiles>CS(=O)(=O)Nc1cccnc1</smiles>

$\underset{\mathrm{K}_{3} \mathrm{PO}_{4}, \mathrm{MeCN} \text {, air, rt }}{\stackrel{\mathrm{Cu}(\mathrm{MeCN})_{4} \mathrm{PF}_{6}(50 \mathrm{~mol} \%)}{\longrightarrow}}$<smiles>Cc1ccc(NC(=O)c2ccc(CN3CCN(C)CC3)cc2)cc1Nc1nccc(-c2cccnc2)n1</smiles><smiles>CS(=O)(=O)N(c1cccnc1)c1cccnc1</smiles>

$51 \%$ yield

24 other examples 35-96\% yield 
Clark and coworkers reported the amination of benzylamine-based arylBPin under catalytic Chan-Lam conditions using simple $\mathrm{Cu}(\mathrm{OAc})_{2}$, although the addition of $\mathrm{KF}$ was beneficial in some cases (Scheme 11d). ${ }^{140}$ The typical recalcitrant BPin reactivity is overcome by site-directed activation where $\mathrm{Cu}$-coordination to the benzylamine is proposed to aid transmetalation. The group later applied the same activation process for ChanLam etherification of phenols under similar conditions. ${ }^{141}$ Similar to Clark, Xu subsequently demonstrated that a range of carbonyl groups could also promote ArBPin cross-coupling via $\mathrm{Cu}$-coordination. ${ }^{159}$

In 2016, Watson and coworkers found that a 20:1 MeCN/EtOH system allowed effective Chan-Lam amination using arylBPin (Scheme 11e). ${ }^{100} \mathrm{~A}$ small quantity of EtOH significantly improved reaction efficiency using stoichiometric $\mathrm{Cu}(\mathrm{OAc})_{2}$ across a broad range of substrates and with minimal etherification reported. The same group subsequently reported a mechanistic investigation of the amination process (see Section 4) where they identified $\mathrm{B}(\mathrm{OH})_{3}$ had positive effects on specific mechanistic events. ${ }^{75}$ Use of $\mathrm{B}(\mathrm{OH})_{3}$ as an additive instead of $\mathrm{Et}_{3} \mathrm{~N}$ allowed effective catalytic Chan-Lam amination of arylBPin using alkyl and aryl amines as well as several other nucleophile classes, with utility exemplified in the synthesis of the tyrosine-kinase inhibitor Imatinib on $0.5 \mathrm{~g}$ scale (Scheme 11f). However, the $\mathrm{B}(\mathrm{OH})_{3}$ conditions were found to be ineffective for general arylation of $N$-aryl sulfonamides using arylBPin, with Watson and coworkers subsequently identifying alternative conditions for this substrate class (Scheme $11 \mathrm{~g}){ }^{78}$

\subsection{Aryl Amines (Anilines)}

As noted above, aryl amines are valuable pharmacophores and a primary target for the development of TMcatalyzed arylation methodology. Unsurprisingly, aryl amines have been thoroughly explored as one of the main amine classes within Chan-Lam amination. Selected recent examples within drug discovery are provided below.

The Chan-Lam amination was used for the library synthesis of 4-aryloxy anilines for succinate-cytochrome C reductase (SCR) inhibition, an enzyme essential in bacteria and fungi cellular machinery, by $\mathrm{Wu}$ and coworkers (Scheme 12). ${ }^{160}$ Optimization of reaction conditions ( $\mathrm{Cu}$ source, base, solvent) identified essentially classic Chan-Lam conditions as the most effective approach. A small library of compounds was synthesized by variation of the aniline and boronic acid, allowing identification of nanomolar inhibitors of the target.

Scheme 12. $N$-arylation of anilines within SCR drug discovery.

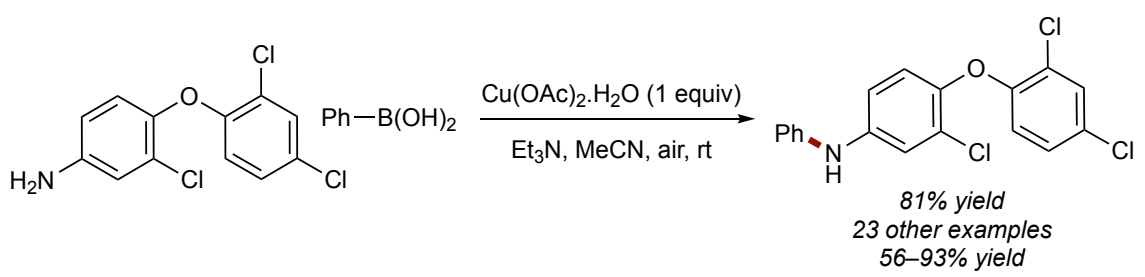


Similarly, Simons and coworkers prepared inhibitors of retinoic acid 4-hydroxylase (CYP26) using ChanLam arylation of an aniline core as an integral part of the route, again under classical Chan-Lam conditions (Scheme 13). ${ }^{143,144,161}$ A small library of final products was prepared using a range of aryl boronic acids, including heterocyclic examples, with some final products ultimately displaying greater potency than marketed drugs in this therapy area.

Scheme 13. $N$-arylation of aniline within CYP26 drug discovery.<smiles>COC(=O)C(O)C(C)(C)C(=O)Oc1ccc(O)cc1</smiles>
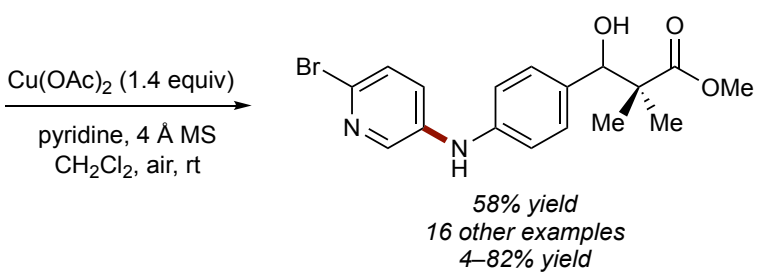

A late stage Chan-Lam amination was used by Asada and coworkers to aid the SAR investigation as part of a program to develop selective antagonists for EP3 (Scheme 14). ${ }^{162}$ Four different boronic acids were coupled to the aniline core, with chemoselectivity over the appended secondary amide, generating the expected products in good yield.

Scheme 14. $N$-arylation of aniline within EP3 drug discovery.<smiles>CCOC(=O)CCc1ccc(N)cc1C(=O)NC(CC(C)C)c1cc(C)cc(C)c1</smiles>

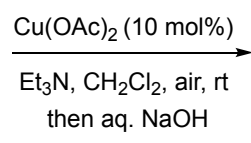

Hattori and coworkers used the Chan-Lam amination as part of a late-stage SAR investigation to access novel agonists for $\beta^{3}$-adrenergic receptors (Scheme 15). ${ }^{163}$ A small selection of arylboronic acids was used to arylate aniline cores and seemed to be chemoselective towards the aniline over the appended secondary alcohol motif; however, the yields were moderate and no comment was given on the mass balance. 
Scheme 15. $N$-arylation of aniline within $\beta^{3}$-adrenergic receptor drug discovery.
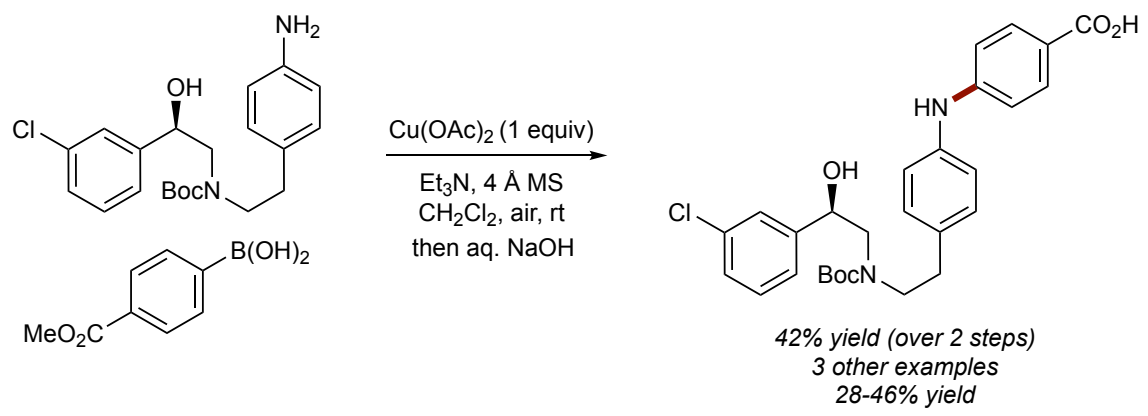

\subsection{Heteroaryl Amines (Heterocyclic Anilines)}

As noted above, variation in substrate electronics can significantly affect reaction performance, which is likely to manifest more profoundly in the Chan-Lam amination of heteroaryl amines. In addition, depending on the heterocyclic component, coordination to $\mathrm{Cu}(\mathrm{I})$ or $\mathrm{Cu}$ (II) has greater potential to affect mechanistic events than in simple aniline systems; however, this can be difficult to deconvolute from other possible factors that may also affect efficiency. Selected examples of heteroaryl amine arylation in medicinal chemistry projects are provided below.

Salvati and coworkers synthesized an array of inhibitors of MEK, a kinase linked to various human cancers. ${ }^{164}$ Late-stage arylation of an amino pyrrolopyridazine intermediate provided access to the expected products (Scheme 16) with apparent chemoselectivity for the primary aniline, although this was not specifically commented upon. Salvati commented that the low yield was likely a result of the density of $\mathrm{N}\left(\mathrm{sp}^{2}\right)$ in the template as well as steric issues imparted due to ortho-substitution.

Scheme 16. $N$-arylation of heterocyclic aniline within kinase drug discovery.<smiles>N#Cc1cnn2cc([O-])c([N+](=O)[O-])c2c1Nc1ccc(O)cc1</smiles>

$$
\mathrm{Ph}-\mathrm{B}(\mathrm{OH})_{2} \underset{\mathrm{Et}_{3} \mathrm{~N}, \mathrm{CH}_{2} \mathrm{Cl}_{2}, \mathrm{rt}}{\stackrel{\mathrm{Cu}(\mathrm{OAC})_{2}}{\longrightarrow}}
$$

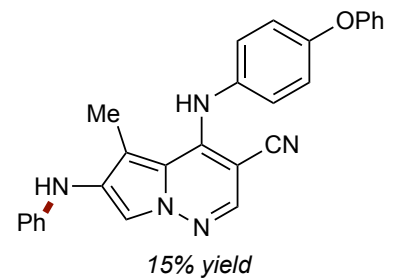

Formyl peptide receptors (FPRs) are associated with a variety of human physiological processes and of particular importance in inflammatory conditions. Giovannoni and coworkers synthesized a variety of selective FPR agonists via arylation of an amino pyridazinone core with methoxyphenyl boronic acids in moderate yields under classic Chan-Lam conditions (Scheme 17). ${ }^{165-167}$ 
Scheme 17. $N$-arylation of heterocyclic aniline within FPR drug discovery.<smiles>[R]c1c(C)nn(CC(=O)c2ccc(Br)cc2)c(=O)c1N</smiles>

$\mathrm{R}=$ ketone, pyrazole<smiles>COc1ccc(OC)cc1</smiles><smiles>CCOCCOCCOCCO</smiles><smiles>[R]c1c(C)nn(CC(=O)c2ccc(Br)cc2)c(=O)c1Nc1cccc(OC)c1</smiles>

Phosphatidylinositol 3 kinases (PI3Ks) have been the subject of interrogation due to their involvement in several pathologies. Smith and coworkers designed and synthesized a series of potential candidates for PI3K inhibition via Chan-Lam amination under classic conditions (Scheme 18) ${ }^{168}$ The low yield highlights the difficulty of coupling relatively simple substrates with multiple $\mathrm{N}\left(\mathrm{sp}^{2}\right)$.

Scheme 18. $N$-arylation of heterocyclic aniline within PI3K drug discovery.<smiles>Nc1ncncc1Br</smiles><smiles>COc1ccc(O)cn1</smiles><smiles>CCCCCCCOCCOCCO</smiles><smiles>COc1ccc(Nc2ncncc2Br)cn1</smiles>

\subsection{Alkyl Amines}

Primary and secondary alkyl amines are the most effective and therefore commonly employed $N$-nucleophiles within Chan-Lam amination. The mildness of the Chan-Lam amination allows the arylation of complex molecules, such as pharmaceuticals or agrochemicals, containing primary or secondary amine moieties at a late stage, providing a method for the generation of compound libraries for SAR analyses.

Judd and coworkers, employed a Chan-Lam amination for the arylation of a primary amine as part of an SAR campaign targeting methylated tetrahydropyran compounds for inhibitors of isoprenylcysteine carboxyl methyltransferase within anticancer research (Scheme 19a). ${ }^{169}$ A small library of analogues was prepared using classic stoichiometric Chan-Lam amination conditions, with variation of the arylboronic acid delivering the products in modest yield.

An oncology team at AstraZeneca demonstrated the use of the Chan-Lam amination to functionalize the core of a PI3K $\beta / \delta$ inhibitor (Scheme 19b). ${ }^{170}$ Arylation of the functionalized chromen-4-one core using 3,4,5trifluorobenzeneboronic acid using stoichiometric $\mathrm{Cu}(\mathrm{OAc})_{2}$ under an $\mathrm{O}_{2}$ atmosphere delivered a modest yield of the desired product. 
A team at GlaxoSmithKline reported the use of Chan-Lam amination in the late stage functionalization of a series of BET bromodomain inhibitors (Scheme 19c). ${ }^{171}$ A variety of aminotetrahydroquinoline cores (with variation of the Ar unit) were arylated using a range of arylboronic acids via Chan-Lam amination under classic stoichiometric conditions. While no yields were reported for these couplings, the scope of arylboronic acid was reasonably diverse, including a variety of electron-donating and electron-withdrawing substituents.

Scheme 19. $N$-arylation of primary amines in drug discovery.

(a) $\mathrm{N}$-arylation of alkyl amines in cancer drug discovery

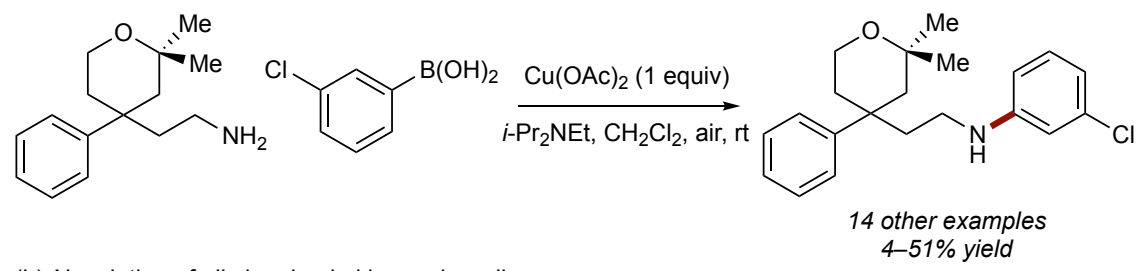

(b) $\mathrm{N}$-arylation of alkyl amine in kinase drug discovery 4-51\% yield

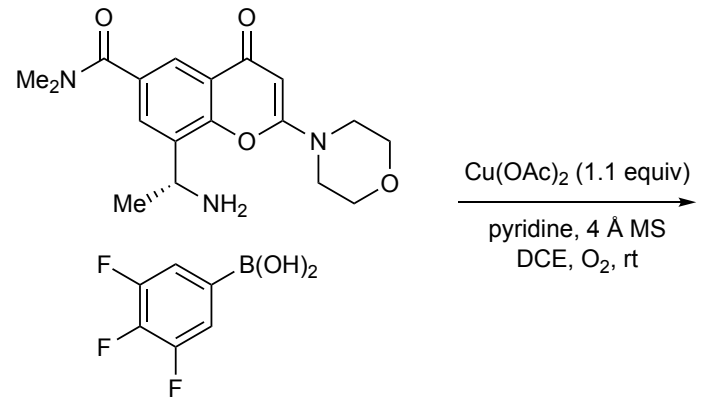

(c) $\mathrm{N}$-arylation of alkyl amines in kinase drug discovery<smiles>C[C@H](Nc1cc(F)c(F)c(F)c1)c1cc(C(=O)[N+](=O)[O-])cc2c(=O)cc(N3CCOCC3)oc12</smiles>

$31 \%$ yield

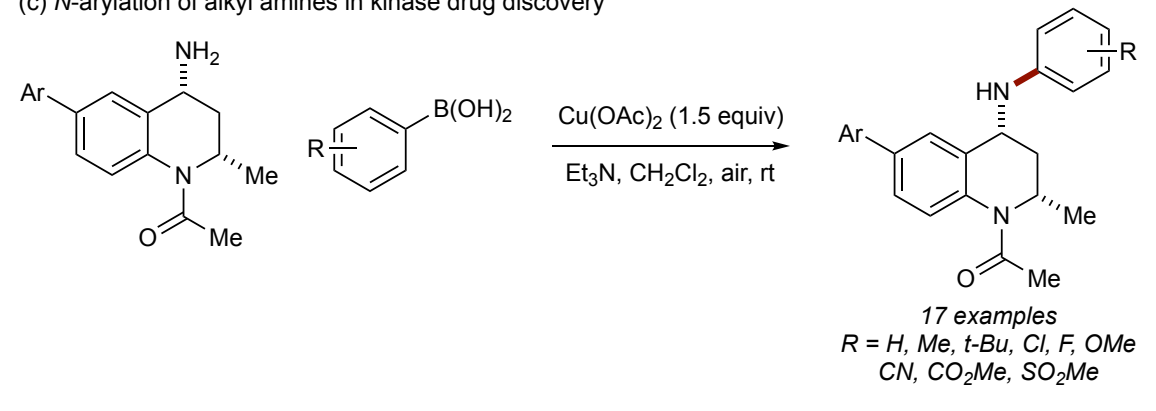

$\mathrm{Li}$ and Stamford used the Chan-Lam amination for the arylation of a piperidine derivative as part of an SAR campaign to develop neuropeptide Y (NPY) Y5 receptor antagonists (Scheme 20a). ${ }^{172}$ The late stage ChanLam amination using a wide variety arylboronic acids provided access to the desired library in generally low yield.

While the use of secondary cyclic amines, such as piperidine, within Chan-Lam amination is well known, the equivalent processes with smaller cyclic secondary amines are less well documented. One report from Yudin details the $N$-arylation of aziridines using a catalytic Chan-Lam reaction (Scheme 20b). ${ }^{138}$ While the authors report a limited scope of only two arylboronic acids and two aziridine derivatives, the couplings do proceed in moderate to good yield under the catalytic conditions developed by Buchwald. ${ }^{137}$ 
Scheme 20. $N$-arylation of cyclic secondary amines.

(a) $\mathrm{N}$-arylation of piperidine<smiles>CO[SH](C)(=O)N1CCC(N(C)C(=O)NC2CCNCC2)CC1</smiles><smiles>CCN(CC)CCOC(=O)OCC(C)Br</smiles>

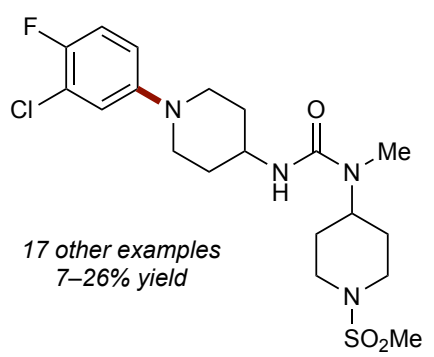

(b) $\mathrm{N}$-arylation of aziridine<smiles>C1CCC2NC2C1</smiles><smiles>COc1ccccc1Br</smiles>

$$
\begin{gathered}
\underset{\text { myristic acid, } 2,6 \text {-lutidine }}{\mathrm{ChMe} \text {, air, rt }} \\
\stackrel{\mathrm{PhMc})_{2}(10 \mathrm{~mol} \%)}{\longrightarrow}
\end{gathered}
$$

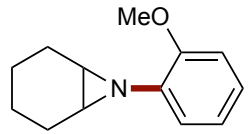

$78 \%$ yield

5 other examples

$40-87 \%$ yield

\subsection{Amides}

As one of the most prevalent groups in drug molecules, the preparation of amides remains one of the most practiced reactions in pharmaceutical research and development. ${ }^{3,5}$ The Chan-Lam amination has been used as a method for the functionalization of primary and secondary amides, providing an alternative method for secondary amide formation (i.e., by functionalization of a primary amide) or for the direct functionalization of secondary amides (e.g., for library synthesis).

Watson and coworkers reported the alkylation of primary amides using Chan-Lam amination with alkyl boronic acids, giving a range of secondary amides (Scheme 21). ${ }^{173}$ Despite alkylboronic acids being generally problematic, this was not reported to be an issue under the catalytic conditions. Similar to Koninobu, $(t-\mathrm{BuO})_{2}$ was used as an oxidant. Unusually, $\mathrm{NaOSiMe}_{3}$ was found to be the optimal base, with the authors suggesting this allowed generation of sufficient concentration of amide anion but without over-ligation of the $\mathrm{Cu}$ catalyst. The conditions were broadly effective to allow synthesis of a range of secondary amides, varying both the alkylboronic acid and substituents on the primary amides, and with no over alkylation reported.

Scheme 21. $N$-alkylation of primary amides.<smiles>CC1(C)C=C(C(N)=O)C(C)(C)N1</smiles><smiles>CC(C)CPO</smiles><smiles></smiles><smiles>CC(C)CNC(=O)C1=CC(C)(C)NC1(C)C</smiles>

Charton and coworkers prepared TGR5 agonists via arylation of a triazole-derived secondary amide under classic Chan-Lam conditions in moderate yield but on a relatively functional group-dense template, including several Cu-chelating sites (Scheme 22). ${ }^{174}$ 
Scheme 22. $N$-arylation of a secondary amide for TGR5 drug discovery.<smiles>COc1ccc([Se]O)cc1OCCNc1nnc(SCc2c(F)cccc2F)n1-c1ccc(F)cc1</smiles><smiles>COc1ccc(N(C)c2nnc(SCc3c(F)cccc3[PH](C)(=O)=O)n2-c2ccc(F)cc2)cc1OC</smiles>

While $\mathrm{Cu}$-chelation could be expected to interfere with catalytic Chan-Lam processes, Baidya and coworkers used this to their advantage, developing a chelation-assisted Chan-Lam coupling of secondary amides with arylboronic acids (Scheme 23). ${ }^{175}$ A picolinamide directing group allowed chemoselective amide $N$-arylation in the presence of a free indole $\mathrm{NH}$ and other functionalities using catalytic $\mathrm{Cu}$ with air as the terminal oxidant. The picolinamide could subsequently be removed via basic hydrolysis.

Scheme 23. Chemoselective $N$-arylation of amide $v s$. indole.<smiles>O=C(NCCc1c[nH]c2ccccc12)c1ccccn1</smiles><smiles>Oc1ccccc1</smiles><smiles>COC(=O)OCCOC(C)C</smiles><smiles>O=C(c1ccccn1)N(CCc1c[nH]c2ccccc12)c1ccccc1</smiles>

$90 \%$ yield 35 other examples $52-96 \%$ yield

Jones and Guy explored a new method of synthesizing 1-arylquinazolinediones by direct $N$-arylation of quinazolinediones via classic Chan-Lam conditions using arylboronic acids and with some success employing arylBPin and arylBF ${ }_{3} \mathrm{~K}$ (Scheme 24). ${ }^{176}$ Catalytic $\mathrm{Cu}$ could be used with TEMPO as terminal oxidant but at the expense of overall efficiency.

Scheme 24. Chemoselective $N$-arylation of amide $v s$. carboxylic acid.<smiles>Cn1c(=O)[nH]c2ccccc2c1=O</smiles><smiles>COc1ccc(C(=O)O)cc1</smiles><smiles>CCOC(=O)OCCOCCO</smiles><smiles>Cn1c(=O)c2ccccc2n(-c2ccc(C(=O)O)cc2)c1=O</smiles> 


\subsection{NH-Heterocycles}

Aromatic heterocycles are key constituents of bioactive molecules, with azaheterocycles particularly prevalent. Methods for alkylation or arylation of NH-heterocycles has been a focus of metal-catalyzed processes for many years, in particular via the Ullmann-Goldberg and Buchwald-Hartwig reactions. ${ }^{14,29-32}$ As with the $\mathrm{N}$-arylations discussed in the previous sections, the Chan-Lam amination offers an alternative for NH-heterocycle $N$-arylation with the associated benefits.

Zhang and coworkers used a Chan-Lam amination as the first step in their synthesis of a series of GPR120 inhibitors (Scheme 25) ${ }^{177}$ Substituted pyrroles or imidazoles were arylated to access the biaryl core which could then undergo further functionalization steps to furnish the desired compound collection. Despite using $\mathrm{MeOH}$ as solvent, the authors reported no competing etherification.

Scheme 25. $N$-arylation of pyrrole and imidazole.

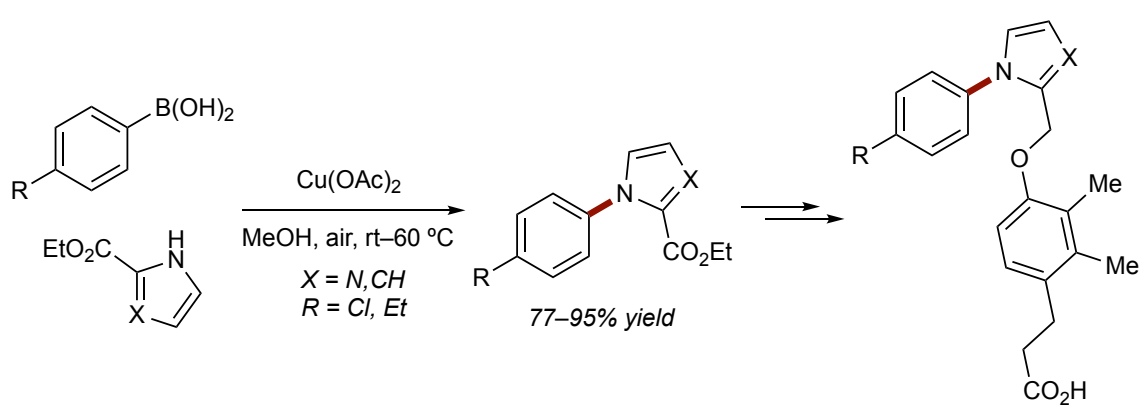

Perhaps one of the best demonstrations of the use of the Chan-Lam amination in the synthesis of bioactive molecules comes from researchers at Eli Lilly, who used a continuous reaction setup to synthesize the penultimate intermediate en route to an API on multikilo scale (Scheme 26). ${ }^{178}$ The pyrazole intermediate was alkylated with $c$-propylboronic acid under homogeneous catalytic conditions using diluted air $\left(5 \% \mathrm{O}_{2}\right.$ in $\left.\mathrm{N}_{2}\right)$ in order to deliver over $50 \mathrm{~kg}$ of the desired intermediate.

Scheme 26. Large scale $N$-alkylation of pyrazole.<smiles>Clc1cc(Oc2c[nH]nc2C2CCOCC2)ccn1</smiles>
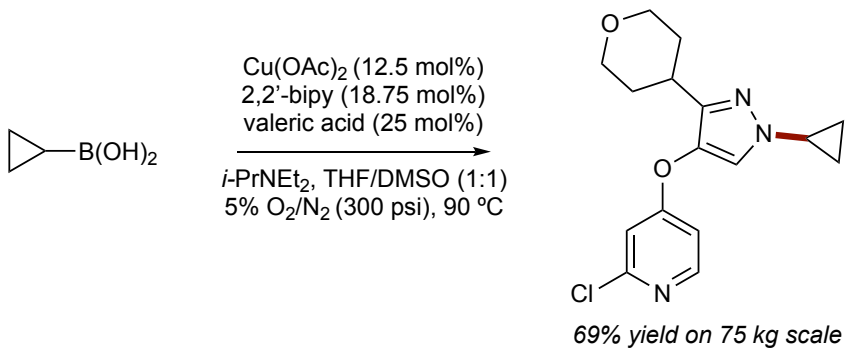

Han and coworkers demonstrated the $N$-arylation of tetrazoles under Chan-Lam conditions (Scheme 27). ${ }^{179,180}$ Their initial report in 2012 demonstrated this could be achieved using a low loading of $\mathrm{Cu}_{2} \mathrm{O}$ in DMSO under an $\mathrm{O}_{2}$ atmosphere, varying both the arylboronic acid and aryl tetrazole. ${ }^{179}$ Notably the reaction proceeds in the 
absence of any exogenous base or ligand. This prompted the authors to further investigate the mechanism of this reaction, and in 2014 they reported that both tetrazole and DMSO are crucial in forming the active $\mathrm{Cu}$ species through a series of coordination and oxidation processes. ${ }^{180}$ Latyshev and coworkers recently reported a complementary process for the $N$-vinylation of both triazoles and tetrazoles. ${ }^{181}$

Scheme 27. $N$-arylation of tetrazole.<smiles>c1ccc(-c2nn[nH]n2)cc1</smiles><smiles>COc1cccc([N+](=O)[O-])c1</smiles><smiles></smiles><smiles>O=[N+]([O-])c1cccc(-n2nnc(-c3ccccc3)n2)c1</smiles>

Researchers at Merck employed a Chan-Lam $N$-arylation to generate a library for SAR interrogation of a peroxisome proliferator-activated receptor $\gamma(\operatorname{PPAR} \gamma)$ partial antagonists (Scheme 28). ${ }^{182}$ Four substituted arylboronic acids were coupled to the indole core under classic Chan-Lam conditions and, following deprotection of the methyl ether, a second Chan-Lam achieved the desired $O$-arylation. The scope of the $O$ arylation was more varied, with nine different arylboronic acids employed.

Scheme 28. $N$-arylation of indole.

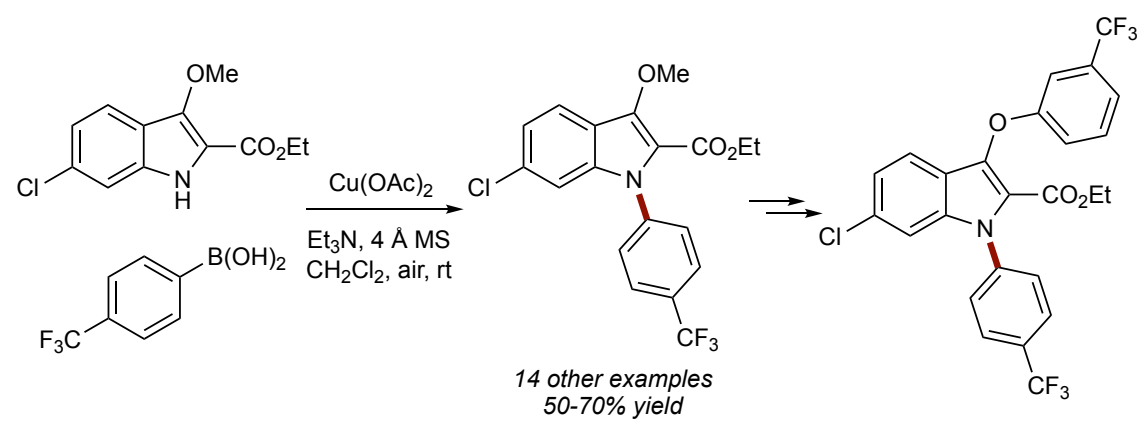

Van der Eycken and coworkers investigated the Chan-Lam reaction on pyrazinone compounds (Scheme 29a). ${ }^{183}$ An unusual set of conditions was developed where classic stoichiometric Chan-Lam conditions was subjected to microwave irradiation with simultaneous cooling. This is a rare example of a Chan-Lam amination being run below room temperature; however, it was found to be key in this process, as room temperature reactions were sluggish and heating caused a sharp drop off in yield. The authors reported the coupling of a range of arylboronic acids, many in excellent yield, with the unsuccessful reactions attributed to steric hindrance or instability of the boronic acids. No variation of the pyrazinone was reported.

On a related template, Kennedy and coworkers described the use of Chan-Lam amination to vary cytosinebased cores in their exploration of TET enzyme inhibitors; however, while this is a Chan-Lam process, this was incorrectly identified as "copper-mediated Ullman conditions" in the manuscript (Scheme 29b). ${ }^{145}$ This 
example builds on earlier work from $\mathrm{Yu}$ and coworkers who identified the $\mathrm{MeOH} / \mathrm{H}_{2} \mathrm{O}$ mixed solvent system as optimum for the coupling of similar nucleobases..$^{90}$ Interestingly, the coupling proceeds with complete chemoselectivity - neither Kennedy nor Yu report any competing coupling of the primary amine.

Scheme 29. $N$-arylation of pyrazinone and pyrimidinone (cytosine) scaffolds.

(a) $\mathrm{N}$-arylation of pyrazinone

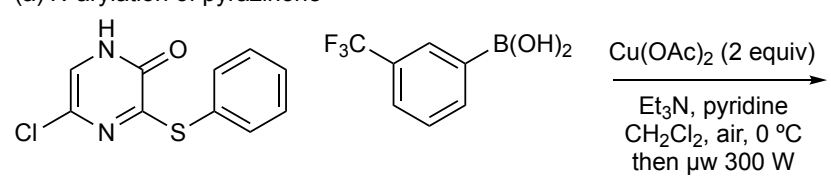<smiles>O=c1c(Sc2ccccc2)nc(Cl)cn1-c1cccc(C(F)(F)F)c1</smiles>

93\% yield 11 other examples

(b) $\mathrm{N}$-arylation of chlorocytosine 0-97\% yield<smiles>Nc1nc(=O)[nH]cc1Cl</smiles>

In an example involving a purine base, Nielsen and coworkers used the Chan-Lam amination to prepare a pleuromutilin derivative (Scheme 30a). ${ }^{184}$ The protected adenosine $N^{9}$ was arylated using 3- and 4iodophenylboronic acid using stoichiometric $\mathrm{Cu}(\mathrm{OAc})_{2}$. Further manipulations provided a series of compounds that were assessed against three different bacteria strains.

Das and coworkers developed a method for chemoselective $\mathrm{N}$-arylation of unprotected $1 \mathrm{H}$-pyrazolo[3,4b]pyridin-3-amines (Scheme 30b). ${ }^{185}$ The optimized conditions facilitated selective $N^{1}$-arylation over the anilinic position and was applicable to a range of aryl- and heteroarylboronic acids as well as variation of the azole. Following the initial $N^{1}$-arylation, optimized conditions were developed for arylation of the anilinic position, providing a method for sequential Chan-Lam arylation of this chemotype. It should also be noted that Das has developed conditions for chemoselective $N$-arylation in the presence of phenols providing further tools for discrimination of common functional groups. ${ }^{186}$

Ishikawa and coworkers employed the Chan-Lam amination as part of their route towards centromereassociated protein-E (CENP-E) inhibitors (Scheme 30c). ${ }^{187} \mathrm{~N}$-arylation of indole and thieno[3,2-b]pyrrole cores under classic Chan-Lam conditions delivered the desired $\mathrm{N}$-aryl products that were converted to the target compounds in several steps and assessed as inhibitors for CENP-E. 
Scheme 30. $N$-arylation of fused azaheterocycles.

(a) $\mathrm{N}$-arylation of purine<smiles>CC(C)(C)OC(=O)c1ncnc2[nH]cnc12</smiles><smiles>COc1ccc(I)cc1</smiles>

$\underset{\mathrm{Et}_{3} \mathrm{~N}, 3 \AA \mathrm{MS}, \mathrm{DMF}, \mathrm{rt}}{\stackrel{\mathrm{Cu}(\mathrm{OAc})_{2} \text { (1.5 equiv) }}{\longrightarrow}}$<smiles>CCCCNc1ncnc2c1ncn2-c1ccccc1</smiles>

42 and $51 \%$ yield 2 examples

(b) $N$-arylation of pyrazolo[3,4-b]pyridine<smiles>Nc1n[nH]c2ncccc12</smiles><smiles>Oc1ccc2c(c1)OCO2</smiles>

$\underset{\mathrm{MeOH}, \text { air, rt }}{\stackrel{\mathrm{Cu}(\mathrm{OAc})_{2}(20 \mathrm{~mol} \%)}{\longrightarrow}}$<smiles>Nc1nn(-c2ccc3c(c2)OCO3)c2ncccc12</smiles>

$85 \%$ yield 30 other examples $60-92 \%$ yield

(c) $\mathrm{N}$-arylation of thieno[3,2-b]pyrrole<smiles>CCOC(=O)c1cc2scc(Br)c2[nH]1</smiles><smiles>Oc1ccc(F)cc1</smiles><smiles>CCOC(=O)c1cc2scc(Br)c2n1-c1ccc(F)cc1</smiles>

$85 \%$ yield

\subsection{C-N Bond Formation to non-NH-Nucleophiles}

While the majority of Chan-Lam processes proceed using the remit of functionalization of the $N$-nucleophile by replacement of the $\mathrm{N}-\mathrm{H}$ with the $\mathrm{N}-\mathrm{C}$ bond, there are exceptions.

In an interesting example of chemoselectivity, $\mathrm{Xu}, \mathrm{Su}$, and Mo reported the $N$-selective alkenylation/arylation of hydroxybenzotriazole derivatives (Scheme 31a). ${ }^{188}$ While previous uses of $\mathrm{HOBt}$ in TM-catalyzed couplings reacted solely at the $O$-site, ${ }^{189}$ the authors found that stoichiometric Chan-Lam conditions, with the addition of $\mathrm{Na}_{2} \mathrm{SO}_{4}$, afforded the $\mathrm{N}$-coupled products. DFT calculations were performed to rationalize this selectivity, proposing that the $N$-atom binding and subsequent reductive elimination was more favorable by $3.0 \mathrm{kcal} \mathrm{mol}^{-1}$. The process was found to be very general, with a wide range of alkenyl and arylboronic acids tolerated in addition to substituted HOBt derivatives. The authors exemplify their study with the late stage functionalization of a steroid in good yield.

Similarly, Mo and coworkers developed a methodology for the synthesis of $N$-alkenyl nitrones employing Chan-Lam methodology and building on previous work from Anderson (Scheme 31b). ${ }^{190,191}$ The optimized conditions allowed for selective catalytic $N$-aryl/alkenylation of the nitrone motif, over the possible $-\mathrm{OH}$ and $-\mathrm{NH}$ sites. A large selection of alkenyl boronic acids were showcased, as well as variation of substituents on the benzene nucleus of the nitrone. Increasing the $\mathrm{Cu}$ equivalents led to arylation of both the nitrone and 
oxindole $(-\mathrm{NH})$ motifs and, interestingly, removal of the $\mathrm{C} 2$ carbonyl led to alkenylation of the $-\mathrm{OH}$ and $-\mathrm{NH}$ sites, highlighting the importance of the carbonyl moiety.

Scheme 31. $N$-aryl/alkenylation of non-NH-nucleophiles.

(a) $\mathrm{N}$-alkenyl/arylation of $\mathrm{HOBt}$<smiles>C=C1CC[C@H]2[C@@H]3CCc4cc([R9]O)ccc4[C@H]3CC[C@]12C</smiles>

$\mathrm{Cu}(\mathrm{OAc})_{2}$ (1 equiv)

$\mathrm{Na}_{2} \mathrm{SO}_{4}$, pyridine 1,4-dioxane, air, $40^{\circ} \mathrm{C}$

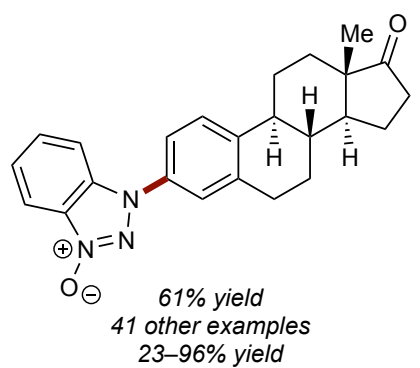

(b) $\mathrm{N}$-alkenylation of oxime

23-96\% yield
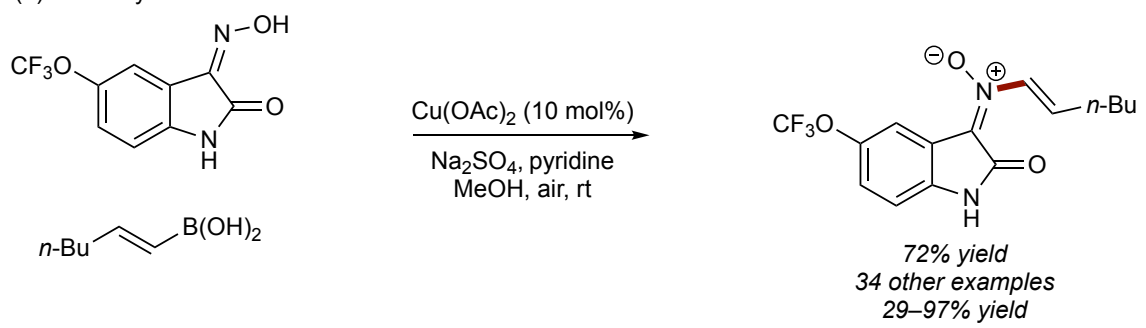

\subsection{Sulfonamides and Sulfoximes}

Similar to the amide functional group, sulfonamides are commonplace throughout medicinal chemistry, with the value of this unit clearly demonstrated by its presence in drug compounds for a wide range of diseases. Accordingly, methods for preparation or derivitization of sulfonamides are broadly valued in synthetic medicinal chemistry.

Manukonda and coworkers designed a series of potential inhibitors of PTP1B, a member of the protein tyrosine phophatases (PTP) family, using molecular docking. ${ }^{192}$ The Chan-Lam amination was used to carry out late stage SAR analysis via a selective $N$-arylation of a primary sulfonamide motif (Scheme 32a). Coupling of four different arylboronic acids, and subsequent hydroysis of the ethyl glyoxamide gave the desired oxamic acid products that were evaluated in a PTP1B inhibition assay.

In an example of large scale industrial Chan-Lam amination, Eastgate and coworkers improved on a previous synthesis of dicyclopropylamine hydrochloride (Scheme 32b). ${ }^{193}$ A thorough optimization was performed, identifying that $\mathrm{MeCN}$ addressed solubility issues and allowed full conversion of starting materials. Similarly, ligands were found to promote the process with 2,2'-bipyridine and 1,10-phenanthroline delivering the best performance, and 2,2'-bipyridine selected due to bulk availability and economics. On smaller scale, an $\mathrm{O}_{2}$ atmosphere was used as the stoichiometric oxidant; however, while this is a safety concern on large scale, moving to $5 \% \mathrm{O}_{2} / \mathrm{N}_{2}$ addressed these concerns and allowed effective arylation. Solid oxidants (e.g., $\mathrm{KMnO}_{4}$ and TEMPO) were ineffective. Regarding work-up, treatment with $1 \mathrm{~N} \mathrm{HCl}$ provided the lowest residual $\mathrm{Cu}$ 
concentration in the product $(<10 \mathrm{ppm})$. Ultimately, the arylation was carried out on scales of $60-80 \mathrm{~kg}$ in reliably high yields and purity.

Watson and coworkers developed the arylation of $\mathrm{N}$-aryl sulfonamides, a motif known to be difficult in ChanLam amination (Scheme 32c). ${ }^{78}$ Mechanistic reasoning identified $\mathrm{Cu}(\mathrm{MeCN})_{4} \mathrm{PF}_{6}$ as the $\mathrm{Cu}$ source as it avoided problems associated with denucleation with more common $\mathrm{Cu}$ sources $\left(\right.$ e.g., $\left.\mathrm{Cu}(\mathrm{OAc})_{2}\right) . N-$ methylpiperidine was used as the base for arylboronic acids, proposed to increase the concentration of $N$ arylsulfonamide anion and thereby the rate of $\mathrm{Cu}(\mathrm{I})$ oxidation. $\mathrm{K}_{3} \mathrm{PO}_{4}$ was found to perform better in the arylBPin system, thought to be due to its increased base strength increasing substrate anion concentration and limiting $\mathrm{Cu}$ inhibition by pinacol. A variety of arylboronic acids, arylBPins, and $N$-arylsulfonamides were explored, giving good to excellent yields. In a final showcase of the methodology, drug intermediate NS5B inhibitor GSK8175 was synthesized in good yield on multigram scale under tailored conditions.

Jia and $\mathrm{Xu}$ demonstrated that chemoselective $N$-arylation of aminobenzene sulfonamides was possible under two different sets of reaction conditions (Scheme 32d). ${ }^{194} \mathrm{Using} \mathrm{CuCl}$ and $\mathrm{Et}_{3} \mathrm{~N}$, selective $\mathrm{N}$-arylation of primary sulfonamides was effective across a range of substrates in generally good yield. Alternatively, CuTC and 2,6-lutidine enabled selective $N$-arylation of the appended aniline instead, again in good yield.

Bolm and Moessner developed catalytic Chan-Lam conditions for $\mathrm{N}$-arylation of sulfoximines using arylboronic acids under mild, base-free conditions (Scheme 32e). ${ }^{126}$ A notable absence of problematic side reactions was observed; no homocoupling and only small quantities of the methyl ether. A range of arylboronic acids were accomodated delivering some excellent yields, with the expected steric limitations observed (e.g., 2,6-dimethylphenylboronic acid was completely ineffective).

Scheme 32. Chan-Lam arylation of sulfonamides and sulfoximes. 
(a) Primary sulfonamide<smiles>CCOC(=O)C(=O)Nc1ccc(CC(c2nc3ccccc3o2)S(N)(=O)=O)cc1</smiles>

$\mathrm{R}=\mathrm{Me}, \mathrm{CF}_{3}$, OMe, $\mathrm{O}-\mathrm{Pr}$

(b) Secondary sulfonamide<smiles>O=[N+]([O-])c1ccc(S(=O)(=O)NC2CC2)cc1</smiles><smiles>[R]Oc1ccc(OC)cc1</smiles>

$\underset{\text { pyridine, } \mathrm{CH}_{2} \mathrm{Cl}_{2}, \mathrm{rt}}{\stackrel{\mathrm{Cu}(\mathrm{OAc})_{2} \text { (2 equiv) }}{\longrightarrow}}$ then hydrolysis<smiles>[R]c1ccc(NS(=O)(=O)C(Cc2ccc(NC(=O)C(=O)O)cc2)c2nc3ccccc3o2)cc1</smiles>

4 examples $30-38 \%$ yield

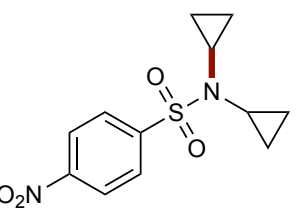

$90 \%$ yield on $60-80 \mathrm{~kg}$ scale

(c) Multigram synthesis of an API intermediate<smiles>O=C([O-])Nc1cc2oc(-c3ccc(F)cc3)c(C(=O)O)c2cc1C1CC1</smiles><smiles>CC(=O)c1cc(Br)cc(Cl)c1Br</smiles>

$\mathrm{Cu}(\mathrm{MeCN}){ }_{4} \mathrm{PF}_{6}$ (0.6 equiv)

$\overrightarrow{\mathrm{Et}_{3} \mathrm{~N}, \mathrm{MeCN}, 5 \% \mathrm{O}_{2} / \mathrm{N}_{2}, 10^{\circ} \mathrm{C}}$ then $\mathrm{MeNH}_{2}$

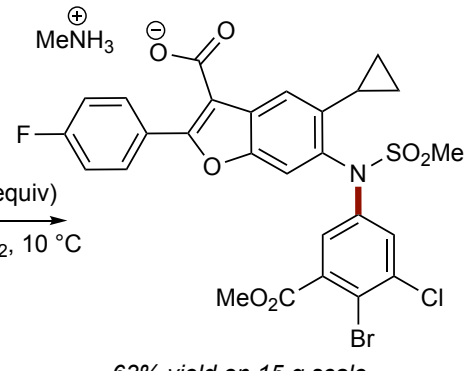

$63 \%$ yield on $15 \mathrm{~g}$ scale

(d) Chemoselective $\mathrm{N}$-arylation of sulfonamides/anilines
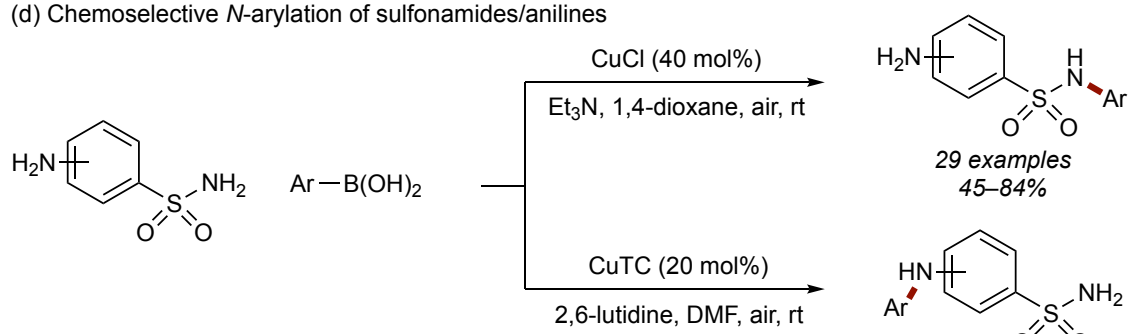

(e) $\mathrm{N}$-arylation of sulfoximine<smiles>CS(=N)(=O)c1ccccc1</smiles><smiles>Cc1ccccc1Br</smiles>

$\underset{\mathrm{MeOH}, \mathrm{rt}}{\stackrel{\mathrm{Cu}(\mathrm{OAc})_{2}(10 \mathrm{~mol} \%)}{\longrightarrow}}$

\subsection{Sequential Processes}

The ability of $\mathrm{Cu}$ to mediate several different catalytic reactions has allowed the development of reactions where two separate events are catalyzed by the same $\mathrm{Cu}$ additive. Guo and coworkers developed a one-pot synthesis of functionalized 1,2,3-triazoles from arylboronic acids, $\mathrm{NaN}_{3}$, and alkynes (Scheme 33a). ${ }^{127} \mathrm{An}$ initial Chan-Lam amination of arylboronic acids with $\mathrm{NaN}_{3}$ could be catalyzed by $\mathrm{CuSO}_{4}$ in $\mathrm{MeOH}$ under air. 
Subsequent addition of $\mathrm{H}_{2} \mathrm{O}, \mathrm{NaAsc}$, and terminal alkyne allowed formation of the triazole via a CuAAC process.

Busca and Prestat reported the diarylation of aminopyrazoles via chemoselective sequential $\mathrm{Cu}$ catalysis, in which aminopyrazoles first underwent a selective Ullmann-Goldberg reaction at the pyrazole $\mathrm{NH}$, followed by a Chan-Lam $N$-arylation of the primary amine using the same Cu catalyst (Scheme 33b). ${ }^{195}$ In order to achieve sequential $\mathrm{Cu}(\mathrm{I}) / \mathrm{Cu}(\mathrm{II})$ catalysis using the same $\mathrm{Cu}$ source, the reaction required the addition of several additives to neutralize byproducts from the initial Ullmann-Goldberg reaction. $\mathrm{AgBF}_{4}$ and $\mathrm{AcOH}$ were found to effectively neutralize $\mathrm{CsI}$ and $\mathrm{CsHCO}_{3}$, respectively, both of which were found to inhibit the second stage Chan-Lam reaction.

The Chan-Lam amination has been used in sequential processes to prepare a range of fused heterocycles. Neuville and Zhu showed that Chan-Lam amination could be merged with $\mathrm{C}-\mathrm{H}$ activation to allow the onepot synthesis of benzimidazoles via $N$-arylation of an amidine (Scheme 33c). ${ }^{196}$ Zhang demonstrated that acridines could be prepared via Chan-Lam amination of $o$-aminoaryl ketones followed by a Freidel-Crafts cyclization/dehydration process (Scheme 33d). ${ }^{197}$ The same authors also reported the synthesis of acridones via a similar process using $o$-aminoacetophenones. ${ }^{198}$ Wei and coworkers developed a synthesis of indazolones via Chan-Lam amination of $o$-amino benzamides and subsequent dehydrogenative $\mathrm{N}-\mathrm{N}$ bond formation (Scheme 33e). ${ }^{199}$

Alternative methods for the preparation of $\mathrm{N}$-arylcarbamates were reported by the groups of Kim (Scheme 33f $)^{119}$ and Baghersad (Scheme 33g) ${ }^{129}$ using acyl azides and KOCN, respectively. Kim and coworkers described the reaction of several azidoformates with arylboronic acids with catalytic $\mathrm{CuCl}$ under very mild conditions to deliver arylcarbamate products (Scheme 33f). Variation of the organoboron was tolerated but with a range of yields.

Baghersad and coworkers prepared carbamates from arylboronic acid and KOCN in the presence of an alcohol using catalytic $\mathrm{CuBr}_{2}$ under air (Scheme 33g). A variety of alcohols were compatible to give the corresponding carbamate ( $\mathrm{MeOH}, \mathrm{EtOH}, n-\mathrm{PrOH}, i-\mathrm{PrOH}$, and allyl alcohol used). A range of arylboronic acids gave generally moderate yields, with BPin species less effective. 
Scheme 33. Sequential reactions involving the Chan-Lam amination.

(a) Sequential Chan-Lam amination/CuAAC
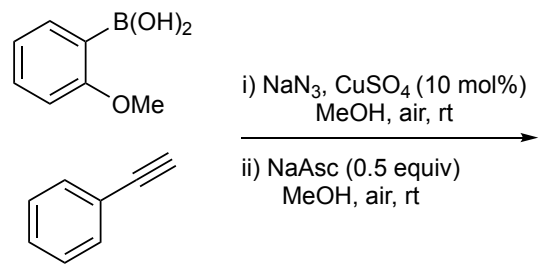

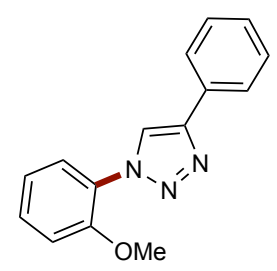

$92 \%$ yield

10 other examples $63-96 \%$ yield

(b) Sequential Ullmann-Goldberg/Chan-Lam amination<smiles>Nc1cc[nH]n1</smiles>

\section{i) $\mathrm{Ar}^{1}-\mathrm{I}, \mathrm{Cul}(10 \mathrm{~mol} \%), \mathrm{Cs}_{2} \mathrm{CO}_{3}, \mathrm{NMP}, 120^{\circ} \mathrm{C}$}

ii) $\mathrm{Ar}^{2} \mathrm{-B}(\mathrm{OH})_{2}, \mathrm{AgBF}_{4}, \mathrm{AcOH}, 3 \AA \mathrm{MS}$, air, $80^{\circ} \mathrm{C}$

(c) Sequential Chan-Lam amination/C-H activation

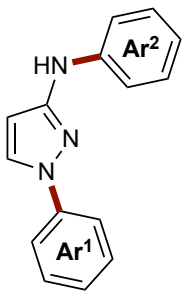

14 examples $14-63 \%$ yield<smiles>Cc1ccccc1C(=N)N</smiles><smiles>COc1ccc(Br)cc1</smiles>

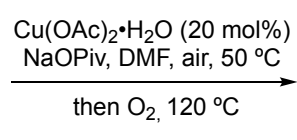<smiles>COc1ccc2nc(-c3ccccc3C)[nH]c2c1</smiles>

$78 \%$ yield 21 other examples 6-90\% yield

(d) Sequential Chan-Lam amination/Friedel-Crafts

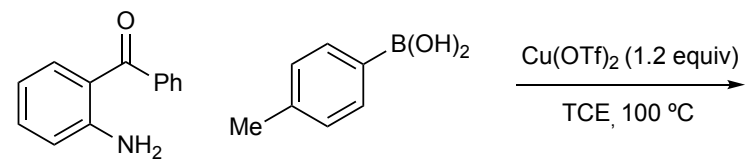<smiles>Cc1ccc2nc3ccccc3c(-c3ccccc3)c2c1</smiles>

$70 \%$ yield 23 other examples 40-93\% yield

(e) Sequential Chan-Lam amination/Dehydrogenation<smiles>Nc1ccccc1C(=O)Nc1ccccc1</smiles><smiles>Oc1ccc(F)cc1</smiles>
i) $\mathrm{CuCl}(20 \mathrm{~mol} \%)$
$\mathrm{Et}_{3} \mathrm{~N}, \mathrm{MeOH}, \mathrm{air}, \mathrm{rt}$
$\underset{\mathrm{ii}) \mathrm{DMSO}, 120^{\circ} \mathrm{C}}{\longrightarrow}$

(f) Coupling of acyl azides<smiles>[N]C(=O)OCc1ccccc1</smiles><smiles>Oc1ccsc1</smiles>

(g) Coupling of potassium cyanate

$$
\underset{\mathrm{MeOH}, \text { air, rt }}{\stackrel{\mathrm{CuCl}(20 \mathrm{~mol} \%)}{\longrightarrow}}
$$<smiles>O=C(Nc1ccsc1)OCc1ccccc1</smiles>

$77 \%$ yield 27 other examples 0-94\% yield<smiles>COC(=O)Nc1ccc(OC)cc1</smiles> 


\subsection{C-N Bond Formation on Nucleobases and Peptides}

The use of biomolecules offers significant challenges for catalysis. With specific regard to the Chan-Lam reaction, as this is an oxidative process, oxidative degradation could be assumed to be problematic, as it can be in other $\mathrm{Cu}$-catalyzed processes such as the CuAAC reaction. ${ }^{200}$ However, recent examples have shown that the Chan-Lam amination can be compatible with biomolecules and offer unique access to bioconjugates.

Peng and co-workers utilized the Chan-Lam amination to create an array of $N$-arylaminotriazole ribonucleosides for an SAR investigation for pancreatic cancer drug discovery (Scheme 34a). ${ }^{201}$ In total 11 arylboronic acids were coupled to an $N$-aryltriazole ribonucleoside core to deliver the expected products in a range of yields and, again, with the standard steric observations. Following the arylation, aminolysis with $\mathrm{NH}_{3} / \mathrm{MeOH}$ gave the primary amide products that were tested for antiproliferation activity against cancer cell lines.

Ball and coworkers achieved the selective $N$-arylation of peptides using mild reaction conditions (Scheme $34 \mathrm{~b}){ }^{202}$ The site- and chemoselectivity of the arylation is controlled by a histidine residue, directing arylation to a specific prolinone. A small selection of arylboronic acids were used for the aryl- and alkenylation of leuprolide (shown in Scheme 34b) and angiotensin I, with alkenylboronic acids found to offer the greatest efficiency, possibly due to limited steric hindrance. Three further polypeptides were also shown to undergo selective $N$-arylation: neuromedin B, LHRH, and N-Hippuryl-HL. The selective aryl/alkenylation was also replicated in more challenging systems using cell lysates. ${ }^{203}$

Scheme 34. Chan-Lam amination of biomolecules.

(a) $\mathrm{N}$-arylation of aminotriazole ribonucleosides

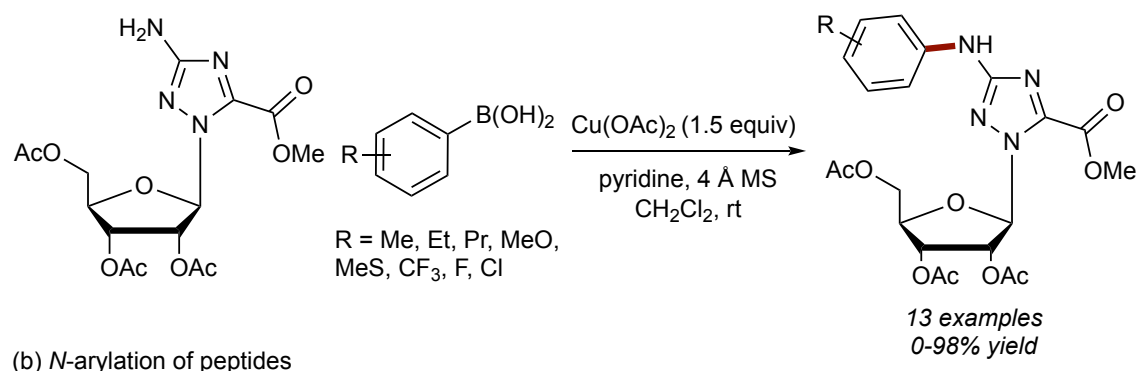

(b) $\mathrm{N}$-arylation of peptides<smiles>NC(=O)[C@H]1CCC(=O)N1</smiles><smiles>O=C(O)Oc1ccccc1C(=O)O</smiles>

$\underset{\text { HEPES buffer (pH 7.4) }}{\stackrel{\mathrm{Cu}(\mathrm{OAc})_{2} \text { (10 equiv) }}{\longrightarrow}}$

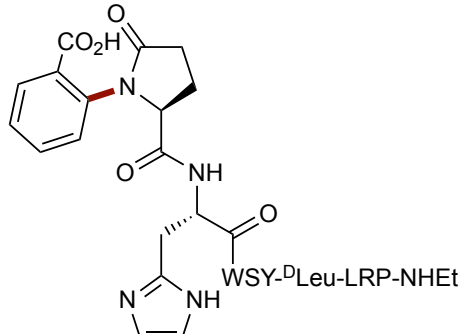

$24 \%$ conversion

19 other examples $0-100 \%$ conversion 


\section{MECHANISM}

\subsection{Historical Context}

In the first of the trilogy of initial papers, Chan ${ }^{58}$ initially suggested the reaction mechanism to be related to the Bi-based arylation methods where, following initial studies by David and Thieffry, ${ }^{204,205}$ Barton observed a significant rate acceleration in the presence of $\mathrm{Cu}(\mathrm{OAc})_{2} .{ }^{206}$ The mechanism of this process is believed to be formation of a nucleophilic $\mathrm{Cu}$-alkoxide complex 5 followed by oxidative arylation to form a $\mathrm{Cu}(\mathrm{III})$ species 6 that enables a facile reductive elimination (Scheme 35).

Scheme 35. Proposed mechanism of Cu-catalyzed arylation using $\mathrm{Bi}(\mathrm{V})$ reagents.

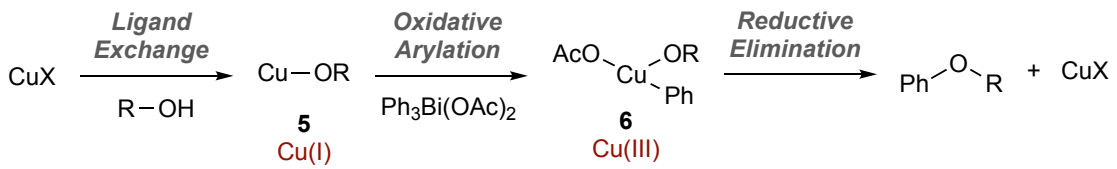

Evans suggested a slightly different sequence of events, specifically suggesting two options for the reaction mechanism (Scheme 36). ${ }^{59}$ Since transmetalation of organoboron compounds to $\mathrm{Cu}(\mathrm{I})$ and $\mathrm{Cu}(\mathrm{II})$ was known at the time, ${ }^{207}$ Evans suggested formation of a $\mathrm{Cu}(\mathrm{II})(\mathrm{Ar})(\mathrm{X})$ complex 7, which undergoes ligand exchange with the heteroatomic nucleophile (in this case, a phenol) to deliver $\mathrm{Cu}(\mathrm{II})(\mathrm{Ar})(\mathrm{OR})$ complex 8. At this stage, Evans noted the possible ambiguity over the oxidation state of $\mathrm{Cu}$ prior to reductive elimination: reductive elimination from 8 would deliver the desired product and $\mathrm{Cu}(0)$, while oxidation to $\mathrm{Cu}(\mathrm{III})$ complex $\mathbf{9}$, would allow reductive elimination to give the ether product and $\mathrm{Cu}(\mathrm{I})$, with the latter being analogous to reductive elimination in the related, but mechanistically distinct, Ullmann-Goldberg reaction. ${ }^{17-22}$ Based on Evans' observation that the reaction was more effective in its presence, $\mathrm{O}_{2}$ was proposed as the oxidant for the $\mathrm{Cu}(\mathrm{II}) \rightarrow \mathrm{Cu}(\mathrm{III})$ event.

Scheme 36. Initial mechanistic possibilities by Evans.

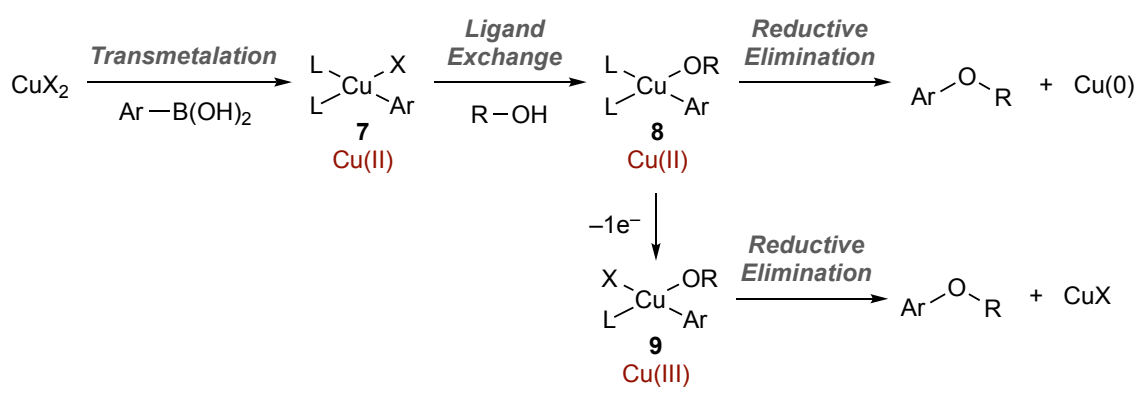

In the final of the three initial studies, Chan and Lam subsequently proposed formation of a complex between the heteroatomic nucleophile and $\mathrm{Cu}(\mathrm{OAc})_{2}$ before transmetalation and reductive elimination from a "het/Cu/Ar" complex, but did not comment on the structure or oxidation state of the $\mathrm{Cu} .{ }^{60}$ 
Following Evans' initial hypothesis of reductive elimination from $\mathrm{Cu}(\mathrm{III})$ to generate the $\mathrm{C}-\mathrm{X}$ bond, ${ }^{59}$ in 2000, Collman reported the first example of a ligand-based Chan-Lam that allowed some additional insight (Scheme 37a). ${ }^{71,72}$ The complex $[\mathrm{Cu}(\mathrm{OH}) \bullet T M E D A]_{2} \mathrm{Cl}_{2}$ (10) was found to enable the catalytic Chan-Lam arylation of imidazoles. Transmetalation was proposed to allow access to monomeric $\mathrm{Cu}(\mathrm{II})$ complex $\mathbf{1 1}$. Association of the $\mathrm{N}$-nucleophile enables access to $\mathrm{Cu}(\mathrm{II})$ complex 12 that undergoes oxidation using $\mathrm{O}_{2}$, based on Evans' proposal, to give the required $\mathrm{Cu}(\mathrm{III})$ species 13. Reductive elimination then gives $\mathrm{Cu}(\mathrm{I})$ complex 14, which undergoes oxidation with $\mathrm{O}_{2}$ to complete the catalytic cycle. More importantly from a mechanistic standpoint, the realization that the substrate affects the $\mathrm{Cu}$ (II) reduction potential was put forward. ${ }^{208}$ Specifically, the increased electron density at proposed $\mathrm{Cu}$ complex $\mathbf{1 2}$ due to the presence of the aryl and $\mathrm{N}$-nucleophile was proposed to enable more facile $\mathrm{Cu}(\mathrm{II}) \rightarrow \mathrm{Cu}(\mathrm{III})$ oxidation using $\mathrm{O}_{2}$. Very soon after, Lam proposed a similar mechanism for the related Cu-promoted amination of hypervalent aryl siloxanes, ${ }^{56}$ and, subsequently, favored the $\mathrm{Cu}(\mathrm{III})$ mechanism for the Chan-Lam amination (Scheme $37 b){ }^{70,106}$

Scheme 37. (a) Collman's proposed mechanism. (b) Lam's proposal favoring $\mathrm{Cu}(\mathrm{III})$.

(a) Collman's proposed catalytic mechanism using $[\mathrm{Cu}(\mathrm{OH}) \bullet T M E D A]_{2} \mathrm{Cl}_{2}$
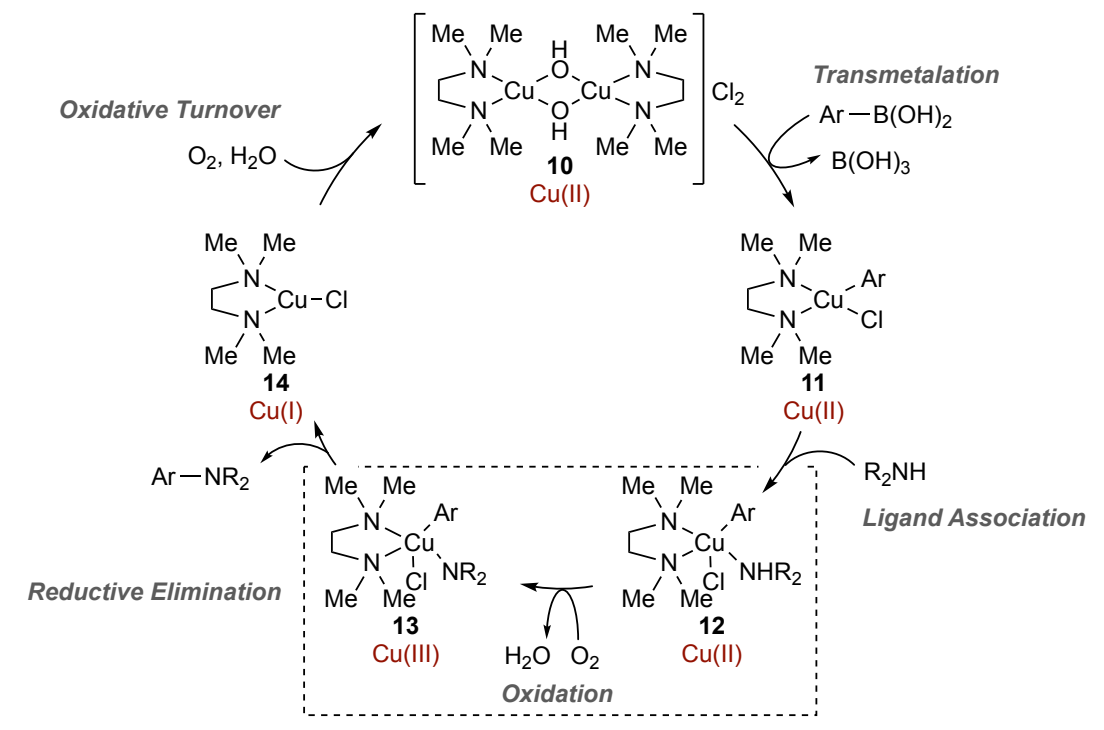

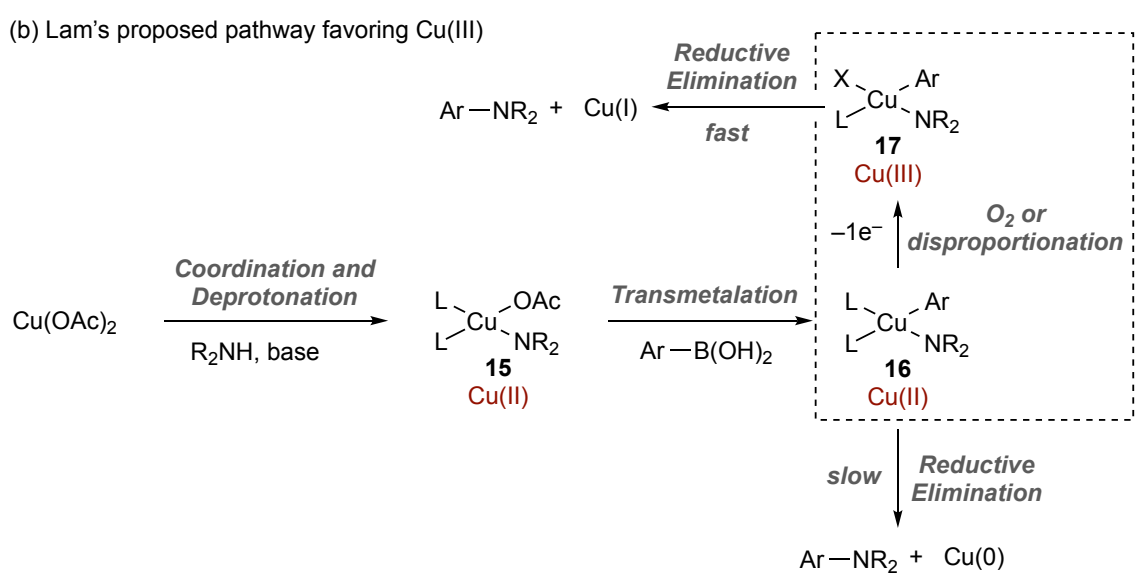


Lam proposed that the amine nucleophile undergoes coordination to $\mathrm{Cu}(\mathrm{OAc})_{2}$ with subsequent deprotonation giving $\mathrm{Cu}$ (II) amide 15. Transmetalation was proposed to deliver the $\mathrm{Cu}$ (II) complex $\mathbf{1 6}$ that could undergo either of the reductive elimination pathways proposed by Evans. Direct reductive elimination to give the product and $\mathrm{Cu}(0)$ was disfavored based on the trace amount of $\mathrm{Cu}(0)$ detected in the reaction mixture. ${ }^{70}$ The $\mathrm{Cu}(\mathrm{III})$ route (via 17) was the favored pathway and was proposed to be based on $\mathrm{O}_{2}$ oxidation or, for the first time, via disproportionation.

The $\mathrm{Cu}(\mathrm{III})$-based mechanism became increasingly favored; however, the issue of whether this was driven by $\mathrm{O}_{2}$ or disproportionation remained unclear. Support for an $\mathrm{O}_{2}$-based oxidation was readily available from inorganic studies of the metalloproteins where binding of $\mathrm{O}_{2}$ to $\mathrm{Cu}$ (II) complexes and subsequent oxidation to $\mathrm{Cu}$ (III) was well known. ${ }^{209}$ Similarly, disproportionation was also well established. ${ }^{96}$ In addition, Ribas documented $\mathrm{Cu}(\mathrm{III})$ complexes that were similar to the proposed $\mathrm{Cu}(\mathrm{III})$ intermediates in the Chan-Lam process, ${ }^{210,211}$ and Stahl subsequently demonstrated that these can undergo reductive elimination with amine nucleophiles. $^{212}$

\subsection{Mechanistic Investigations in the Etherification Reaction}

In 2009 more substantive mechanistic data emerged. In a seminal study by Stahl, a combination of gas $\left(\mathrm{O}_{2}\right)$ uptake kinetic studies and EPR began to provide important detail to support various aspects of the proposed mechanistic pathway. ${ }^{73,74}$ The model system was based on the Chan-Lam etherification of $p$-tolylboronic acid dimethyl ester with $\mathrm{MeOH}$ using catalytic $\mathrm{Cu}(\mathrm{OAc})_{2}$ (Scheme 38a). ${ }^{125}$ This led to the proposed catalytic cycle shown in Scheme 38b.

Scheme 38. (a) Stahl's model system for mechanistic development. (b) Stahl's proposed mechanism for the Chan-Lam etherification reaction.

(a) Model system used by Stahl

$$
p \text {-tol-B(OMe })_{2} \underset{\mathrm{MeOH}, \mathrm{O}_{2}, 27^{\circ} \mathrm{C}}{\stackrel{\mathrm{Cu}(\mathrm{OAc})_{2}(5 \mathrm{~mol} \%)}{\longrightarrow}} \text {-tol-OMe }
$$

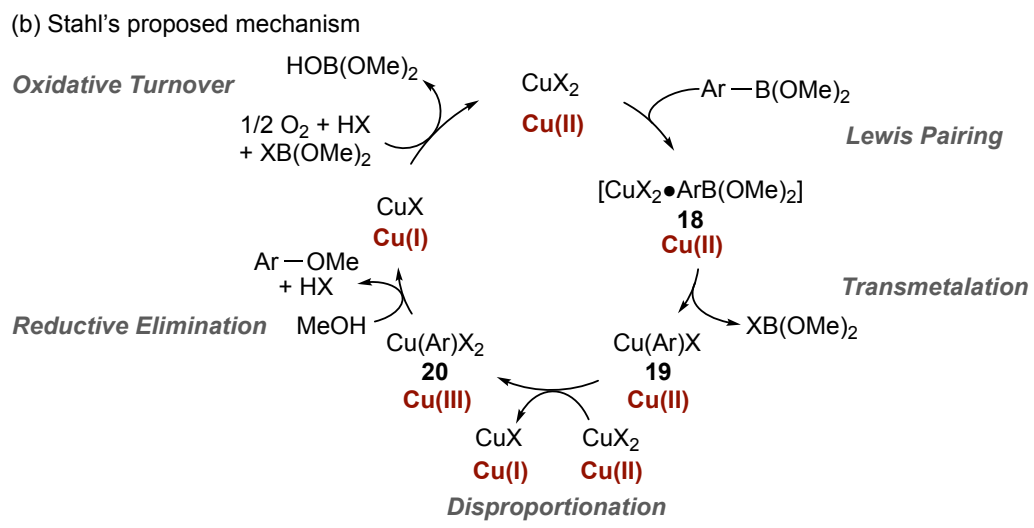


From the mechanistic standpoint, Stahl proposed that the reaction begins with an undefined $\mathrm{Cu}(\mathrm{II})$ species that undergoes turnover-limiting transmetalation via initial formation of a complex with the organoboron (18). This delivers aryl $\mathrm{Cu}(\mathrm{II})$ complex 19 that undergoes oxidation to the key $\mathrm{Cu}(\mathrm{III})$ complex 20 by disproportionation. Reductive elimination delivers $\mathrm{Cu}(\mathrm{I})$, which is reoxidized to $\mathrm{Cu}(\mathrm{II})$ in the presence of the byproduct from transmetalation, $\mathrm{HX}$, and $\mathrm{O}_{2}$. Specific data that underpinned this mechanistic proposal is worth noting as it has been invoked in subsequent mechanistic studies:

(1) The process had an observed stoichiometry of 2:1 Cu(II)/organoboron and the reaction proceeded in the absence of $\mathrm{O}_{2}$ suggesting that $\mathrm{Cu}(\mathrm{II})$ can act as the oxidant, supporting the disproportionation pathway.

(2) The reaction demonstrated a first-order dependence on $\left[\mathrm{Cu}(\mathrm{OAc})_{2}\right]$, saturation dependence on $\left[\mathrm{ArB}(\mathrm{OMe})_{2}\right]$, and zero-order dependence on $\left[\mathrm{O}_{2}\right]$, suggesting $\mathrm{Cu}(\mathrm{I})$ reoxidation is faster than substrate oxidation.

(3) The noted dependence on $\left[\mathrm{Cu}(\mathrm{OAc})_{2}\right]$ and $\left[\mathrm{ArB}(\mathrm{OMe})_{2}\right]$ suggests the transmetalation event is turnover limiting under standard conditions.

(4) EPR studies of reaction aliquots determined that almost all $\mathrm{Cu}$ in solution was $\mathrm{Cu}$ (II) and that this $\mathrm{Cu}$ (II) species lacked strong donor ligands. This supported the above observation that transmetalation is turnover limiting.

Consistent with the proposals of Evans and Lam, ${ }^{59,70}$ Stahl noted that these data supported reductive elimination from $\mathrm{Cu}(\mathrm{III})$ and that the potential reductive elimination from $\mathrm{Cu}(\mathrm{II})$ was unlikely.

Stahl subsequently enhanced the understanding of this mechanism by providing further detail relating to competing processes and a proposal for the mechanism of transmetalation within the model system used in Scheme 38a (Scheme 39). ${ }^{73}$ In relation to the $\mathrm{Cu}$ source used, the addition of $\mathrm{AcO}^{-}$or $\mathrm{AcOH}$ was detrimental to reaction efficiency in the model system that used $\mathrm{Cu}(\mathrm{OAc})_{2}$; however, $\mathrm{Cu}\left(\mathrm{ClO}_{4}\right)$ was ineffective in the model reaction unless $\mathrm{AcO}^{-}$was added, suggesting a pivotal role for $\mathrm{AcO}^{-}$. Consistent with their proposed transmetalation hypothesis (vide infra), the addition of $\mathrm{MeO}^{-}$also accelerated reactions using $\mathrm{Cu}\left(\mathrm{ClO}_{4}\right)$.

Scheme 39. Stahl's proposed bridged complexes and transmetalation pathway.

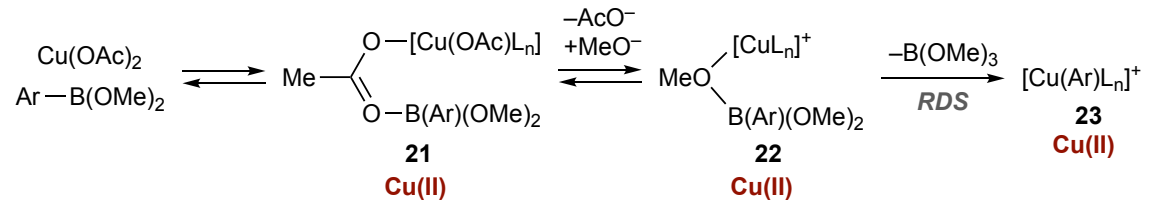

With respect to transmetalation, additional EPR studies suggested the presence of two similar $\mathrm{Cu}$ species that arise from the combination of the organoboron and $\left[\mathrm{Cu}(\mathrm{OAc})_{2}\right]_{2}$. While full structural determination was not possible, Stahl proposed related complexes 21 and $\mathbf{2 2}$ or related MeO-bridged or higher aggregate species as 
resting states prior to the transmetalation pathway: the initial acetate-bridged complex $\mathbf{2 1}$ was proposed to undergo rearrangement to the methoxide-bridged 22 allowing transmetalation similar to other TM-catalyzed reactions of organoborons.

The proposal that structures $\mathbf{2 1}$ and $\mathbf{2 2}$ were part of a pre-RDS equilibrium was consistent with experimental observations including (i) the inhibitory effect of $\mathrm{AcO}^{-}$and $\mathrm{AcOH}$, which would be expected to inhibit conversion of $\mathbf{2 1}$ to $\mathbf{2 2}$, (ii) the need for $\mathrm{AcO}^{-}$in reactions where this was not already present (i.e., when using $\mathrm{Cu}\left(\mathrm{ClO}_{4}\right)$ ), and (iii) the promotive effect of $\mathrm{MeO}^{-}$in reactions without $\mathrm{AcO}^{-}$(when using $\mathrm{CuClO}_{4}$ and $\left.\mathrm{Cu}(\mathrm{OTf})_{2}\right)$.

\subsection{Mechanistic Investigations in the Amination Reaction}

Building on the work of Stahl, in 2017, Watson and coworkers reported a mechanistic investigation of the Chan-Lam amination reaction using mass spectroscopy, crystallography, and EPR. ${ }^{75}$ The primary focus of this study was to address a common problem in the Chan-Lam amination when using arylboronic acid pinacol esters (BPin), which are known to be significantly less effective in Chan-Lam processes with the exception of several specific reports. ${ }^{139-142}$ This reactivity problem was also reported to be more profound with arylamines than alkylamines. ${ }^{100}$

Watson investigated a benchmark stoichiometric amination reaction using an arylboronic acid with exemplar aryl and alkyl amines as shown in Scheme 40a leading to the mechanistic proposal shown in Scheme 40b. 
Scheme 40. Watson's proposed mechanism for the amination reaction.

(a) Model system used by Watson

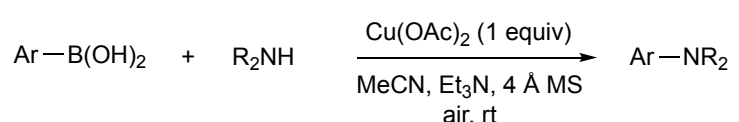

(b) Watson's proposed mechanism

$$
\left[\mathrm{Cu}(\mathrm{OAc})_{2}\right]_{2} \cdot 2 \mathrm{H}_{2} \mathrm{O}
$$
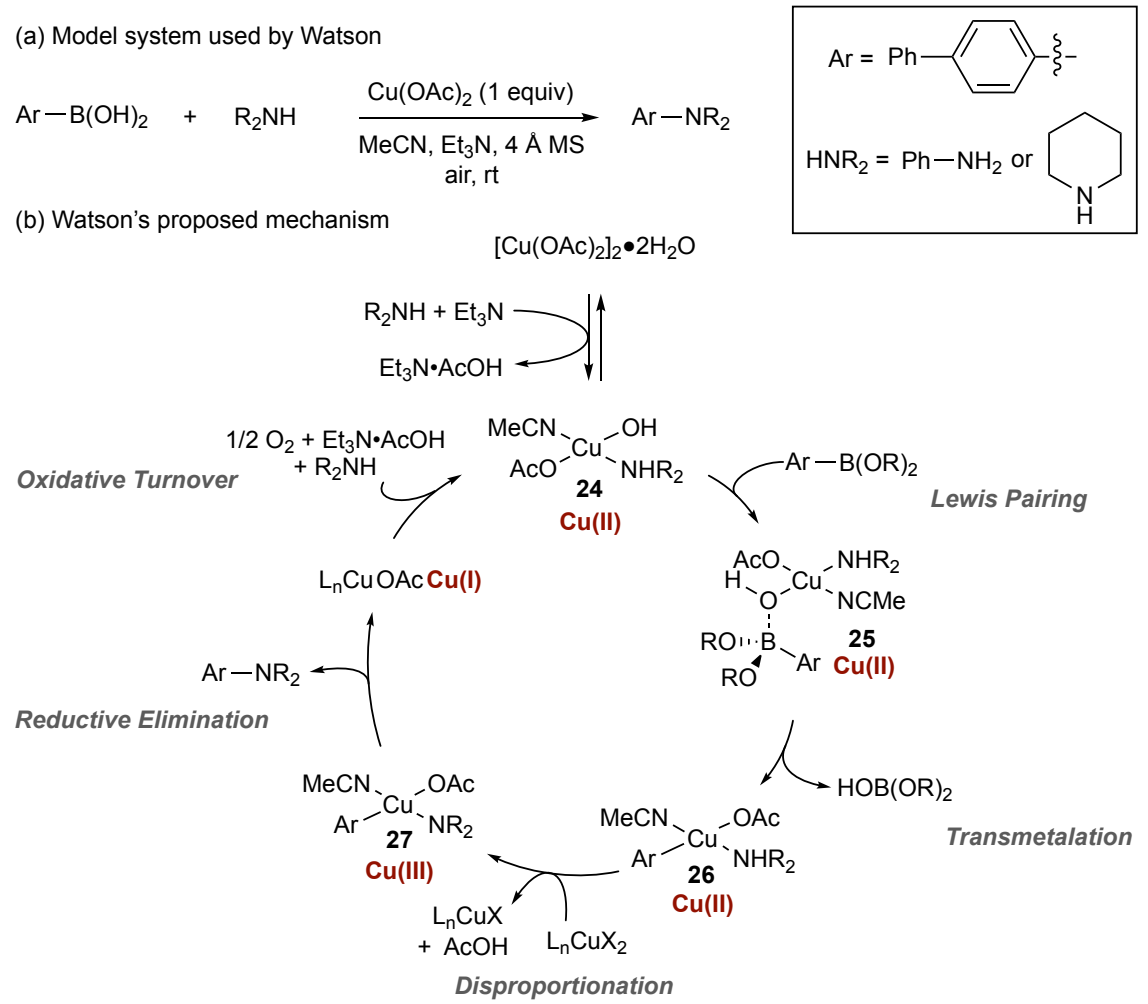

Watson proposed that the $\mathrm{Cu}(\mathrm{OAc})_{2}$ dimer is denucleated to a monocopper species 24 by action of the amine substrate. This results in the amine substrate being bound to $\mathrm{Cu}$ from the outset, similar to the proposal by Lam but lacking the deprotonation event. ${ }^{70,106}$ Similar to Stahl, ${ }^{73,74}$ Watson suggested that a Lewis pairing process occurs between hydroxycopper complex $\mathbf{2 4}$ and the organoboron giving $\mathbf{2 5}$ that facilitates transmetalation in the same way to Stahl's methoxide-bridged species (22, Scheme 39) to deliver aryl copper complex 26. ${ }^{73}$ Invoking Stahl's disproportionation pathway, ${ }^{73,74}$ this delivers $\mathrm{Cu}(\mathrm{III})$ species 27 that allows reductive elimination to generate $\mathrm{Cu}(\mathrm{I})$, which is oxidized to $\mathrm{Cu}(\mathrm{II})$ using $\mathrm{O}_{2}$ to complete the cycle.

The main construct for this mechanism was based on Stahl's earlier work but with a focus on determining the origin of the observed difference in reactivity of different amine (alkyl vs. aryl) and organoboron $\left(\mathrm{RB}(\mathrm{OH})_{2}\right.$ vs. RBPin) chemotypes. The overall picture of this mechanism is similar to that of Stahl but with some key differences and subtleties established between the etherification and amination processes.

(1) EPR demonstrated that the amine is involved in the $\mathrm{Cu}(\mathrm{OAc})_{2}$ dimer denucleation (Scheme 41, right). This is similar to the proposed denucleation by $\mathrm{MeOH}$ in the Stahl study, which was both the nucleophile and solvent. ${ }^{73,74}$ In the amination, the Lewis basicity affects the denucleation with alkyl amines driving this process more effectively than aryl amines providing a clear reactivity difference at the very outset of the reaction. 
Scheme 41. Denucleation and inhibition in the amination process.

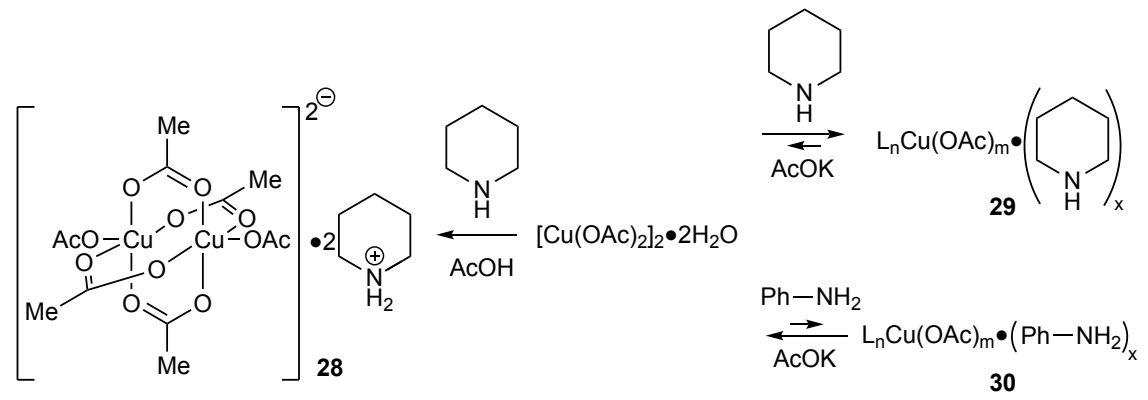

(2) Similar to Stahl's findings, ${ }^{73} \mathrm{AcO}^{-}$inhibits the denucleation but only for aryl amines: Alkyl amines were found to drive denucleation in the presence of KOAc while the aryl amines were less effective (Scheme 41, right).

(3) Perhaps unsurprisingly based on the above, $\mathrm{AcOH}$ inhibited denucleation for both amine classes due to $\mathrm{N}$ protonation of the amine. This also resulted in the formation of new $\mathrm{Cu}(\mathrm{II})$ dimer species $\mathbf{2 8}$ (Scheme 41, left). Independent preparation of this complex and exposure to arylboronic acid under identical reaction conditions resulted in a poorer yield, suggesting that this is a parasitic off-cycle species that is detrimental to reaction efficiency.

(4) The complex formed from amine-driven denucleation (29 and 30, Scheme 41) are assumed to have structure similar to that of $\mathbf{2 4}$ (Scheme 40). $\mathrm{Cu}$ (II) complex $\mathbf{2 4}$ was believed to be the catalytically active species; however, this was found to exist in an equilibrium with its dimer, 31, and tetramer, 32 (Scheme 42). 32 was believed to be an off-cycle reservoir since independent synthesis and exposure to arylboronic acid under identical reaction conditions delivered the expected product in good yield.

Scheme 42. Equilibration of proposed Cu(II) complex 24 to reservoir 32.

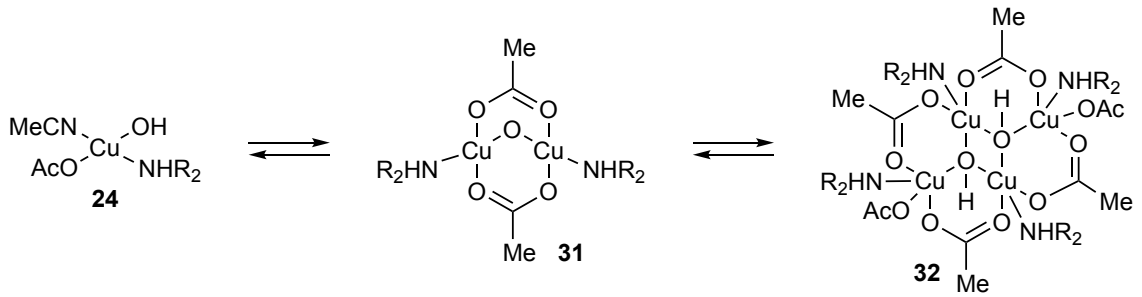

(5) Stahl suggested $\mathrm{HX}$ is involved in the oxidation of $\mathrm{Cu}(\mathrm{I}) \rightarrow \mathrm{Cu}(\mathrm{II})$ (oxidative turnover; Scheme 38b). ${ }^{73,74}$ UV studies by Watson confirmed that $\mathrm{AcOH}$ promotes this process and that this is slowed down in the presence of $\mathrm{Et}_{3} \mathrm{~N}$ - the most commonly used base for Chan-Lam reactions - due to buffering. 
(6) In addition to the amine substrate driving denucleation of $\left[\mathrm{Cu}(\mathrm{OAc})_{2}\right]_{2}$ at the outset of catalysis, UV experiments demonstrated that the amine also influenced the rate of oxidation of $\mathrm{Cu}(\mathrm{I}) \rightarrow \mathrm{Cu}$ (II) (oxidative turnover). Both aryl and alkyl amine substrates slowed down the oxidation relative to $\mathrm{AcOH}$ as would be expected based on observations with $\mathrm{Et}_{3} \mathrm{~N}$; however, more significantly, the rate of $\mathrm{Cu}(\mathrm{I})$ oxidation was faster with alkyl amines than aryl, even in the presence of $\mathrm{AcOH}$. This suggested some involvement of the amine within the oxidation, likely via coordination to $\mathrm{Cu}(\mathrm{I})$, with the stronger donor allowing faster oxidation. ${ }^{208}$

(7) While not mechanistically important, the origin of poorer reactivity using BPin was attributed to inhibition of catalysis by formation of $\left[\mathrm{Cu}(\mathrm{II})(\mathrm{Pin})_{2}\right]^{2-}$ complexes.

With specific regards to the Chan-Lam amination, in one of the earliest studies, Cundy commented on the "capricious nature" of the reaction in terms of variability of yield with different substrates. ${ }^{95}$ The Watson data assists in explaining this:

The denucleation is driven by the amine substrate and this is clearly dependent on the Lewis basicity of the amine. Aggregation equilibria of the proposed mononuclear complex $\mathbf{2 4}$ will be affected by the stereoelectronic parameters of the amine, potentially affecting the solution concentration of the mononuclear complex. The amine is proposed to remain ligated to $\mathrm{Cu}$ (II) up to and including the oxidation to $\mathrm{Cu}(\mathrm{III})$. Changes in electron density at $\mathrm{Cu}(\mathrm{II})$ will likely affect the rate of transmetalation, which is known to be sensitive to electronic changes at the organoboron, and the key disproportionation process, as alluded to by Collman. ${ }^{71,72}$ With specific regard to catalytic processes, since oxidative turnover is also influenced by the amine, this means that every individual mechanistic step in the catalytic cycle is affected by changes in the amine substrate. This perhaps explains Cundy's comment on the perceived capriciousness with respect to substrates and, therefore, why there are so many variants to the reaction conditions depending on the Nnucleophile used. This also means that a priori identification of suitable reaction conditions for an untested substrate class is rather difficult and the identification of a panacea is especially challenging.

\subsection{Mechanistic Investigations in the Amination Reaction: Ligand-based Systems}

The bulk of the mechanistic work discussed above is related to classic conditions where ligands are not employed. However, as noted earlier, there are numerous examples of Chan-Lam reactions that employ a specific ligand. Of these, the only in-depth mechanistic understanding comes from the work of Schaper, ${ }^{76,77,213,214}$ with significant data arising from well-defined iminoarylsulfonate complexes (e.g., 33, Figure 2). ${ }^{77}$ 
Figure 2. Schaper's iminoarylsulfonate complex.<smiles></smiles>

As noted previously, solution speciation processes in classic systems using simple $\mathrm{Cu}$ salts render identification of specific complexes, and thereby the rationalization of their reactivities, particularly difficult. Ligand-based systems such as $\mathbf{3 3}$ have allowed a targeted interrogation.

Schaper's mechanism (Scheme 43) ${ }^{77}$ suggested discrete complex 33 undergoes ionization to solvated cationic complex 34 that undergoes Lewis pairing with the arylboronic acid to deliver 35, followed by ratedetermining transmetalation consistent with 36, similar to Stahl's mechanism. ${ }^{73,74}$ An incoming $N$-nucleophile and expulsion of the boron byproduct promotes formation of complex 37. Disproportionation by combination of 37 and 33 delivers key $\mathrm{Cu}(\mathrm{III})$ species 38 and $\mathrm{Cu}(\mathrm{I})$ complex 39. This allows reductive elimination and subsequent catalyst turnover by oxidation similar to Stahl's proposal.

Scheme 43. Schaper's proposed catalytic cycle.

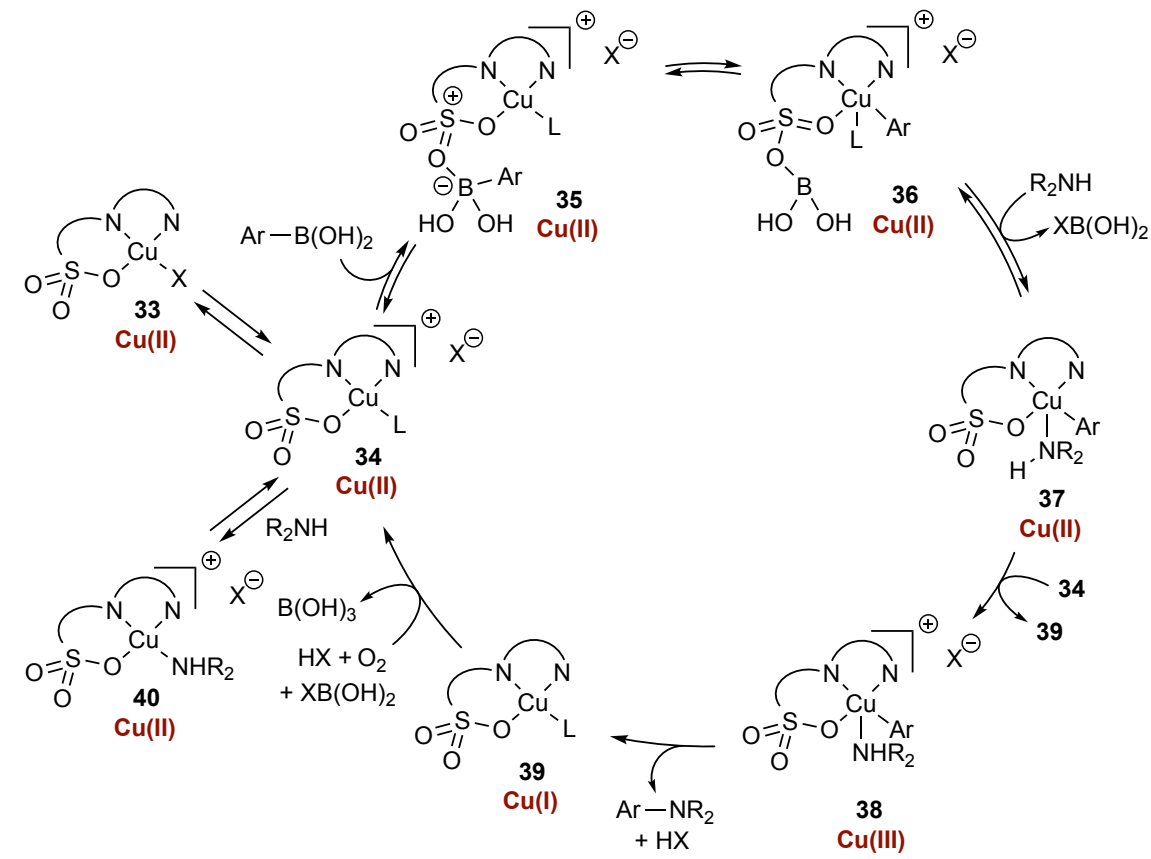

Importantly, Schaper provided in depth kinetic data on this process and, interestingly, much of the underpinning kinetic and spectroscopic data from Schaper's analysis using $\mathbf{3 3}$ in the context of amination aligned with the observations and conclusions made by Stahl in the etherification process ${ }^{73,74}$ and some similarities with Watson's data, ${ }^{75}$ hinting at some level of mechanistic consistency across three different 
processes. Similarities to Stahl's process ${ }^{73,74}$ included (i) the reaction required $2 \times \mathrm{Cu}$ per molecule of product formed and (ii) transmetalation is turnover limiting. The observation of the off-cycle amine-bound $\mathrm{Cu}$ complex $\mathbf{4 0}$ is similar in nature to the off-cycle complex 32 proposed as a reservoir by Watson. ${ }^{75}$ Finally, Schaper's system was also consistent with the general Chan-Lam observation with respect to the organoboron in that electron-rich boronic acids were generally faster.

Several differences were also notable and likely attributable to the ligand-based system, such as (i) aminebound complex 40 was proposed as the resting state in contrast to the Lewis complexes (21 and 22) in Stahl's system, ${ }^{73}$ (ii) generally lower amounts of byproducts with the main byproduct being reductive homocoupling in contrast to protodeboronation and oxidation for the majority of Chan-Lam processes, (iii) two additional byproducts derived from amine oxidation (aryl and alkyl) were observed that are otherwise uncommon in Chan-Lam amination, (iv) there was a reversal in the generally observed trend for the electronics of anilines, with electron-poor performing better than electron-rich and, in addition, binding of electron-rich anilines to the $\mathrm{Cu}$ catalyst could inhibit the reaction, and, (v) the formation of aniline-boronic acid complexes influenced the reaction kinetics, which was unexplored by Stahl and Watson.

\subsection{Mechanism Summary}

Overall, many pieces of data have been collected over the past 20 years that have helped to describe the Chan-Lam reaction in an empirical sense. The breadth of different reaction conditions described over numerous alongside various 'plausible' mechanisms have likely contributed to some development of ambiguity and compounding the notion that this chemistry is capricious. However, alongside key early experimental findings of Chan, Lam, Evans, and Collman, the more recent in-depth studies of Stahl, Watson, and Schaper have now begun to provide a reasonable overall description of the Chan-Lam reaction that, importantly, demonstrates some signs of consistency in core mechanistic events. This now allows the community to begin to understand why seemingly straightforward changes in substrates can lead to, sometimes vastly, different outcomes.

An important point to note is the significant difference in operation between the Chan-Lam reaction and the often-compared Buchwald-Hartwig amination. The ill-advised comparison between these processes leads to confusion. The differences in metal and nature of the catalysis (classic vs. oxidative) notwithstanding, the discrete catalysis and predictable ligand effects means that Pd-based methodology is generally much better behaved allowing for a more digestible understanding and rationalization of observations. In comparison, the Chan-Lam reaction is significantly more complex with substrates profoundly affecting the catalysis at the most fundamental levels, the involvement of more than one $\mathrm{Cu}$, and solution speciation leads to a system that is not as readily understood or rationally manipulated in order to solve a synthetic problem. 
Having said this, the developing mechanistic knowledge, coupled with emerging DFT insight into oxidative coupling processes ${ }^{215}$ is beginning to provide the insight that may soon allow a more intuitive understanding and allow a more facile selection of reaction conditions for a given set of substrates.

\section{CONCLUSIONS AND OUTLOOK}

In summary, over the past 20 years the Chan-Lam amination, and $\mathrm{Cu}$-mediated oxidative $\mathrm{C}-\mathrm{X}$ bond formation in general, has become a valuable synthetic methodology. The advantages arising from the mild reaction conditions, inexpensive reagents, and scope of coupling partners have provided a go-to general method for $\mathrm{C}-\mathrm{N}$ (and $\mathrm{C}-\mathrm{X}$ ) bond formation for discrete or library synthesis at discovery level chemistry through to scale-up processes for API or commodity chemical synthesis. The limitations of the methodology have mainly been empirically defined but have lacked explanation, frustrating development of guides for general a priori identification of reaction conditions for a given transformation. However, the emergence of mechanistic understanding is now offering insight that has assisted in explaining observations and, with sustained progress in this area, may allow development of more authoritative guidance for efficient reaction design and offer new strategies for $\mathrm{Cu}-$ mediated $\mathrm{C}-\mathrm{X}$ bond formation.

\section{ACKNOWLEDGMENTS}

We thank the University of St Andrews for a $\mathrm{PhD}$ studentship (MJW), the Leverhulme Trust for a postdoctoral fellowship (grant no.: RPG-2018-362; JWBF), and Prof. Patrick Y. S. Lam for helpful discussions.

\footnotetext{
ABBREVIATIONS

acac, Acetylacetonate ligand; API, Active Pharmaceutical Ingredient; BET, Bromodomain and Extra Terminal; 2,2'-bipy, 2,2'-bipyridine; CENP-E, Centromere-associated protein-E; CuAAC, Cu-catalyzed Azide-Alkyne Cycloaddition; CYP26, Retinoic acid 4-hydroxylase; DCE, 1,2-Dichloroethane; DFT, Density functional theory; DMAP, 4-Dimethylaminopyridine; DMF, Dimethylformamide; DMSO, Dimethyl sulfoxide; EP3, Prostaglandin E receptor 3; EPR, Electron Paramagnetic Resonance; FAP, Fluorapatite; FPR, Formyl peptide receptors; GPR120, a member of the rhodopsin family of G protein-coupled receptors; HOBt, 1-Hydroxybenzotriazole; LHRH, Luteinizing hormone-releasing hormone; MEK, Mitogen-activated protein kinase kinase; MS, Molecular sieves; NaAsc, Sodium ascorbate; NacNac, 1,3-Diketiminate ligand; NHipuryl-HL, an angiotensin converting enzyme; NMP, $N$-Methyl-2-pyrrolidone; NPY, Neuropeptide Y; NR, no reaction; NS5B, Nonstructural protein 5B; 1,10-Phen, 1,10-Phenanthroline; PI3K $\beta / \gamma$, Phosphatidylinositol 3 kinase $\beta / \gamma$; Pin, Pinacol/pinacolate; PTP, Protein tyrosine phosphatases; R\&D, Research and Development; RDS, Rate-Determining Step; SAR, Structure-Activity Relationship(s); SCR, Succinate-cytochrome C reductase; TBDMS, $t$-Butyldimethylsilyl; TEMPO, (2,2,6,6-Tetramethylpiperidin-1-yl)oxyl; TGR5, Takeda-
} 
G-protein-receptor-5; THF, Tetrahydrofuran; TMEDA, Tetramethylethylenediamine; UV, Ultraviolet-Visible spectroscopy.

\section{AUTHOR CONTRIBUTION}

Conceptualization: M.J.W., J.W.B.F., A.J.B.W.; Writing of the paper: M.J.W., J.W.B.F., J.C.V., A.J.B.W.

\section{References}

(1) Carey, J. S.; Laffan, D.; Thomson, C.; Williams, M. T. Analysis of the Reactions Used for the Preparation of Drug Candidate Molecules. Org. Biomol. Chem. 2006, 4, 2337-2347.

(2) Tasler, S.; Mies, J.; Lang, M. Applicability Aspects of Transition Metal-Catalyzed Aromatic Amination Protocols in Medicinal Chemistry. Adv. Synth. Catal. 2007, 349, 2286-2300.

(3) Cooper, T. W. J.; Campbell, I. B.; Macdonald, S. J. F. Factors Determining the Selection of Organic Reactions by Medicinal Chemists and the Use of These Reactions in Arrays (Small Focused Libraries). Angew. Chem. Int. Ed. 2010, 49, 8082-8091.

(4) Magano, J.; Dunetz, J. R. Large-Scale Applications of Transition Metal-Catalyzed Couplings for the Synthesis of Pharmaceuticals. Chem. Rev. 2011, 111, 2177-2250.

(5) Roughley, S. D.; Jordan, A. M. The Medicinal Chemist's Toolbox: An Analysis of Reactions Used in the Pursuit of Drug Candidates. J. Med. Chem. 2011, 54, 3451-3479.

(6) Vitaku, E.; Smith, D. T.; Njardarson, J. T. Analysis of the Structural Diversity, Substitution Patterns, and Frequency of Nitrogen Heterocycles among U.S. FDA Approved Pharmaceuticals. J. Med. Chem. 2014, 57, 10257-10274.

(7) Palladium in Organic Synthesis; Tsuji, J., Ed; Topics in Organometallic Chemistry; Springer: Berlin, Heidelberg, 2005; Vol. 14.

(8) Palladium in Heterocyclic Chemistry: A Guide for the Synthetic Chemist, $2^{\text {nd }}$ Edition; Li, J. J.; Gribble, G. W., Eds.; Elsevier: Amsterdam, 2006.

(9) Palladium-Catalyzed Coupling Reactions. Practical Aspects and Future Developments; Molnár A., Ed.; Wiley-VCH: Weinheim, 2005.

(10) Nicolaou, K. C.; Bulger, P. G.; Sarlah, D. Palladium-Catalyzed Cross-Coupling Reactions in Total Synthesis. Angew. Chem. Int. Ed. 2005, 44, 4442-4489.

(11) D’Souza, D. M.; Müller, T. J. J. Multi-Component Syntheses of Heterocycles by Transition-Metal Catalysis. Chem. Soc. Rev. 2007, 36, 1095-1108.

(12) Cross-Coupling Reactions in Organic Synthesis (thematic issue). Chem. Soc. Rev. 2011, 40, 48775208.

(13) Catalyzed Carbon-Heteroatom Bond Formation; Yudin, A. K., Ed.; Wiley-VCH: Weinheim, 2010.

(14) Bariwal, J.; Van der Eycken, E. C-N Bond Forming Cross-Coupling Reactions: An Overview. Chem. Soc. Rev. 2013, 42, 9283-9303.

(15) Ullmann, F. Ueber Eine Neue Bildungsweise von Diphenylaminderivaten. Ber. Dtsch. Chem. Ges. 
1903, 36, 2382-2384.

(16) Goldberg, I. Ueber Phenylirungen Bei Gegenwart von Kupfer Als Katalysator. Ber. Dtsch. Chem. Ges. 1906, 39, 1691-1692.

(17) Lin, H.; Sun, D. Recent Synthetic Developments and Applications of the Ullmann Reaction. A Review. Org. Prep. Proced. Int. 2013, 45, 341-394.

(18) Monnier, F.; Taillefer, M. Copper-Catalyzed C(Aryl)-N Bond Formation in Amination and Formation of $s p^{2} C-N$ Bonds; Taillefer M., Ma D., Eds.; Topics in Organometallic Chemistry; Springer: Berlin, Heidelberg, 2013; Vol. 46, pp 173-204.

(19) Sambiagio, C.; Marsden, S. P.; Blacker, A. J.; McGowan, P. C. Copper Catalysed Ullmann Type Chemistry: From Mechanistic Aspects to Modern Development. Chem. Soc. Rev. 2014, 43, 35253550.

(20) Copper-Mediated Cross-Coupling Reactions; Evano, G.; Blanchard, N., Eds.; John Wiley \& Sons, Inc.: Hoboken, NJ, 2014.

(21) Shaughnessy, K. H.; Ciganek, E.; DeVasher, R. B. Copper-Catalyzed Amination of Aryl and Alkenyl Electrophiles In Organic Reactions; John Wiley \& Sons, Inc.: Hoboken, NJ, 2014.

(22) Bhunia, S.; Pawar, G. G.; Kumar, S. V.; Jiang, Y.; Ma, D. Selected Copper-Based Reactions for C-N, $\mathrm{C}-\mathrm{O}, \mathrm{C}-\mathrm{S}$, and $\mathrm{C}-\mathrm{C}$ Bond Formation. Angew. Chem. Int. Ed. 2017, 56, 16136-16179.

(23) Kosugi, M.; Kameyama, M.; Migita, T. Palladium-Catalyzed Aromatic Amination of Aryl Bromides with N,N-Diethylaminotributyltin. Chem. Lett. 1983, 12, 927-928.

(24) Boger, L. D.; Panek, J. S. Palladium (0) Mediated $\beta$-Carboline Synthesis: Preparation of the CDE Ring System of Lavendamycin. Tetrahedron Lett. 1984, 25, 3175-3178.

(25) Paul, F.; Patt, J.; Hartwig, J. F. Palladium-Catalyzed Formation of Carbon-Nitrogen Bonds. Reaction Intermediates and Catalyst Improvements in the Hetero Cross-Coupling of Aryl Halides and Tin Amides. J. Am. Chem. Soc. 1994, 116, 5969-5970.

(26) Louie, J.; Hartwig, J. F. Palladium-Catalyzed Synthesis of Arylamines from Aryl Halides. Mechanistic Studies Lead to Coupling in the Absence of Tin Reagents. Tetrahedron Lett. 1995, 36, 3609-3612.

(27) Guram, A. S.; Buchwald, S. L. Palladium-Catalyzed Aromatic Aminations with In Situ Generated Aminostannanes. J. Am. Chem. Soc. 1994, 116, 7901-7902.

(28) Guram, A. S.; Rennels, R. A.; Buchwald, S. L. A Simple Catalytic Method for the Conversion of Aryl Bromides to Arylamines. Angew. Chem. Int. Ed. 1995, 34, 1348-1350.

(29) Hartwig, J. F. Evolution of a Fourth Generation Catalyst for the Amination and Thioetherification of Aryl Halides. Acc. Chem. Res. 2008, 41, 1534-1544.

(30) Surry, D. S.; Buchwald, S. L. Biaryl Phosphane Ligands in Palladium-Catalyzed Amination. Angew. Chem. Int. Ed. 2008, 47, 6338-6361.

(31) Lemen, G. S.; Wolfe, J. P. Palladium-Catalyzed $s^{2} C-N$ Bond Forming Reactions: Recent Developments and Applications In Amination and Formation of $s p^{2} C-N$ Bonds; Taillefer M., Ma D., Eds.; Topics in Organometallic Chemistry; Springer: Berlin, Heidelberg, 2013; Vol. 46, pp 1-53. 
(32) Ruiz-Castillo, P.; Buchwald, S. L. Applications of Palladium-Catalyzed C-N Cross-Coupling Reactions. Chem. Rev. 2016, 116, 12564-12649.

(33) Dennis, J. M.; White, N. A.; Liu, R. Y.; Buchwald, S. L. Pd-Catalyzed C-N Coupling Reactions Facilitated by Organic Bases: Mechanistic Investigation Leads to Enhanced Reactivity in the Arylation of Weakly Binding Amines. ACS Catal. 2019, 9, 3822-3830.

(34) Dennis, J. M.; White, N. A.; Liu, R. Y.; Buchwald, S. L. Breaking the Base Barrier: An ElectronDeficient Palladium Catalyst Enables the Use of a Common Soluble Base in C-N Coupling. J. Am. Chem. Soc. 2018, 140, 4721-4725.

(35) Montgomery, J. Organonickel Chemistry In Organometallics in Synthesis: Fourth Manual; Lipshutz, B. H., Ed.; John Wiley \& Sons, Inc.: Hoboken, NJ, 2013; Chapter 3, pp 317-425.

(36) Tasker, S. Z.; Standley, E. A.; Jamison, T. F. Recent Advances in Homogeneous Nickel Catalysis. Nature 2014, 509, 299-309.

(37) Hughes, E. C.; Veatch, F.; Elersich, V. N-Methylaniline from Chlorobenzene and Methylamine. Ind. Eng. Chem. 1950, 42, 787-790.

(38) Cramer, R.; Coulson, D. R. Nickel-Catalyzed Displacement Reactions of Aryl Halides. J. Org. Chem. 1975, 40, 2267-2273.

(39) Cristau, H.-J.; Desmurs, J.-R. Arylation of Hard Heteroatomic Nucleophiles Using Bromoarenes Substrates and $\mathrm{Cu}$, Ni, Pd-Catalysts In Industrial Chemistry Library; Desmurs, J. R.; Gérard, B.; Goldstein, M. J., Eds.; Elsevier: Amsterdam, 1995; Vol. 7, pp 240-263.

(40) Wolfe, J. P.; Buchwald, S. L. Nickel-Catalyzed Amination of Aryl Chlorides. J. Am. Chem. Soc. 1997, $119,6054-6058$.

(41) Brenner, E.; Fort, Y. New Efficient Nickel(0) Catalysed Amination of Aryl Chlorides. Tetrahedron Lett. 1998, 39, 5359-5362.

(42) For a discussion, see: Lavoie, C. M.; MacQueen, P. M.; Rotta-Loria, N. L.; Sawatzky, R. S.; Borzenko, A.; Chisholm, A. J.; Hargreaves, B. K. V.; McDonald, R.; Ferguson, M. J.; Stradiotto, M. Challenging Nickel-Catalysed Amine Arylations Enabled by Tailored Ancillary Ligand Design. Nat. Commun. 2016, 7, 11073.

(43) Wu, K.; Doyle, A. G. Parameterization of Phosphine Ligands Demonstrates Enhancement of Nickel Catalysis via Remote Steric Effects. Nat. Chem. 2017, 9, 779-784.

(44) Corcoran, E. B.; Pirnot, M. T.; Lin, S.; Dreher, S. D.; DiRocco, D. A.; Davies, I. W.; Buchwald, S. L.; MacMillan, D. W. C. Aryl Amination Using Ligand-Free Ni(II) Salts and Photoredox Catalysis. Science 2016, 353, 279-283.

(45) Li, C.; Kawamata, Y.; Nakamura, H.; Vantourout, J. C.; Liu, Z.; Hou, Q.; Bao, D.; Starr, J. T.; Chen, J.; Yan, M.; Baran, P. S. Electrochemically Enabled, Nickel-Catalyzed Amination. Angew. Chem. Int. Ed. 2017, 56, 13088-13093.

(46) Kawamata, Y.; Vantourout, J. C.; Hickey, D. P.; Bai, P.; Chen, L.; Hou, Q.; Qiao, W.; Barman, K.; Edwards, M. A.; Garrido-Castro, A. F.; et al. Electrochemically Driven, Ni-Catalyzed Aryl Amination: 
Scope, Mechanism, and Applications. J. Am. Chem. Soc. 2019, 141, 6392-6402.

(47) Ruffoni, A.; Juliá, F.; Svejstrup, T. D.; McMillan, A. J.; Douglas, J. J.; Leonori, D. Practical and Regioselective Amination of Arenes Using Alkyl Amines. Nat. Chem. 2019, 11, 426-433.

Dodonov, V. A.; Gushchin, A. V.; Brilkina, T. G. No Catalytic Phenylation of Primary and Secondary Amines with Triphenylbismuth Diacetates in the Presence of Copper. Zh. Obshch. Khim. 1985, 55, $466-467$.

(49) Barton, D. H. R.; Finet, J.-P.; Khamsi, J. Metallic Copper Catalysis of N-Arylation of Amines by Triarylbismuth Diacylates. Tetrahedron Lett. 1986, 27, 3615-3618.

(50) Barton, D. H. R.; Finet, J.-P.; Khamsi, J. N-Phenylation of Amino Acid Derivatives. Tetrahedron Lett. 1989, 30, 937-940.

(51) Dodonov, V. A.; Gushchin, A. V. Triphenylbismuth Diacylates as Novel Reagents for Fine Organic Synthesis. Russ. Chem. Bull. 1993, 42, 1955-1959.

(52) Chan, D. M. T. Promotion of Reaction of N-H Boths with Triarylbismuth and Cupric Acetate. Tetrahedron Lett. 1996, 37, 9013-9016.

(53) Barton, D. H. R.; Yadav-Bhatnagar, N.; Finet, J.-P.; Khamsi, J. Phenylation of Aromatic and Aliphatic Amines by Phenyllead Triacetate Using Copper Catalysis. Tetrahedron Lett. 1987, 28, 3111-3114.

(54) Barton, D. H. R.; Donnelly, D. M. X.; Finet, J.-P.; Guiry, P. J. Arylation of Amines by Aryllead Triacetates Using Copper Catalysis. Tetrahedron Lett. 1989, 30, 1377-1380.

(55) López-Alvarado, P.; Avendaño, C.; Menéndez, J. C. N-Arylation of Azoles and Their Benzo Derivatives by $p$-Tolyllead Triacetate. Tetrahedron Lett. 1992, 33, 659-662.

(56) Lam, P. Y. S.; Deudon, S.; Averill, K. M.; Li, R.; He, M. Y.; DeShong, P.; Clark, C. G. CopperPromoted $\mathrm{C}-\mathrm{N}$ Bond Cross-Coupling with Hypervalent Aryl Siloxanes and Room-Temperature $\mathrm{N}$ Arylation with Aryl Iodide. J. Am. Chem. Soc. 2000, 122, 7600-7601.

(57) Lam, P. Y. S.; Vincent, G.; Bonne, D.; Clark, C. G. Copper-Promoted C-N Bond Cross-Coupling with Phenylstannane. Tetrahedron Lett. 2002, 43, 3091-3094.

(58) Chan, D. M. T.; Monaco, K. L.; Wang, R.-P.; Winters, M. P. New $N$ - and $O$-Arylations with Phenylboronic Acids and Cupric Acetate. Tetrahedron Lett. 1998, 39, 2933-2936.

(59) Evans, D. A.; Katz, J. L.; West, T. R. Synthesis of Diaryl Ethers through the Copper-Promoted Arylation of Phenols with Arylboronic Acids. An Expedient Synthesis of Thyroxine. Tetrahedron Lett. 1998, 39, 2937-2940.

(60) Lam, P. Y. S.; Clark, C. G.; Saubern, S.; Adams, J.; Winters, M. P.; Chan, D. M. T.; Combs, A. New Aryl/Heteroaryl C-N Bond Cross-Coupling Reactions via Arylboronic Acid/Cupric Acetate Arylation. Tetrahedron Lett. 1998, 39, 2941-2944.

(61) Lam, P. Y. S. Chan-Lam Coupling Reaction: Copper-promoted C-Element Bond Oxidative Coupling Reaction with Boronic Acids In Synthetic Methods in Drug Discovery; Blakemore, D. C., Doyle, P. M., Fobian, Y. M., Eds.; Royal Society of Chemistry: Cambridge, 2016; Vol. 1, Chapter 7, pp 242-273.

(62) Ley, S. V.; Thomas, A. W. Modern Synthetic Methods for Copper-Mediated C(Aryl)-O, C(Aryl)-N, 
and C(Aryl)-S Bond Formation. Angew. Chem. Int. Ed. 2003, 42, 5400-5449.

(63) Theil, F. Synthesis of Diaryl Ethers: A Long-Standing Problem Has Been Solved In Organic Synthesis Highlights V; Schmalz, H.-G.; Wirth T., Eds.; Wiley-VCH: Weinheim, 1999; pp 15-21.

(64) Thomas, A. W.; Ley, S. V. Copper-Catalyzed Arylations of Amines and Alcohols with Boron-Based Arylating Reagents In Modern Arylation Methods; Ackermann, L., Ed.; Wiley-VCH: Weinheim, 2009; Chapter 4, pp 121-154.

(65) Qiao, J. X.; Lam, P. Y. S. Copper-Promoted Carbon-Heteroatom Bond Cross-Coupling with Boronic Acids and Derivatives. Synthesis 2011, 829-856.

(66) Qiao, J. X.; Lam, P. Y. S. Recent Advances in Chan-Lam Coupling Reaction: Copper-Promoted CHeteroatom Bond Cross-Coupling Reactions with Boronic Acids and Derivatives In Boronic Acids: Preparation and Applications in Organic Synthesis and Medicine; Hall, D. G., Ed.; Wiley-VCH: Weinheim, 2011; Chapter 6, pp 315-361.

(67) Munir, I.; Zahoor, A. F.; Rasool, N.; Naqvi, S. A. R.; Zia, K. M.; Ahmad, R. Synthetic Applications and Methodology Development of Chan-Lam Coupling: A Review. Mol. Divers. 2019, 23, 215-259.

(68) Rao, K. S.; Wu, T.-S. Chan-Lam Coupling Reactions: Synthesis of Heterocycles. Tetrahedron 2012, $68,7735-7754$.

(69) Pinto, D. J. P.; Orwat, M. J.; Koch, S.; Rossi, K. A.; Alexander, R. S.; Smallwood, A.; Wong, P. C.; Rendina, A. R.; Luettgen, J. M.; Knabb, R. M.; et al. Discovery of 1-(4-Methoxyphenyl)-7-oxo-6-(4(2-oxopiperidin-1-yl)phenyl)-4,5,6,7-tetrahydro-1H-pyrazolo[3,4-c]pyridine-3-carboxamide (Apixaban, BMS-562247), a Highly Potent, Selective, Efficacious, and Orally Bioavailable Inhibitor of Blood Coagulation Factor Xa. J. Med. Chem. 2007, 50, 5339-5356.

(70) Lam, P. Y. S.; Bonne, D.; Vincent, G.; Clark, C. G.; Combs, A. P. N-Arylation of $\alpha$-Aminoesters with p-Tolylboronic Acid Promoted by Copper(II) Acetate. Tetrahedron Lett. 2003, 44, 1691-1694.

(71) Collman, J. P.; Zhong, M. An Efficient Diamine-Copper Complex-Catalyzed Coupling of Arylboronic Acids with Imidazoles. Org. Lett. 2000, 2, 1233-1236.

(72) Collman, J. P.; Zhong, M.; Zhang, C.; Costanzo, S. Catalytic Activities of $\mathrm{Cu}(\mathrm{II})$ Complexes with Nitrogen-Chelating Bidentate Ligands in the Coupling of Imidazoles with Arylboronic Acids. J. Org. Chem. 2001, 66, 7892-7897.

(73) King, A. E.; Ryland, B. L.; Brunold, T. C.; Stahl, S. S. Kinetic and Spectroscopic Studies of Aerobic Copper(II)-Catalyzed Methoxylation of Arylboronic Esters and Insights into Aryl Transmetalation to Copper(II). Organometallics 2012, 31, 7948-7957.

(74) King, A. E.; Brunold, T. C.; Stahl, S. S. Mechanistic Study of Copper-Catalyzed Aerobic Oxidative Coupling of Arylboronic Esters and Methanol: Insights into an Organometallic Oxidase Reaction. $J$. Am. Chem. Soc. 2009, 131, 5044-5045.

(75) Vantourout, J. C.; Miras, H. N.; Isidro-Llobet, A.; Sproules, S.; Watson, A. J. B. Spectroscopic Studies of the Chan-Lam Amination: A Mechanism-Inspired Solution to Boronic Ester Reactivity. J. Am. Chem. Soc. 2017, 139, 4769-4779. 
(76) Duparc, V. H.; Schaper, F. Sulfonato-Diketimine Copper(II) Complexes: Synthesis and Application as Catalysts in Chan-Evans-Lam Couplings. Organometallics 2017, 36, 3053-3060.

(77) Duparc, V. H.; Bano, G. L.; Schaper, F. Chan-Evans-Lam Couplings with Copper Iminoarylsulfonate Complexes: Scope and Mechanism. ACS Catal. 2018, 8, 7308-7325.

(78) Vantourout, J. C.; Li, L.; Bendito-Moll, E.; Chabbra, S.; Arrington, K.; Bode, B. E.; Isidro-Llobet, A.; Kowalski, J. A.; Nilson, M. G.; Wheelhouse, K. M. P.; et al. Mechanistic Insight Enables Practical, Scalable, Room Temperature Chan-Lam N-Arylation of $N$-Aryl Sulfonamides. ACS Catal. 2018, 8, $9560-9566$.

(79) Kundu, S.; Greene, C.; Williams, K. D.; Salvador, T. K.; Bertke, J. A.; Cundari, T. R.; Warren, T. H. Three-Coordinate Copper(II) Aryls: Key Intermediates in $\mathrm{C}-\mathrm{O}$ Bond Formation. J. Am. Chem. Soc. 2017, 139, 9112-9115.

(80) Ziegler, M. S.; Levine, D. S.; Lakshmi, K. V.; Tilley, T. D. Aryl Group Transfer from Tetraarylborato Anions to an Electrophilic Dicopper(I) Center and Mixed-Valence $\mu$-Aryl Dicopper(I,II) Complexes. $J$. Am. Chem. Soc. 2016, 138, 6484-6491.

(81) Kaboudin, B.; Abedi, Y.; Yokomatsu, T. $\mathrm{Cu}^{\mathrm{II}}-\beta-C y c l o d e x t r i n$ Complex as a Nanocatalyst for the Homo- and Cross-Coupling of Arylboronic Acids under Ligand- and Base-Free Conditions in Air: Chemoselective Cross-Coupling of Arylboronic Acids in Water. Eur. J. Org. Chem. 2011, 6656-6662.

(82) Demir, A. S.; Reis, Ö.; Emrullahoglu, M. Role of Copper Species in the Oxidative Dimerization of Arylboronic Acids: Synthesis of Symmetrical Biaryls. J. Org. Chem. 2003, 68, 10130-10134.

(83) Kirai, N.; Yamamoto, Y. Homocoupling of Arylboronic Acids Catalyzed by 1,10-PhenanthrolineLigated Copper Complexes in Air. Eur. J. Org. Chem. 2009, 1864-1867.

(84) Cheng, G.; Luo, M. Homocoupling of Arylboronic Acids Catalyzed by $\mathrm{CuCl}$ in Air at Room Temperature. Eur. J. Org. Chem. 2011, 2519-2523.

(85) Mulla, S. A. R.; Chavan, S. S.; Pathan, M. Y.; Inamdar, S. M.; Shaikh, T. M. Y. Ligand-, Base-, CoCatalyst-Free Copper Fluorapatite (CuFAP) as a Versatile, Ecofriendly, Heterogeneous and Reusable Catalyst for an Efficient Homocoupling of Arylboronic Acid at Ambient Reaction Conditions. RSC Adv. 2015, 5, 24675-24680.

(86) Wang, Y.-H.; Xu, M.-C.; Liu, J.; Zhang, L.-J.; Zhang, X.-M. Three-Coordinate Copper(I) 2-Hydroxy1,10-Phenanthroline Dinuclear Complex Catalyzed Homocoupling of Arylboronic Acids Towards Biphenyls Under Air Condition. Tetrahedron 2015, 71, 9598-9601.

Parshamoni, S.; Telangae, J.; Sanda, S.; Konar, S. A Copper-Based Metal-Organic Framework Acts as a Bifunctional Catalyst for the Homocoupling of Arylboronic Acids and Epoxidation of Olefins. Chem. Asian J. 2016, 11, 540-547.

Agrahari, B.; Layek, S.; Kumari, S.; Anuradha; Ganguly, R.; Pathak, D. D. Synthesis, Characterization and Crystal Structure of $\mathrm{Cu}(\mathrm{II})$ Complex of Trans-Cyclohexane-1,2-Diamine: Application in Synthesis of Symmetrical Biaryls. J. Mol. Struct. 2017, 1134, 85-90.

(89) Cao, Y.-N.; Tian, X.-C.; Chen, X.-X.; Yao, Y.-X.; Gao, F.; Zhou, X.-L. Rapid Ligand-Free Base- 
Accelerated Copper-Catalyzed Homocoupling Reaction of Arylboronic Acids. Synlett 2017, 28, 601606.

(90) Yue, Y.; Zheng, Z.-G.; Wu, B.; Xia, C.-Q.; Yu, X.-Q. Copper-Catalyzed Cross-Coupling Reactions of Nucleobases with Arylboronic Acids: An Efficient Access To N-Arylnucleobases. Eur. J. Org. Chem. 2005, 5154-5157.

(91) Nishiura, K.; Urawa, Y.; Soda, S. N-Arylation of Benzimidazole with Arylboronate, Boroxine and Boronic Acids. Acceleration with an Optimal Amount of Water. Adv. Synth. Catal. 2004, 346, 16791684.

(92) Nasrollahzadeh, M.; Ehsani, A.; Maham, M. Copper-Catalyzed N-Arylation of Sulfonamides with Boronic Acids in Water under Ligand-Free and Aerobic Conditions. Synlett 2014, 25, 505-508.

(93) Ainley, A. D.; Challenger, F. CCLXXX.-Studies of the Boron-Carbon Linkage. Part I. The Oxidation and Nitration of Phenylboric Acid. J. Chem. Soc. 1930, 2171-2180.

(94) Kuivila, H. G.; Reuwer, J. F.; Mangravite, J. A. Electrophilic Displacement Reactions. XVI. Metal Ion Catalysis in the Protodeboronation of Areneboronic Acids. J. Am. Chem. Soc. 1964, 86, 2666-2670.

(95) Cundy, D. J.; Forsyth, S. A. Cupric Acetate Mediated N-Arylation by Arylboronic Acids: A Preliminary Investigation into the Scope of Application. Tetrahedron Lett. 1998, 39, 7979-7982.

(96) Rosen, B. M.; Jiang, X.; Wilson, C. J.; Nguyen, N. H.; Monteiro, M. J.; Percec, V. The Disproportionation of $\mathrm{Cu}(\mathrm{I}) \mathrm{X}$ Mediated by Ligand and Solvent into $\mathrm{Cu}(0)$ and $\mathrm{Cu}(\mathrm{II}) \mathrm{X}$ and Its Implications for SET-LRP. J. Polym. Sci. Part A Polym. Chem. 2009, 47, 5606-5628.

(97) Zhang, J.; Richardson, H. W. Copper Compounds In Ullmann's Encyclopedia of Industrial Chemistry; Wiley-VCH: Weinheim, 2016; pp 1-31.

(98) CRC Handbook of Tables for Applied Engineering Science; Bolz, R. E.; Tuve, G. L., Eds.; CRC Press: Boca Raton, FL, 1973.

(99) Zhang, L.; Zhang, G.; Zhang, M.; Cheng, J. Cu(OTf)2-Mediated Chan-Lam Reaction of Carboxylic Acids to Access Phenolic Esters. J. Org. Chem. 2010, 75, 7472-7474.

(100) Vantourout, J. C.; Law, R. P.; Isidro-Llobet, A.; Atkinson, S. J.; Watson, A. J. B. Chan-Evans-Lam Amination of Boronic Acid Pinacol (BPin) Esters: Overcoming the Aryl Amine Problem. J. Org. Chem. 2016, 81, 3942-3950.

(101) Lam, P. Y. S.; Vincent, G.; Clark, C. G.; Deudon, S.; Jadhav, P. K. Copper-Catalyzed General C-N and C-O Bond Cross-Coupling with Arylboronic Acid. Tetrahedron Lett. 2001, 42, 3415-3418.

(102) Kantam, M. L.; Venkanna, G. T.; Sridhar, C.; Sreedhar, B.; Choudary, B. M. An Efficient Base-Free $\mathrm{N}$-Arylation of Imidazoles and Amines with Arylboronic Acids Using Copper-Exchanged Fluorapatite. J. Org. Chem. 2006, 71, 9522-9524.

(103) Chiang, G. C. H.; Olsson, T. Polymer-Supported Copper Complex for C-N and C-O Cross-Coupling Reactions with Aryl Boronic Acids. Org. Lett. 2004, 6, 3079-3082.

(104) Islam, M.; Mondal, S.; Mondal, P.; Roy, A. S.; Tuhina, K.; Mobarok, M.; Paul, S.; Salam, N.; Hossain, D. An Efficient Recyclable Polymer Supported Copper(II) Catalyst for C-N Bond Formation by $N$ - 
Arylation. Catal. Lett. 2011, 141, 1171-1181.

(105) Allen, S. E.; Walvoord, R. R.; Padilla-Salinas, R.; Kozlowski, M. C. Aerobic Copper-Catalyzed Organic Reactions. Chem. Rev. 2013, 113, 6234-6458.

(106) Lam, P. Y. S.; Vincent, G.; Bonne, D.; Clark, C. G. Copper-Promoted/Catalyzed C-N and C-O Bond Cross-Coupling with Vinylboronic Acid and its Utilities. Tetrahedron Lett. 2003, 44, 4927-4931.

(107) Strouse, J. J.; Jeselnik, M.; Tapaha, F.; Jonsson, C. B.; Parker, W. B.; Arterburn, J. B. Copper Catalyzed Arylation with Boronic Acids for the Synthesis of $N^{1}$-Aryl Purine Nucleosides. Tetrahedron Lett. 2005, 46, 5699-5702.

(108) van Berkel, S. S.; van den Hoogenband, A.; Terpstra, J. W.; Tromp, M.; van Leeuwen, P. W. N. M.; van Strijdonck, G. P. F. Base-Free Anaerobic Cu(II) Catalysed Aryl-Nitrogen Bond Formations. Tetrahedron Lett. 2004, 45, 7659-7662.

(109) Tromp, M.; van Strijdonck, G. P. F.; van Berkel, S. S.; van den Hoogenband, A.; Feiters, M. C.; de Bruin, B.; Fiddy, S. G.; van der Eerden, A. M. J.; van Bokhoven, J. A.; van Leeuwen, P. W. N. M.; et al. Multitechnique Approach to Reveal the Mechanism of Copper(II)-Catalyzed Arylation Reactions. Organometallics 2010, 29, 3085-3097.

(110) Yoo, W.-J.; Tsukamoto, T.; Kobayashi, S. Visible-Light-Mediated Chan-Lam Coupling Reactions of Aryl Boronic Acids and Aniline Derivatives. Angew. Chem. Int. Ed. 2015, 54, 6587-6590.

(111) Wexler, R. P.; Nuhant, P.; Senter, T. J.; Gale-Day, Z. J. Electrochemically Enabled Chan-Lam Couplings of Aryl Boronic Acids and Anilines. Org. Lett. 2019, 21, 4540-4543.

(112) Quach, T. D.; Batey, R. A. Ligand- and Base-Free Copper(II)-Catalyzed C-N Bond Formation: CrossCoupling Reactions of Organoboron Compounds with Aliphatic Amines and Anilines. Org. Lett. 2003, $5,4397-4400$.

(113) Yu, X.-Q.; Yamamoto, Y.; Miyaura, N. Aryl Triolborates: Novel Reagent for Copper-Catalyzed NArylation of Amines, Anilines, and Imidazoles. Chem. Asian J. 2008, 3, 1517-1522.

(114) Liu, B.; Liu, B.; Zhou, Y.; Chen, W. Copper(II) Hydroxide Complexes of $N$-Heterocyclic Carbenes and Catalytic Oxidative Amination of Arylboronic Acids. Organometallics 2010, 29, 1457-1464.

(115) Garnier, T.; Sakly, R.; Danel, M.; Chassaing, S.; Pale, P. Chan-Lam-Type C-N Cross-Coupling Reactions under Base- and Ligand-Free CuI-Zeolite Catalysis. Synthesis 2016, 49, 1223-1230.

(116) Standard Potentials in Aqueous Solution; Bard, A. J.; Parsons, R.; Jordan, J., Eds.; CRC Press: Boca Raton, Florida, 1985.

(117) Hall, D. G. Structure, Properties, and Preparation of Boronic Acid Derivatives In Boronic Acids: Preparation and Applications in Organic Synthesis and Medicine; Hall, D. G., Ed.; Wiley-VCH: Weinheim, 2005; Chapter 1, pp 1-133.

(118) Lan, J.-B.; Chen, L.; Yu, X.-Q.; You, J.-S.; Xie, R.-G. A Simple Copper Salt Catalysed the Coupling of Imidazole with Arylboronic Acids in Protic Solvent. Chem. Commun. 2004, 188-189.

(119) Moon, S.-Y.; Kim, U. B.; Sung, D.-B.; Kim, W.-S. A Synthetic Approach to $N$-Aryl Carbamates via Copper-Catalyzed Chan-Lam Coupling at Room Temperature. J. Org. Chem. 2015, 80, 1856-1865. 
(120) Roy, S.; Sarma, M. J.; Kashyap, B.; Phukan, P. A Quick Chan-Lam C-N and C-S Cross Coupling at Room Temperature in the Presence of Square Pyramidal $\left[\mathrm{Cu}(\mathrm{DMAP})_{4} \mathrm{I}\right] \mathrm{I}$ as a Catalyst. Chem. Commun. 2016, 52, 1170-1173.

(121) Liu, S.; Zu, W.; Zhang, J.; Xu, L. Chemoselective $N$-Arylation of Aminobenzamides via Copper Catalysed Chan-Evans-Lam Reactions. Org. Biomol. Chem. 2017, 15, 9288-9292.

(122) Grimes, K. D.; Gupte, A.; Aldrich, C. C. Copper(II)-Catalyzed Conversion of Aryl/Heteroaryl Boronic Acids, Boronates, and Trifluoroborates into the Corresponding Azides: Substrate Scope and Limitations. Synthesis 2010, 1441-1448.

(123) Sreedhar, B.; Venkanna, G. T.; Kumar, K. B. S.; Balasubrahmanyam, V. Copper(I) Oxide Catalyzed $\mathrm{N}$-Arylation of Azoles and Amines with Arylboronic Acid at Room Temperature under Base-Free Conditions. Synthesis 2008, 795-799.

(124) Qiao, Y.; Li, G.; Liu, S.; Yangkai, Y.; Tu, J.; Xu, F. Synthesis of N-Aryl Amides by Ligand-Free Copper-Catalyzed ipso-Amidation of Arylboronic Acids with Nitriles. Synthesis 2016, 49, 1834-1838.

(125) Lan, J.-B.; Zhang, G.-L.; Yu, X.-Q.; You, J.-S.; Chen, L.; Yan, M.; Xie, R.-G. A Simple Copper Salt Catalyzed $\mathrm{N}$-Arylation of Amines, Amides, Imides, and Sulfonamides with Arylboronic Acids. Synlett 2004, 1095-1097.

(126) Moessner, C.; Bolm, C. $\mathrm{Cu}(\mathrm{OAc})_{2}$-Catalyzed N-Arylations of Sulfoximines with Aryl Boronic Acids. Org. Lett. 2005, 7, 2667-2669.

(127) Tao, C.-Z.; Cui, X.; Li, J.; Liu, A.-X.; Liu, L.; Guo, Q.-X. Copper-Catalyzed Synthesis of Aryl Azides and 1-Aryl-1,2,3-Triazoles from Boronic Acids. Tetrahedron Lett. 2007, 48, 3525-3529.

(128) Rao, H.; Fu, H.; Jiang, Y.; Zhao, Y. Easy Copper-Catalyzed Synthesis of Primary Aromatic Amines by Couplings Aromatic Boronic Acids with Aqueous Ammonia at Room Temperature. Angew. Chem. Int. Ed. 2009, 48, 1114-1116.

(129) Kianmehr, E.; Baghersad, M. H. Copper-Catalyzed Coupling of Arylboronic Acids with Potassium Cyanate: A New Approach to the Synthesis of Aryl Carbamates. Adv. Synth. Catal. 2011, 353, 25992603.

(130) Xu, H.-J.; Zhao, Y.-Q.; Feng, T.; Feng, Y.-S. Chan-Lam-Type S-Arylation of Thiols with Boronic Acids at Room Temperature. J. Org. Chem. 2012, 77, 2878-2884.

(131) Moon, S.-Y.; Nam, J.; Rathwell, K.; Kim, W.-S. Copper-Catalyzed Chan-Lam Coupling between Sulfonyl Azides and Boronic Acids at Room Temperature. Org. Lett. 2014, 16, 338-341.

(132) Huang, F.; Batey, R. A. Cross-Coupling of Organoboronic Acids and Sulfinate Salts Using Catalytic Copper(II) Acetate and 1,10-Phenanthroline: Synthesis of Aryl and Alkenylsulfones. Tetrahedron 2007, 63, 7667-7672.

(133) Wentzel, M. T.; Hewgley, J. B.; Kamble, R. M.; Wall, P. D.; Kozlowski, M. C. Copper-Catalyzed NArylation of Hindered Substrates Under Mild Conditions. Adv. Synth. Catal. 2009, 351, 931-937.

(134) Sun, N.; Che, L.; Mo, W.; Hu, B.; Shen, Z.; Hu, X. A Mild Copper-Catalyzed Aerobic Oxidative Thiocyanation of Arylboronic Acids with TMSNCS. Org. Biomol. Chem. 2015, 13, 691-696. 
(135) Sun, N.; Zhang, H.; Mo, W.; Hu, B.; Shen, Z.; Hu, X. Synthesis of Aryl Thiocyanates via CopperCatalyzed Aerobic Oxidative Cross-Coupling between Arylboronic Acids and KSCN. Synlett 2013, $24,1443-1447$.

(136) Zhuang, R.; Xu, J.; Cai, Z.; Tang, G.; Fang, M.; Zhao, Y. Copper-Catalyzed C-P Bond Construction via Direct Coupling of Phenylboronic Acids with H-Phosphonate Diesters. Org. Lett. 2011, 13, 2110 2113.

(137) Antilla, J. C.; Buchwald, S. L. Copper-Catalyzed Coupling of Arylboronic Acids and Amines. Org. Lett. 2001, 3, 2077-2079.

(138) Sasaki, M.; Dalili, S.; Yudin, A. K. N-Arylation of Aziridines. J. Org. Chem. 2003, 68, 2045-2047.

(139) Sueki, S.; Kuninobu, Y. Copper-Catalyzed $N$ - and $O$-Alkylation of Amines and Phenols Using Alkylborane Reagents. Org. Lett. 2013, 15, 1544-1547.

(140) McGarry, K. A.; Duenas, A. A.; Clark, T. B. Selective Formation of ortho-Aminobenzylamines by the Copper-Catalyzed Amination of Benzylamine Boronate Esters. J. Org. Chem. 2015, 80, 7193-7204.

(141) Marcum, J. S.; McGarry, K. A.; Ferber, C. J.; Clark, T. B. Synthesis of Biaryl Ethers by the CopperCatalyzed Chan-Evans-Lam Etherification from Benzylic Amine Boronate Esters. J. Org. Chem. 2016, 81, 7963-7969.

(142) Tzschucke, C. C.; Murphy, J. M.; Hartwig, J. F. Arenes to Anilines and Aryl Ethers by Sequential Iridium-Catalyzed Borylation and Copper-Catalyzed Coupling. Org. Lett. 2007, 9, 761-764.

(143) Gomaa, M. S.; Bridgens, C. E.; Aboraia, A. S.; Veal, G. J.; Redfern, C. P. F.; Brancale, A.; Armstrong, J. L.; Simons, C. Small Molecule Inhibitors of Retinoic Acid 4-Hydroxylase (CYP26): Synthesis and Biological Evaluation of Imidazole Methyl 3-(4-(aryl-2-ylamino)phenyl)propanoates. J. Med. Chem. 2011, 54, 2778-2791.

(144) Gomaa, M. S.; Bridgens, C. E.; Illingworth, N. A.; Veal, G. J.; Redfern, C. P. F.; Brancale, A.; Armstrong, J. L.; Simons, C. Novel Retinoic Acid 4-Hydroxylase (CYP26) Inhibitors Based on a 3(1H-Imidazol- and triazol-1-yl)-2,2-dimethyl-3-(4-(phenylamino)phenyl)propyl Scaffold. Bioorg. Med. Chem. 2012, 20, 4201-4207.

(145) Chua, G. N. L.; Wassarman, K. L.; Sun, H.; Alp, J. A.; Jarczyk, E. I.; Kuzio, N. J.; Bennett, M. J.; Malachowsky, B. G.; Kruse, M.; Kennedy, A. J. Cytosine-Based TET Enzyme Inhibitors. ACS Med. Chem. Lett. 2019, 10, 180-185.

(146) Pudlo, M.; Luzet, V.; Ismaïli, L.; Tomassoli, I.; Iutzeler, A.; Refouvelet, B. QuinoloneBenzylpiperidine Derivatives as Novel Acetylcholinesterase Inhibitor and Antioxidant Hybrids for Alzheimer Disease. Bioorg. Med. Chem. 2014, 22, 2496-2507.

(147) Reichelt, A.; Martin, S. F. Synthesis and Properties of Cyclopropane-Derived Peptidomimetics. Acc. Chem. Res. 2006, 39, 433-442.

(148) Bénard, S.; Neuville, L.; Zhu, J. Copper-Promoted N-Cyclopropylation of Anilines and Amines by Cyclopropylboronic Acid. Chem. Commun. 2010, 46, 3393-3395.

(149) Singh, K.; Kumar, M.; Pavadai, E.; Naran, K.; Warner, D. F.; Ruminski, P. G.; Chibale, K. Synthesis 
of New Verapamil Analogues and Their Evaluation in Combination with Rifampicin against Mycobacterium Tuberculosis and Molecular Docking Studies in the Binding Site of Efflux Protein Rv1258c. Bioorg. Med. Chem. Lett. 2014, 24, 2985-2990.

(150) Zheng, Z.-G.; Wen, J.; Wang, N.; Wu, B.; Yu, X.-Q. N-Arylation of Amines, Amides, Imides and Sulfonamides with Arylboroxines Catalyzed by Simple Copper Salt/EtOH System. Beilstein J. Org. Chem. 2008, 4, 40.

(151) Yamamoto, Y.; Takizawa, M.; Yu, X.-Q.; Miyaura, N. Cyclic Triolborates: Air- and Water-Stable Ate Complexes of Organoboronic Acids. Angew. Chem. Int. Ed. 2008, 47, 928-931.

(152) Cox, P. A.; Leach, A. G.; Campbell, A. D.; Lloyd-Jones, G. C. Protodeboronation of Heteroaromatic, Vinyl, and Cyclopropyl Boronic Acids: pH-Rate Profiles, Autocatalysis, and Disproportionation. J. Am. Chem. Soc. 2016, 138, 9145-9157.

(153) Cox, P. A.; Reid, M.; Leach, A. G.; Campbell, A. D.; King, E. J.; Lloyd-Jones, G. C. Base-Catalyzed Aryl-B $(\mathrm{OH})_{2}$ Protodeboronation Revisited: From Concerted Proton Transfer to Liberation of a Transient Aryl Anion. J. Am. Chem. Soc. 2017, 139, 13156-13165.

(154) Jouvin, K.; Couty, F.; Evano, G. Copper-Catalyzed Alkynylation of Amides with Potassium Alkynyltrifluoroborates: A Room-Temperature, Base-Free Synthesis of Ynamides. Org. Lett. 2010, 12, $3272-3275$.

(155) Bolshan, Y.; Batey, R. A. Enamide Synthesis by Copper-Catalyzed Cross-Coupling of Amides and Potassium Alkenyltrifluoroborate Salts. Angew. Chem. Int. Ed. 2008, 47, 2109-2112.

(156) Huang, F.; Quach, T. D.; Batey, R. A. Copper-Catalyzed Nondecarboxylative Cross Coupling of Alkenyltrifluoroborate Salts with Carboxylic Acids or Carboxylates: Synthesis of Enol Esters. Org. Lett. 2013, 15, 3150-3153.

(157) Derosa, J.; O’Duill, M. L.; Holcomb, M.; Boulous, M. N.; Patman, R. L.; Wang, F.; Tran-Dubé, M.; McAlpine, I.; Engle, K. M. Copper-Catalyzed Chan-Lam Cyclopropylation of Phenols and Azaheterocycles. J. Org. Chem. 2018, 83, 3417-3425.

(158) Mori-Quiroz, L. M.; Shimkin, K. W.; Rezazadeh, S.; Kozlowski, R. A.; Watson, D. A. CopperCatalyzed Amidation of Primary and Secondary Alkyl Boronic Esters. Chem. Eur. J. 2016, 22, 1565415658.

(159) Liu, S.; Xu, L. Copper-Catalyzed N-Arylation with Boronic Acid Pinacol Esters. Asian J. Org. Chem. 2018, 7, 1856-1863.

(160) Cheng, H.; Song, W.; Nie, R.; Wang, Y.-X.; Li, H.-L.; Jiang, X.-S.; Wu, J.-J.; Chen, C.; Wu, Q.-Y. Synthesis of New 4-Aryloxy- $N$-Arylanilines and Their Inhibitory Activities against SuccinateCytochrome C Reductase. Bioorg. Med. Chem. Lett. 2018, 28, 1330-1335.

(161) Gomaa, M. S.; Lim, A. S. T.; Lau, S. C. W.; Watts, A.-M.; Illingworth, N. A.; Bridgens, C. E.; Veal, G. J.; Redfern, C. P. F.; Brancale, A.; Armstrong, J. L.; et al. Synthesis and CYP26A1 Inhibitory Activity of Novel Methyl 3-[4-(arylamino)phenyl]-3-(azole)-2,2-dimethylpropanoates. Bioorg. Med. Chem. 2012, 20, 6080-6088. 
(162) Asada, M.; Obitsu, T.; Kinoshita, A.; Nagase, T.; Yoshida, T.; Yamaura, Y.; Takizawa, H.; Yoshikawa, K.; Sato, K.; Narita, M.; et al. 3-(2-Aminocarbonylphenyl)Propanoic Acid Analogs as Potent and Selective EP3 Receptor Antagonists. Part 3: Synthesis, Metabolic Stability, and Biological Evaluation of Optically Active Analogs. Bioorg. Med. Chem. 2010, 18, 3212-3223.

(163) Imanishi, M.; Tomishima, Y.; Itou, S.; Hamashima, H.; Nakajima, Y.; Washizuka, K.; Sakurai, M.; Matsui, S.; Imamura, E.; Ueshima, K.; et al. Discovery of a Novel Series of Biphenyl Benzoic Acid Derivatives as Potent and Selective Human 33 -Adrenergic Receptor Agonists with Good Oral Bioavailability. Part I. J. Med. Chem. 2008, 51, 1925-1944.

(164) Chen, Z.; Kim, S.-H.; Barbosa, S. A.; Huynh, T.; Tortolani, D. R.; Leavitt, K. J.; Wei, D. D.; Manne, V.; Ricca, C. S.; Gullo-Brown, J.; et al. Pyrrolopyridazine MEK Inhibitors. Bioorg. Med. Chem. Lett. 2006, 16, 628-632.

(165) Vergelli, C.; Schepetkin, I. A.; Ciciani, G.; Cilibrizzi, A.; Crocetti, L.; Giovannoni, M. P.; Guerrini, G.; Iacovone, A.; Kirpotina, L. N.; Khlebnikov, A. I.; et al. 2-Arylacetamido-4-phenylamino-5-substituted Pyridazinones as Formyl Peptide Receptors Agonists. Bioorg. Med. Chem. 2016, 24, 2530-2543.

(166) Giovannoni, M. P.; Schepetkin, I. A.; Cilibrizzi, A.; Crocetti, L.; Khlebnikov, A. I.; Dahlgren, C.; Graziano, A.; Piaz, V. D.; Kirpotina, L. N.; Zerbinati, S.; et al. Further Studies on 2-Arylacetamide Pyridazin-3(2H)-Ones: Design, Synthesis and Evaluation of 4,6-Disubstituted Analogs as Formyl Peptide Receptors (FPRs) Agonists. Eur. J. Med. Chem. 2013, 64, 512-528.

(167) Cilibrizzi, A.; Quinn, M. T.; Kirpotina, L. N.; Schepetkin, I. A.; Holderness, J.; Ye, R. D.; Rabiet, M.J.; Biancalani, C.; Cesari, N.; Graziano, A.; et al. 6-Methyl-2,4-Disubstituted Pyridazin-3(2H)-Ones: A Novel Class of Small-Molecule Agonists for Formyl Peptide Receptors. J. Med. Chem. 2009, 52, 5044-5057.

(168) Smith, A. L.; D’Angelo, N. D.; Bo, Y. Y.; Booker, S. K.; Cee, V. J.; Herberich, B.; Hong, F.-T.; Jackson, C. L. M.; Lanman, B. A.; Liu, L.; et al. Structure-Based Design of a Novel Series of Potent, Selective Inhibitors of the Class I Phosphatidylinositol 3-Kinases. J. Med. Chem. 2012, 55, 51885219.

(169) Judd, W. R.; Slattum, P. M.; Hoang, K. C.; Bhoite, L.; Valppu, L.; Alberts, G.; Brown, B.; Roth, B.; Ostanin, K.; Huang, L.; et al. Discovery and SAR of Methylated Tetrahydropyranyl Derivatives as Inhibitors of Isoprenylcysteine Carboxyl Methyltransferase (ICMT). J. Med. Chem. 2011, 54, 50315047.

(170) Barlaam, B.; Cosulich, S.; Degorce, S.; Fitzek, M.; Green, S.; Hancox, U.; Lambert-van der Brempt, C.; Lohmann, J.-J.; Maudet, M.; Morgentin, R.; et al. Discovery of (R)-8-(1-(3,5Difluorophenylamino)ethyl)- $N, N$-dimethyl-2-morpholino-4-oxo-4 $H$-chromene-6-carboxamide (AZD8186): A Potent and Selective Inhibitor of PI3K $\beta$ and PI3K $\delta$ for the Treatment of PTENDeficient Cancers. J. Med. Chem. 2015, 58, 943-962.

(171) Gosmini, R.; Nguyen, V. L.; Toum, J.; Simon, C.; Brusq, J.-M. G.; Krysa, G.; Mirguet, O.; RiouEymard, A. M.; Boursier, E. V.; Trottet, L.; et al. The Discovery of I-BET726 (GSK1324726A), a 
Potent Tetrahydroquinoline ApoA1 Up-Regulator and Selective BET Bromodomain Inhibitor. J. Med. Chem. 2014, 57, 8111-8131.

(172) Li, G.; Stamford, A. W.; Huang, Y.; Cheng, K.-C.; Cook, J.; Farley, C.; Gao, J.; Ghibaudi, L.; Greenlee, W. J.; Guzzi, M.; et al. Discovery of Novel Orally Active Ureido NPY Y5 Receptor Antagonists. Bioorg. Med. Chem. Lett. 2008, 18, 1146-1150.

(173) Rossi, S. A.; Shimkin, K. W.; Xu, Q.; Mori-Quiroz, L. M.; Watson, D. A. Selective Formation of Secondary Amides via the Copper-Catalyzed Cross-Coupling of Alkylboronic Acids with Primary Amides. Org. Lett. 2013, 15, 2314-2317.

(174) Lasalle, M.; Hoguet, V.; Hennuyer, N.; Leroux, F.; Piveteau, C.; Belloy, L.; Lestavel, S.; Vallez, E.; Dorchies, E.; Duplan, I.; et al. Topical Intestinal Aminoimidazole Agonists of G-Protein-Coupled Bile Acid Receptor 1 Promote Glucagon Like Peptide-1 Secretion and Improve Glucose Tolerance. J. Med. Chem. 2017, 60, 4185-4211.

(175) Sahoo, H.; Mukherjee, S.; Grandhi, G. S.; Selvakumar, J.; Baidya, M. Copper Catalyzed C-N CrossCoupling Reaction of Aryl Boronic Acids at Room Temperature through Chelation Assistance. J. Org. Chem. 2017, 82, 2764-2771.

(176) Guy, C. S.; Jones, T. C. Copper-Mediated N-Arylation of Quinazolinediones. Synlett 2009, 22532256 .

(177) Zhang, X.; Cai, C.; Winters, M.; Wells, M.; Wall, M.; Lanter, J.; Sui, Z.; Ma, J.; Novack, A.; Nashashibi, I.; et al. Design, Synthesis and SAR of a Novel Series of Heterocyclic Phenylpropanoic Acids as GPR120 Agonists. Bioorg. Med. Chem. Lett. 2017, 27, 3272-3278.

(178) Brewer, A. C.; Hoffman, P. C.; Martinelli, J. R.; Kobierski, M. E.; Mullane, N.; Robbins, D. Development and Scale-Up of a Continuous Aerobic Oxidative Chan-Lam Coupling. Org. Process Res. Dev. 2019, 23, 1484-1498.

(179) Li, Y.; Gao, L.-X.; Han, F.-S. Efficient Synthesis of 2,5-Disubstituted Tetrazoles via the $\mathrm{Cu}_{2} \mathrm{O}$ Catalyzed Aerobic Oxidative Direct Cross-Coupling of N-H Free Tetrazoles with Boronic Acids. Chem. Commun. 2012, 48, 2719-2721.

(180) Liu, C.-Y.; Li, Y.; Ding, J.-Y.; Dong, D.-W.; Han, F.-S. The Development of Copper-Catalyzed Aerobic Oxidative Coupling of H-Tetrazoles with Boronic Acids and an Insight into the Reaction Mechanism. Chem. Eur. J. 2014, 20, 2373-2381.

(181) Motornov, V.; Latyshev, G. V.; Kotovshchikov, Y. N.; Lukashev, N. V.; Beletskaya, I. P. Copper(I)-Catalyzed Regioselective Chan-Lam N2-Vinylation of 1,2,3-Triazoles and Tetrazoles. $A d v$. Synth. Catal. 2019, 361, 3306-3311.

(182) Dropinski, J. F.; Akiyama, T.; Einstein, M.; Habulihaz, B.; Doebber, T.; Berger, J. P.; Meinke, P. T.; Shi, G. Q. Synthesis and Biological Activities of Novel Aryl Indole-2-Carboxylic Acid Analogs as PPAR $\gamma$ Partial Agonists. Bioorg. Med. Chem. Lett. 2005, 15, 5035-5038.

(183) Singh, B. K.; Appukkuttan, P.; Claerhout, S.; Parmar, V. S.; Van der Eycken, E. Copper(II)-Mediated Cross-Coupling of Arylboronic Acids and 2(1H)-Pyrazinones Facilitated by Microwave Irradiation 
with Simultaneous Cooling. Org. Lett. 2006, 8, 1863-1866.

(184) Dreier, I.; Kumar, S.; Søndergaard, H.; Rasmussen, M. L.; Hansen, L. H.; List, N. H.; Kongsted, J.; Vester, B.; Nielsen, P. A Click Chemistry Approach to Pleuromutilin Derivatives, Part 2: Conjugates with Acyclic Nucleosides and Their Ribosomal Binding and Antibacterial Activity. J. Med. Chem. 2012, 55, 2067-2077.

(185) Rao, D. N.; Rasheed, S.; Vishwakarma, R. A.; Das, P. Copper-Catalyzed Sequential N-Arylation of CAmino-NH-Azoles. Chem. Commun. 2014, 50, 12911-12914.

(186) Reddy, A. S.; Reddy, K. R.; Rao, D. N.; Jaladanki, C. K.; Bharatam, P. V.; Lam, P. Y. S.; Das, P. Copper(II)-Catalyzed Chan-Lam Cross-Coupling: Chemoselective $N$-Arylation of Aminophenols. Org. Biomol. Chem. 2017, 15, 801-806.

(187) Hirayama, T.; Okaniwa, M.; Imada, T.; Ohashi, A.; Ohori, M.; Iwai, K.; Mori, K.; Kawamoto, T.; Yokota, A.; Tanaka, T.; et al. Synthetic Studies of Centromere-Associated Protein-E (CENP-E) Inhibitors: 1.Exploration of Fused Bicyclic Core Scaffolds Using Electrostatic Potential Map. Bioorg. Med. Chem. 2013, 21, 5488-5502.

(188) Shi, W.-M.; Liu, F.-P.; Wang, Z.-X.; Bi, H.-Y.; Liang, C.; Xu, L.-P.; Su, G.-F.; Mo, D.-L. Synthesis of 1-Vinyl/Arylbenzotriazole 3-Oxides through a Copper-Mediated C-N Bond Coupling Reaction. Adv. Synth. Catal. 2017, 359, 2741-2746.

(189) Andia, A. A.; Miner, M. R.; Woerpel, K. A. Copper(I)-Catalyzed Oxidation of Alkenes Using Molecular Oxygen and Hydroxylamines: Synthesis and Reactivity of $\alpha$-Oxygenated Ketones. Org. Lett. 2015, 17, 2704-2707.

(190) Chen, C.-H.; Liu, Q.-Q.; Ma, X.-P.; Feng, Y.; Liang, C.; Pan, C.-X.; Su, G.-F.; Mo, D.-L. CopperCatalyzed Selective $\mathrm{N}$-Vinylation of 3-(Hydroxyimino)indolin-2-ones with Alkenyl Boronic Acids: Synthesis of $N$-Vinyl Nitrones and Spirooxindoles. J. Org. Chem. 2017, 82, 6417-6425.

(191) Kontokosta, D.; Mueller, D. S.; Mo, D.-L.; Pace, W. H.; Simpson, R. A.; Anderson, L. L. CopperMediated Synthesis of $N$-Alkenyl- $\alpha, \beta$-unsaturated Nitrones and Their Conversion to Tri- and Tetrasubstituted Pyridines. Beilstein J. Org. Chem. 2015, 11, 2097-2104.

(192) Chandrasekharappa, A. P.; Badiger, S. E.; Dubey, P. K.; Panigrahi, S. K.; Manukonda, S. R. V. V. V. Design and Synthesis of 2-Substituted Benzoxazoles as Novel PTP1B Inhibitors. Bioorg. Med. Chem. Lett. 2013, 23, 2579-2584.

(193) Mudryk, B.; Zheng, B.; Chen, K.; Eastgate, M. D. Development of a Robust Process for the Preparation of High-Quality Dicyclopropylamine Hydrochloride. Org. Process Res. Dev. 2014, 18, $520-527$.

(194) Zu, W.; Liu, S.; Jia, X.; Xu, L. Chemoselective N-Arylation of Aminobenzene Sulfonamides via Copper Catalysed Chan-Evans-Lam Reactions. Org. Chem. Front. 2019, 6, 1356-1360.

(195) Beyer, A.; Castanheiro, T.; Busca, P.; Prestat, G. Copper(I)/Copper(II)-Assisted Tandem Catalysis: The Case Study of Ullmann/Chan-Evans-Lam N1,N3-Diarylation of 3-Aminopyrazole. ChemCatChem 2015, 7, 2433-2436. 
(196) Li, J.; Bénard, S.; Neuville, L.; Zhu, J. Copper Catalyzed N-Arylation of Amidines with Aryl Boronic Acids and One-Pot Synthesis of Benzimidazoles by a Chan-Lam-Evans $\mathrm{N}$-Arylation and $\mathrm{C}-\mathrm{H}$ Activation/C-N Bond Forming Process. Org. Lett. 2012, 14, 5980-5983.

(197) Wu, H.; Zhang, Z.; Ma, N.; Liu, Q.; Liu, T.; Zhang, G. Synthesis of Acridines from o-Aminoaryl Ketones and Arylboronic Acids by Copper Trifluoroacetate-Mediated Relay Reactions. J. Org. Chem. 2018, $83,12880-12886$.

(198) Wu, H.; Zhang, Z.; Liu, Q.; Liu, T.; Ma, N.; Zhang, G. Syntheses of Acridones via Copper(II)Mediated Relay Reactions from o-Aminoacetophenones and Arylboronic Acids. Org. Lett. 2018, 20, $2897-2901$.

(199) Liu, S.; Xu, L.; Wei, Y. One-Pot, Multistep Reactions for the Modular Synthesis of $N, N^{\prime}-$ Diarylindazol-3-ones. J. Org. Chem. 2019, 84, 1596-1604.

(200) Li, S.; Cai, H.; He, J.; Chen, H.; Lam, S.; Cai, T.; Zhu, Z.; Bark, S. J.; Cai, C. Extent of the Oxidative Side Reactions to Peptides and Proteins During the CuAAC Reaction. Bioconjug. Chem. 2016, 27, 2315-2322.

(201) Liu, Y.; Xia, Y.; Fan, Y.; Maggiani, A.; Rocchi, P.; Qu, F.; Iovanna, J. L.; Peng, L. N-Aryltriazole Ribonucleosides with Potent Antiproliferative Activity against Drug-Resistant Pancreatic Cancer. Bioorg. Med. Chem. Lett. 2010, 20, 2503-2507.

(202) Ohata, J.; Minus, M. B.; Abernathy, M. E.; Ball, Z. T. Histidine-Directed Arylation/Alkenylation of Backbone N-H Bonds Mediated by Copper(II). J. Am. Chem. Soc. 2016, 138, 7472-7475.

(203) Ohata, J.; Zeng, Y.; Segatori, L.; Ball, Z. T. A Naturally Encoded Dipeptide Handle for Bioorthogonal Chan-Lam Coupling. Angew. Chem. Int. Ed. 2018, 57, 4015-4019.

(204) David, S.; Thieffry, A. Selective Phenylation in Mild Conditions of One Hydroxy Group in Glycols with Triphenylbismuth Diacetate: A New Specific Glycol Reaction. Tetrahedron Lett. 1981, 22, 50635066.

(205) David, S.; Thieffry, A. Conversion of One Hydroxy Group in a Diol to a Phenyl Ether with Triphenylbismuth Diacetate, a New Glycol Reaction Showing Strong Axial Preference in SixMembered Rings. J. Org. Chem. 1983, 48, 441-447.

(206) Barton, D. H. R.; Finet, J.-P.; Pichon, C. The Catalytic Effect of Copper Ions in the Phenylation Reaction of David and Thieffry. J. Chem. Soc. Chem. Commun. 1986, 65-66.

(207) Wipf, P. Transmetalation Reactions in Organocopper Chemistry. Synthesis 1993, 537-557.

(208) Bratsch, S. G. Standard Electrode Potentials and Temperature Coefficients in Water at 298.15 K. J. Phys. Chem. Ref. Data 1989, 18, 1-21.

(209) Tolman, W. B. Making and Breaking the Dioxygen O-O Bond: New Insights from Studies of Synthetic Copper Complexes. Acc. Chem. Res. 1997, 30, 227-237.

(210) Ribas, X.; Jackson, D. A.; Donnadieu, B.; Mahía, J.; Parella, T.; Xifra, R.; Hedman, B.; Hodgson, K. O.; Llobet, A.; Stack, T. D. P. Aryl C-H Activation by $\mathrm{Cu}(\mathrm{II})$ To Form an Organometallic ArylCu(III) Species: A Novel Twist on Copper Disproportionation. Angew. Chem. Int. Ed. 2002, 41, 2991- 
2994.

(211) Xifra, R.; Ribas, X.; Llobet, A.; Poater, A.; Duran, M.; Solà, M.; Stack, T. D. P.; Benet-Buchholz, J.; Donnadieu, B.; Mahía, J.; Parella, T. Fine-Tuning the Electronic Properties of Highly Stable Organometallic $\mathrm{Cu}^{\mathrm{III}}$ Complexes Containing Monoanionic Macrocyclic Ligands. Chem. Eur. J. 2005, $11,5146-5156$.

(212) Huffman, L. M.; Stahl, S. S. Carbon-Nitrogen Bond Formation Involving Well-Defined Aryl-Copper(III) Complexes. J. Am. Chem. Soc. 2008, 130, 9196-9197.

(213) Duparc, V. H.; Dimeck, C.; Schaper, F. Replacing Sulfonate by Carboxylate: Application of Pyridyliminocarboxylato Copper(II) Complexes in rac-Lactide Polymerization and Chan-Evans-Lam Coupling. Can. J. Chem. 2019, 97, 178-190.

(214) Duparc, V. H.; Schaper, F. Sulfonato-Imino Copper(II) Complexes: Fast and General Chan-EvansLam Coupling of Amines and Anilines. Dalton Trans. 2017, 46, 12766-12770.

(215) Funes-Ardoiz, I.; Maseras, F. Oxidative Coupling Mechanisms: Current State of Understanding. ACS Catal. 2018, 8, 1161-1172. 


\section{GRAPHICAL ABSTRACT}

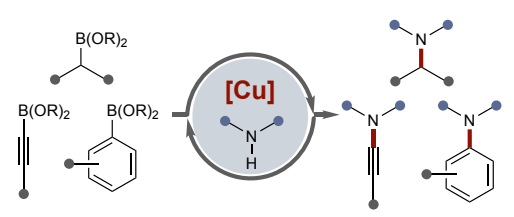




\section{BIOGRAPHIES}

\section{Matthew J. West.}

Matthew J. West obtained a Masters in Chemistry with Medicinal Chemistry from the University of Glasgow (UK) in 2016. He is currently a final year PhD student in the group of Dr Allan J. B. Watson at the University of St Andrews, investigating $\mathrm{C}-\mathrm{C}$ and $\mathrm{C}-\mathrm{N}$ bond forming reactions with the use of non-precious metals.

\section{James W. B. Fyfe}

James W. B. Fyfe obtained a Masters in Chemistry from the University of Strathclyde (Glasgow, UK) in 2013. He remained at Strathclyde to complete his $\mathrm{PhD}$ studies in the area chemoselective cross-coupling under the supervision of Dr Allan J. B. Watson, graduating in 2017. James then spent two years as a postdoctoral fellow at Indiana University (Bloomington, IN) with Prof. Thomas Snaddon working on asymmetric cooperative catalysis before re-joining the Watson group at the University of St Andrews ( $\mathrm{St}$ Andrews, UK) as a postdoctoral fellow in 2019.

\section{Julien C. Vantourout}

Julien C. Vantourout received his Masters in Organic and Medicinal Chemistry from the University of Lyon I (France) in 2014. He obtained his PhD from the University of Strathclyde (Glasgow, UK) where he studied the Chan-Lam reaction in the laboratories of Dr. Allan J. B. Watson, as well as Medicinal Chemistry research in collaboration with GlaxoSmithKline, graduating in 2018. Julien then undertook a post-doctoral appointment at Scripps Research Institute (CA, USA) with Prof. Phil Baran where he is currently staff scientist.

\section{Allan J. B. Watson}

Dr Allan J. B. Watson obtained his Masters and PhD degrees from the University of Strathclyde (Glasgow, UK). Allan was a Lindemann Trust postdoctoral fellow in the group of Prof. David W. C. MacMillan at Princeton University (NJ, USA) and subsequently undertook an industrial postdoctoral position at GlaxoSmithKline prior to starting is independent career at the University of Strathclyde in 2011. Allan moved to the University of St Andrews in 2018 as Reader in Homogeneous Catalysis. His group's interests are in metal-catalyzed and organocatalyzed processes, mechanism, and catalysis applied to target synthesis in Medicinal Chemistry and Agrochemistry. 